NIST

PUBLICATIONS
TRANSCRIPT OF HEARING ON IMPROVING U.S. PARTICIPATION IN INTERNATIONAL STANDARDS ACTIVITIES
U.S. DEPARTMENT OF COMMERCE Natlonal Instltute of Standards and Technology Technolozy Servlces Offlce of Standards Servlces Galthersburg, MD 20899

U.S. DEPARTMENT OF COMMERCE Robert A. Mosbacher, Secretary MATIONAL INSTITUTE OF STANDARDS AND TECHNOLOGY

John W. Lyons, Diroctor 


\section{NATIONAL INSTITUTE OF STANDARDS \& TECHNOLOGY \\ Research Information Center \\ Gaithersburg, MD 20899}

DATE DUE

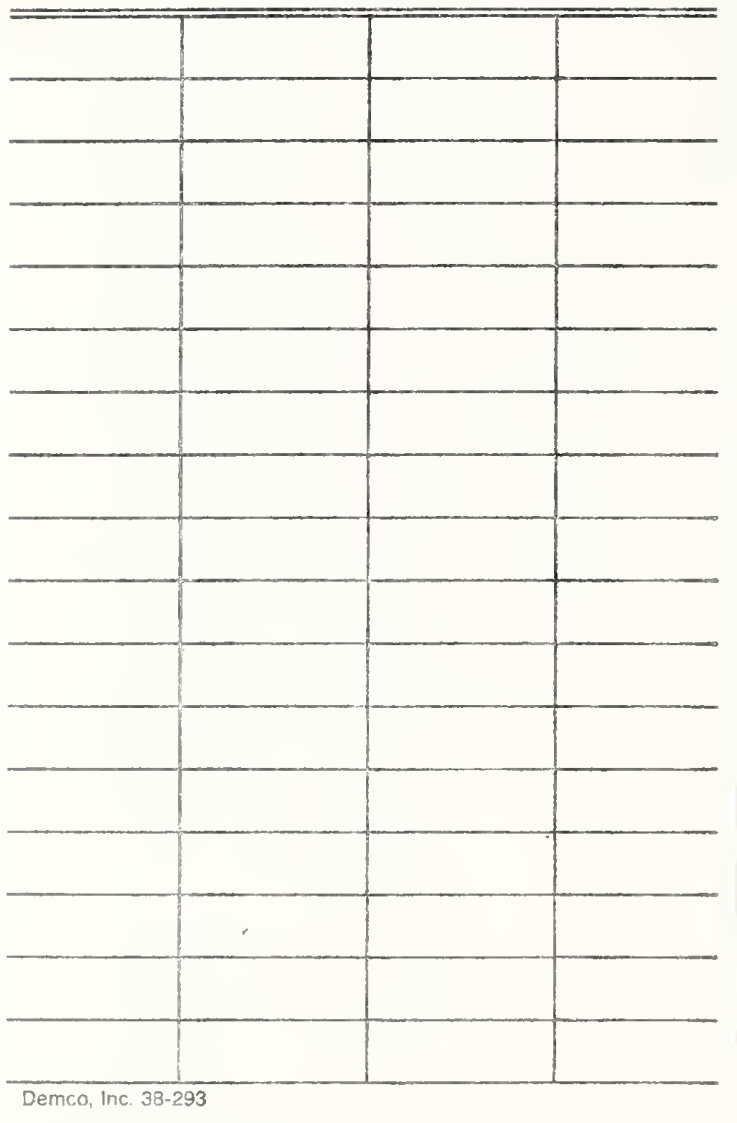


TRANSCRIPT OF HEARING

ON IMPROVING U.S.

PARTICIPATION IN

INTERNATIONAL

STANDARDS ACTIVITIES

FIRST DAY: APRIL 3, 1990
U.S. DEPARTMENT OF COMMERCE Natlonal Institute of standards and Technology Technology Services Offlce of standards services Galthersburg, MD 20899

Aprll 1990

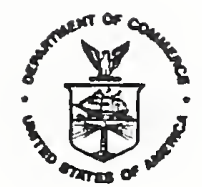

U.S. DEPARTMENT OF COMMERCE Robert A. Mosbacher, Secretary MATIONAL INSTITUTE OF STANDARDS AND TECHNOLOGY

John W. Lyons, Director 



\title{
TRANSCRPT OF PROCEEDINGS
}

\author{
NATIONAL INSTITUTE OF STANDARDS AND TECHNOLOGY \\ DEPARTMENT OF COMMERCE
}

HEARING PANEL MEMBERS' MEETING

Pages: $\quad 1$ through 225

Place: Washington, D.C.

Date: April 3, 1990

\section{HERITAGE REPORTING CORPORATION \\ Opjicid Reportes \\ 1220 L Street, N.W., Suite 600 \\ Werington, D.C. 20005 \\ (202) 622-4898}



NATIONAL INSTITUTE OF STANDARDS AND TECHNOLOGY DEPARTMENT OF COMMERCE

HEARING PANEL MEMBERS' MEETING

\author{
Tuesday \\ April 3, 1990 \\ $9: 30$ a.m. \\ Department of Commerce Auditorium
}


Present on Panel:

DR. STANLEY I. WARSHAW, Chairman

Director, Office of Standards Services

National Institute of Standards and Technology

Admin. Bldg., Rm. A-603

Gaithersburg, Maryland 20899

MR. WALTER G. LEIGHT

Deputy Director, Office of standards Services National Institute of Standards and Technology Admin. Bldg.

Gaithersburg, Maryland 20899

$M R$. JOHN L. DONALDSON

Chief, Standards Code and Information Program Office of Standards Services

NIST

Admin. Bldg., Rm. A-629

Gaithersburg, Maryland 20899

MR. JOHN MCCUTCHEON

Food Safety and Inspection Service

U.S. Department of Agriculture

South Building

Washington, D.C. 20250

MR. PHILLIP B. WHITE

Director, Office of Standards and Regulations Center for Devices and Radiological Health

Food and Drug Administration, HFZ-80

5600 Eishers Lane

Rockville, Maryland 20857

MS . WENDY MOORE

Director, Telecom and Information Standards

CIP Bureau

U.S. Department of state

2201 C Street, N.W., Room 6317

Washington, D.C. 20520

MR. CHARLES IUUDOLPH

Director, Office of European Community Affairs

International Trade Administration

Department of Commerce

Room 3036, Hoover Building

Washington, D.C. 20230 
Presenters Present:

JOSEPH O'GRADY

American Society for Testing and Materials

JAMES PEARSE

MANUEL PERALTA

American National standards Institute

OSCAR FISHER

MELVIN GREEN

American Society of Mechanical Engineers

MARCO MIGLIARO

ANDREW SALEM

Institute of Electrical and Electronics Engineers

WILLIAM CALDER

Instrument Society of America

BEN JOHNSON

Industry Applications society

JAMES DECKER

American Society of Civil Engineers

RICHARD ALLEY

American Welding society

RUSSELL HAHN

ROBERT IANPHIER

American Society of Agricultural Engineers

ANTHONY O'NEILL

ARTHUR COTE

DANIEL PILIERO

National Fire Protection Association

MICHAEL MILLER

DENNIS STUPAK

ROBERT FLINK

MORT LEVIN

Association for the Advancement of Medical Instrumentation

JAMES BIHR

RICHARD KUCHNICKI

WILIIAM TANGYE

PAUL K. HELSTEDT

Council of American Building Officials 
Presenters Present: (continued)

THOMAS FLINT

American Plywood Association

DAVID GRUMMAN

FRANK CODA

JIM HELDENBRAND

American Society of Heating, Regrigerating and Air Conditioning Engineers

JIM FRENCH

American Institute of Aeronautics and Astronautics

MAX ROMBAUGH

LAMONT ELTINGE

Society of Automotive Engineers

RONALD REIMER

United States National Committee of the IEC

TOM CASTINO

JOE BHATIA

Underwriters Laboratories

HERBERT WILGIS

MILTON BUSH

American Council of Independent Laboratories

RICHARD SCHULTE

American Gas Association

WALTER POGGI

Retlif Testing Laboratories

RICHARD FEIGEL

Hartford Steam Boiler Inspection and Insurance Company 
$P R O C E E D I N G S$

MR. LYONS: Good morning and welcome to these

3 proceedings. I am John W. Lyons, the Director of NIST. We

4 are about some very important business this week. The

5 question is how we do standards development, testing,

6 accreditation and certification in the rapidly changing

7 global marketplace.

8 Our concern in the Department of Commerce is the

9 health and prospects of the United States economy and

10 industry's ability to compete on an equal footing in this

11 marketplace.

12 We have a pluralistic, decentralized approach to

13 many aspects of our lives -- included are consensus

14 standards development, product testing and certification,

15 laboratory accreditation, building regulations and the like.

16 We have however a new challenge created by the

17 globalization of markets and compounded by the competitive

18 difficulties facing many of our industries. These

19 difficulties are reflected in the balance of trade

20 statistics.

21 If it were not for the strongly-felt pressures

22 from overseas competition, we would not be holding these

23 proceedings this week.

24

Pressure is building from developments such as the

25 ever-more centralized European community as typified by EC 
192 and by increasingly active governments around the world

2 that have centrally-run standards-related activities.

Can we continue to use the tools and mechanisms of

4 the past in dealing with these new phenomena? If the answer

5 is yes, then what fine-tuning is needed? If the answer is

6 no, then what new mechanisms are desired?

The purpose of this hearing is to build a formal

8 record of views from interested parties and then to use that

9 record in considering the next steps each of us should

10 consider.

We know by the responses to the hearing

12 announcement that there are many parties sufficiently

13 concerned to ask to speak. There will likely be others who

14 will submit written material.

15 We expect to receive a broad spectrum of opinion

16 and we look forward to examining the resultant record and

17 being guided by it.

18 Again, welcome. Please accept our thanks for your

19 concern and dedication to the common cause of helping U.S.

20 industry.

And now to stanley for some administration

22 announcements.

CHAIRMAN WARSHAW: Thank you, John. I will speak

24 from here and just give some administration information. 
1 joining me here today.

Can we raise the level of the microphone? (Pause.)

My name is Stanley I. Warshaw and I will be

5 chairing this discussion. I am the Director of the Office

6 of Standards Services from the National Institute of

7 Standards and Technology.

On my far left is John McCutcheon from the

9 Department of Agriculture. Next to him is Ms. Wendy Moore,

10 from the Department of state and on my immediate left is

11 Charles Ludolph from the Department of Commerce, Director of

12 the Office of the European Community Affairs within the

13 International Trade Administration.

14 On my far right is Phil White from FDA, Food and

15 Drug Administration. Next to him is John Donaldson from the

16 National Institute of Standards and Technology, also in the

17 standards area, and to my immediate right is Walter Leight

18 who is also part of the same standards function in the

19 National Institute of Standards and Technology.

20 Let me point out that the panel members here today

21 are here, particularly those from the other agencies, in an

22 advisory role, to assist the National Institute of Standards

23 and Technology on matters that require some clarification

24 because they can bring a perspective from their specific

25 technical expertise that will really be, we are confident, 

1 of assistance to us at the National Institute of Standards

2 and Technology in terms of getting all the information we

3 can in order to put forth recommendations for possible

4 government actions as the Federal Register announcement of

5 November said with respect to assistance to the Industrial

6 Community in the United States.

7 The questioning during this hearing will only be

8 conducted from the panel that has just been introduced to

9 you. Each speaker has been granted ten minutes to make his

10 presentation. In order to get the 70-some presentations

11 accomplished within these three days, we are going to

12 careful control and monitor that time.

13 We have, in order to assist presenter, lights with

14 timers that will go red, yellow, green and will go yellow

15 one minute before the ten minutes are up, and then red when

16 it is time to stop.

17 This will assist them in order that they can

18 respect others who may be appearing subsequently and allow

19 sufficient time for everybody to get their remarks in within

20 these three days.

21 The program has been arranged in groupings and the

22 groups are well-defined. If you look at the last page of

23 your agenda, there is detailed information on how you can

24 obtain either transcripts of this hearing or other written

25 material and it will also be available in the Department of 
1 Commerce Reading Room after these hearings.

In addition to that, I want to point out that we

3 have extended the comment period for receiving written

4 comments until June 5th -- another 60 days following this

5 hearing -- because of the numerous responses that we are

6 receiving. We want to be sure to get in everybody's

7 thoughts.

If you want to receive information relative to

9 this hearing, or any subsequent actions that are related,

10 you should fill out one of the cards at either entry or

11 leave your business card in order to be certain that you are

12 on the mailing list.

13 The breaks and luncheon times are scheduled in the 14 agenda. There will be a 15-minute break both in the morning 15 and in the afternoon and then there is one hour for lunch. 16 There are restroom facilities at the extreme ends

17 of the corridors of the Department of Commerce. The

18 Commerce building is like a capital $H$. We are on a cross19 leg and you can go out either that way or that way

20 [indicating] and at the extreme ends there are men's rooms 21 and ladies' rooms. The staff here would be happy to assist 22 you.

The cafeteria is located immediately below this

24 auditorium and you can gain access to the cafeteria by going 25 out the rear here, turning left and either taking the 
1 elevators down one level, or the stairwell next to the

2 elevators down one level. It is adjacent to the National

3 Aquarium.

So, if I could have the first two presenters take

5 the podium.

Let me point out, while they are coming up here,

7 that the first two presentations will be made by

8 representatives of the American National Standards Institute

9 and ASTM, the American Society for Testing and Materials, so

10 if you would.

11 What we have done, where people perceived there

12 was a conflict in terms of the agenda or any other purposes,

13 we have said that we will swap slots on the agenda for those

14 requesting such a change, providing we receive in advance,

15 written acknowledge of that from all the parties concerned.

16 The American National Standards Institute has

17 requested the first slot and the American Society for

18 Testing and Materials - ASTM -- will then take the second

19 slot and then the Society for Automotive Engineering will

20 then come on at 3:00 for the slot that had been originally

21 allocated ANSI.

22 So, to repeat, first we have representatives of

23 the American National Standards Institute, following by a

24 representative of $A S T M$ and then we follow the normal agenda,

25 if you will, until 3:00 when ASE will then make their 
1 presentation at that time.

This is the only change in terms of the swapping

3 slots that we have received as of this date. There are two

4 or three cancellations of presentations for the following

5 days.

Tomorrow, April 4th, the presentation scheduled

7 for 9:30 by Dash and others has been cancelled by that

8 party. The presentation at 4:15 p.m. by Bussmann has also

9 been cancelled. Only two presentations for April 4th, then,

10 are cancelled.

On April 5th, at 10:15, AT\&T Bell Labs has

12 cancelled and at 2:15 p.m., the presentation by NKA is

13 cancelled. Again, two cancellations for the 5th.

14 There are no cancellations for today, just this

15 three-way swap, if you will, with respect to time.

I will now ask the representative of ANSI, Mr. Jim

17 Pearse, Chairman of the Board of ANSI if he would present

18 ANSI's views and introduce his associates.

19 MR. PEARSE: Thank you, Mr. Warshaw, and good

20 morning, Mr. Director and members of the panel. My name is

21 James $N$. Pearse and I am Chairman of the Board of the

22 American National Standards Institute.

23 I am accompanied by the President of the

24 Institute, Manuel Peralta. 
1 than 1100 companies of all sizes and shapes, close to 250

2 organizations who collectively account for more than 95

3 percent of the active standards developers in this country,

4 government agencies, educational institutions, consumers and

5 individuals. 19 efforts.

21 both permitted and encouraged. Dr. Lyons of NIST. serve the American public.

Employees of four federal agencies sit on the Institute's large and diverse Board of Directors, including

As identified by our strategic planning process, a major priority of the Institute is to realize a positive, cooperative relationship with the government so as to best

The Institute strongly supports the existing U.S. voluntary system of standards, testing and certification. Our pluralistic, de-centralized system mirrors this country's culture and commitment to free enterprise by allowing the market to determine the optimum allocation of resources devoted to national and international standards

within that system, divergent points of view are Individuals employed by the government should and do participate in the process on an equal footing with parties from the private sector. The controls that exist within our voluntary system are designed to assure due 
1 process and efficiency.

More relevant to this hearing, our country has

3 obtained leadership positions internationally for many

4 important technologies, achieved significant success in

5 enhancing U.S. access to European standards, testing and

6 certification.

8 Institute recognizes that there is a continuing need for the

9 U.S. to strengthen, adapt and enhance its international

10 activities. Given the significant role standards, testing

11 and certification have come to play in global competition,

12 the Institute believes that our most important goal must be

13 to achieve much better government-private sector

14 cooperation.

15 A failure to do so will inure only to the benefit

16 of those with whom the U.S. competes. This can be

17 accomplished by the federal government playing an active and 18 supportive role within the existing voluntary system through 19 an alliance with the private sector so that, to the maximum 20 extent possible, we speak with one voice.

21 This does not mean that the government should

22 create new institutions to regulate the system, thereby

23 undermining our existing private sector structure. Rather,

24 we believe that the federal government should render

25 constructive assistance to the voluntary standards community 
1 within the current system.

The Institute strongly believes that the proposal

3 for the creation of a Standards Council of the United states

4 of American, SCUSA, would be redundant, counterproductive

5 and a step backward at a time when it is imperative that we

6 move ahead.

7 In our view, the present system does not need more

8 regulation and more bureaucracy -- it needs meaningful

9 cooperation and participation.

10 The Institute has long served, and continues to

11 serve, as the U.S. member body to the International

12 Standards Organization, ISO, and through the U.S. National

13 Committee, the International Electrotechnical Commission,

14 IEC -- the two leading non-treaty standards organizations at

15 the international level.

16 In advancing U.S. interests, the Institute is a

17 voting member of virtually all of the most important Iso and

18 IEC technical committees, and subcommittees.

19 In many sectors where U.S. interests are most

20 affected by the promulgation of standards, such as

21 information technology petroleum products, etc., the

22 Institute and its members hold secretariats in the relevant $23 \mathrm{TC} S$ and $S C^{\prime} s$.

24 It is through this process of obtaining important

25 ISO and IEC Secretariats that U.S. industry has achieved a 
1 leadership position in many sectors relevant to our

2 international trade objectives.

In those sectors where Secretariats are held by

4 other countries, the U.S. actively participates in TC and SC

5 work in order to advance U.S. interests.

In response to the important role played by

7 standards in international trade and, more specifically, in

8 response to EC 1992, the Institute has actively and

9 aggressively used its role as the member of ISO/IEC and

10 liaison with CEN/CENELEC to further U.S. interests.

11 This is well-evidenced by the Institute's recent

12 and highly successful interaction with ISO/IEC and

13 CEN/CENEIEC. A highly productive meeting was held last week

14 which concentrated on testing, certification, laboratory

15 accreditation and the formation of the European organization

16 for testing and certification.

Officials of CEN/CENELEC have unequivocally

18 indicated their determination to dialogue with non-EC

19 countries through the ISO/IEC mechanism. In order to

20 further U.S. interests, the Institute opened a Brussels

21 office in August of 1989.

22 Through its Brussels office, the Institute has

23 made significant progress in obtaining meaningful

24 transparency and greater access to information concerning EC

25 standards, testing and certification. 
Extensive efforts have been made to communicate

2 these successes to the Institute's membership and the public

3 at large. One step in that process was the re-opening of

4 the Institute's office in washington, which also permits

5 better interaction with the government.

The Institute understands that the purpose of this

7 hearing is to determine what improvements, if any, should be

8 made in the existing U.S. international standards, testing

9 and certification.

10 The SCUSA proposal, described earlier,

11 contemplates that the new entity would function as a

12 component organization within the Department of Commerce.

13 The responsibilities which would fall within the

14 jurisdiction of the proposed SCUSA include the authority for

15 accrediting standards developers, as well as testing and

16 certification bodies.

17 By giving SCUSA responsibility for accreditation,

18 the proposal is tantamount to government regulation of the

19 U.S. international standards, testing and certification

20 system.

21 The Institute believes that a standards, testing

22 and certification system regulated and led by the government

23 would present enormous difficulties to us and strongly

24 militate against the adopt of this proposal, or any variant

25 thereof, including increased bureaucracy and reduced 
1 efficiency, increased litigation, the need to obtain and

2 allocate funds, potential for political manipulation, time

3 and effort required to create and make operational new

4 government systems, and questions about the competence and 5 capacity.

There is more comment about these specific issues

7 in our written testimony.

CHAIRMAN WARSHAW: We will appreciate your

9 submission of the written comments in the record, if you

10 would.

MR. PEARSE: Yes, we will.

Although the Standards Council of Canada was

13 presumably created to help solve that country's problems a

14 decade ago, the Institute believes that it is not a

15 desirable model for U.S. standards and certification.

16 The significant difference between the standards

17 Council of Canada and the Institute is that the SCC is

18 controlled and funded by the government of Canada, while the

19 Institute is neither controlled nor subsidized by the U.S.

20 Government.

It is interesting to note that SCC's operations

22 have recently been seriously affected by a reduction in

23 financial support due to government budget austerity.

25 certification play in U.S. trade policy, the Institute 
1 recognizes that the government must be an important and

2 active participant in the process.

In addition to establishing a constructive

4 alliance with the private sector, the Institute believes

5 that there are certain specific actions which could and

6 should be taken by the government such as government to

7 government activities, intra-government coordination -- we

8 note here that the interagency committee on standards policy

9 has been somewhat of a disappointment to us -- support for

10 private sector activities, greater educational efforts,

11 greater participation in the existing voluntary standards

12 process, equitable government payment for the voluntary

13 system, creation of tax and other incentives for greater

14 industry participation.

15 Again, these are explained more fully in the

16 written testimony.

17 The most constructive way to achieve helpful

18 improvements in the system is not to fundamentally alter the

19 existing process but instead to provide new means for

20 increased cooperation between the government and the private

21 sector.

22

Because the most immediate international concern

23 facing the U.S. standards, testing and certification

24 community is ED 1992, the Institute has proposed, and will

25 continue to push for, a special private sector/government 
1 alliance in this area.

The private sector would like to be continued to

3 be held responsible for the principal commitment of

4 resources to the international standards, testing area,

5 however the government's funding role could be enhariced and

6 combined with private sector investments through

7 participation in the process.

8

9

10 increasing government/private sector coordination of EC

11 standards issues.

12

13 process can continue in a responsible partnership with the

14 government to advance the interests of the United States.

16

17 included in the hearing record.

18

21 included in the record.

I thank you and I request that a copy of our more Thank you for your time and attention. CHAIRMAN WARSHAW: Thank you, Mr. Pearse. We appreciate it and we certainly will be sure that that is MR. PEARSE: May I leave this here for you then? CHAIRMAN WARSHAW: Please do. Are there any questions from the panel members? Okay, well, thank you very much, Mr. Pearse. 
Next we have Mr. O'Grady, President of ASTM to

2 present the views of ASTM.

MR. O'GRADY: Thank you, Dr. Warshaw. Before we

4 begin, I would like to make a request. I would like to

5 include in the record the 69 volumes of the ASTM Books of

6 Standards.

CHAIRMAN WARSHAW: I'm sorry, sir, but they are

8 copyrighted.

(Laughter.)

MR. O'GRADY: Well, good morning, ladies and

11 gentlemen. Can you all hear up there?

ASTM is pleased to have the opportunity to convey

13 our comments and recommendations on issues critical to the

14 future success of U.S. industry, to the U.S. economy and to

15 the advancement of U.S. technology throughout the world.

Said another way, the success of U.S. industry

17 depends on the advancement of U.S. technology throughout the 18 world.

I had a long thing here, ladies and gentlemen, to

20 tell you about ASTM but in the interests of time, it is in

21 the record and I will pass on it, other than to say we do

22 have 32,000 members. We have 135 technical committees and

23 our committee structure is the most important asset we own.

24 We do not certify or accredit. We do no testing.

25 ASTM has no conformity mark, but in all we do, we must be, 
1 and it is imperative to me, that we be responsive to our

2 ASTM constituency.

ASTM is autonomous. We are not subsidized either

4 by government or industry. Well over half our total sales

5 is attributed to non-members, and a significant portion of

6 our sales continue to prevail in Europe and in other areas

7 outside the U.S.

ASTM applauds the stated policy of the U.S.

9 Government to improve the acceptance of U.S. technology and

10 manufacturing processes in the international standards

11 arena.

For many years, our members have been actively

13 involved in the advancement of U.S. positions in

14 international standards organizations such as ISO and IEC.

15 We currently administer $68 \mathrm{U} . \mathrm{S}$. technical advisory groups to

16 ISO and IEC that are part of the technical committee system

17 of ASTM.

This consists of 1800 members who serve as TAG

19 participants with the objective of developing and promoting 20 U.S. technical positions internationally, a policy which is 21 consistent with what the Board of Directors of ASTM wants to 22 have happen.

The issue of effective participation by U.S.

24 interests in international standards activities has been

25 debated for many years within ASTM and I am aware of debates 
1 going on in other organizations as well.

The issue often comes down to one major subject --

3 finances. Within our heterogeneous society, there are U.S.

4 industries that effectively support a U.S. position in

5 international standards. I am talking now ASTM.

6 However, there are many others that have

7 difficulty maintaining the level of financial commitment

8 necessary to offer consistent and credible U.S.

9 representations, and the reason, of course, are many, but in

10 some instances, the subject matter is perceived by some of

11 our constituents to be more phenomenal logical than product

12 or material oriented.

13 In other cases, the interests involved perceive

14 that there is no direct benefit to the economies of the

15 industries involved.

16 Another variable that may be factored in for some

17 is that the international standards to date may not have

18 been as an important an element in the issue of trade, but

19 we believe all that is changing.

20 To go on, the notice of this hearing addresses the

21 subjects of standards, standards participation, standards

22 usage, testing and certification.

23 The system for developing standards in the U.S.

24 has been for many years demonstrated how an effective

25 partnership, an effective partnership between the private 
1 and the public sectors can work.

Is any of this documented in law? No, it is not.

3 Included in this effective government participation along

4 with ASTM in the process of standards development, I would

5 like to stress to this group and to the panel how important

6 it is that we do thing in an appropriate manner, and much of

7 it has been already described in OMB Circular A-119 and by

8 the presence of government agencies and government employees

9 in the standards process of ASTM.

10 We believe that the system as it is currently

11 constituted works very well.

To us, the issue is not that of a greater presence

13 or a greater role for the federal government in the process

14 of standards development. In fact, we believe in our system

15 that the government is quite pleased with the way it works

16 with us.

I would like now to address some remarks -- moving

18 away from the process of standards development -- but to

19 work on the ultimate objective, and that is the promotion of

20 the final result of the process, the voluntary standard.

21 For many years we have discussed ways in which we

22 could better promote U.S. industry and the economy through

23 the dissemination of ASTM standards. Standards are one of

24 the most effective means of transferring technology to

25 trade, and I doubt if there is one person in this room that 
1 does not believe that.

On the other hand, we are convinced that there is

3 a role for the Federal Government working cooperatively with

4 industry and standards developers to further promote the

5 utilization of private sector standards both domestically

6 and internationally.

7 The key word here is promote the use of the

8 standards.

An element of this promotion may be efforts

10 between specific industries and the Federal Government to

11 promote in the global marketplace existing U.S. standards

12 which are viewed as critical to the advancement of U.S.

13 industry and U.S. objectives.

14 Moreover, it is not beyond the realm of

15 possibility that the U.S. Government could more fully

16 promote, more fully sanction, and endorse the quality of

17 U.S. standards documents. For example, the Federal

18 Government could negotiate, such as with the European

19 community for the acceptance of specifications and test

20 methods developed by ASTM because they are globally

21 recognized technical quality and they are globally used in

22 world trade.

Another cooperative arrangement could include, but

24 not be limited to, programs to provide adequate financial

25 resources for the attendance of U.S. experts at 
1 international meetings.

In all of these arrangements, we should work at defining the problem that exists, and in turn, developing the specific strategies that will assist us.

On the other hand, we should not rush to establish new structures or move in a direction that is responsive only to the attainment of perceived, perceived short-term solutions which in themselves could contribute to long-term problems.

For ASTM, the justification to form a U.S. organization similar to the Standards Council of Canada is not clear. We have therefore concluded that we are not in a position to support the concept, we are not in a position to support the concept of a Standards Council of the United states at this time.

We simply don't know enough about the organization that could be constituted. We are not in a position to comment on the formation of such an organization until adequate documentation is made available. What ASTM does recognize and support is the need for a central coordinating body that neither develops standards nor interferes with the program initiatives of standards developers.

We supported the initial implementation in 1980 of a National Policy on Standards which describes the substance 
1 of what we think is still very important today. Within that position, ASTM recognized the need for

3 a central organization and it offered two fundamental

4 functions: The first, to safeguard the integrity of the

5 process by which voluntary standards are developed and

6 approved by non-government institutions; and secondly, to

7 work closely and cooperatively on standards-related matters

8 with government agencies at all levels -- federal, state and

9 local -- and with the Department of Commerce in its capacity

10 as the government standards coordinating center.

11 In addition, it needs to be demonstrated that the

12 private sector working in cooperation with existing federal

13 organizations is unwilling or unable to find the resources

14 to fill the current needs of the standards, testing and

15 certification systems of the United States, as well as to

16 provide an adequate interface role with the international

17 standards community.

18 ASTM strongly recommends that the role of the

19 Federal Government is to work in cooperation with the 20 private sector to support the voluntary consensus standards 21 system and the accreditation and certification systems of 22 the United States.

23 I see from my signal over there that I am a little 24 bit short on time, so I think then, with your approval, 25 ladies and gentlemen, I will move to the summary. 
ASTM strongly recommends that the role of the

2 Federal Government is to work in cooperation with the

3 private sector. We believe that the Federal Governments

4 needs to take a pro-active role in promoting -- a pro-active

5 role in promoting the worldwide acceptance and use of

6 private sector standards.

By so doing, it will also be promoting the future

8 success of U.S. industry, the U.S. economy and the

9 advancement of U.S. technology throughout the world.

We recommend that the U.S. Government support

11 should be as follows: To work cooperatively with standards

12 developers to ensure that the U.S. has an effective central

13 coordinating body to advance U.S. international standards

14 objectives.

The Government should represent us in negotiations

16 to support U.S. voluntary standards as documents of trade,

17 and to work cooperatively with industry sectors to support

18 an effective U.S. participation in international standards 19 activities.

I will conclude now by saying I once again

21 congratulate our Federal colleagues in convening this

22 meeting and I will look forward to hearing the positions of

23 the rest of the individuals who will be making statements

24 before this group.

I apologize, Dr. Warshaw, for running a tad over 
1 -- oh, there it goes. I thank you for your kind attention CHAIRMAN WARSHAW: Thank you, Mr. O'Grady. You

3 were ten seconds short of the beep.

Questions from the panel? Mr. Donaldson.

MR. DONALDSON: Joe, do you have anything that you

6 would care to amplify with respect to the statement of

7 endorsing the private sector standards. You mentioned that

8 one role for the government would be to endorse private

9 sector standards with respect to international applications.

10 MR. O'GRADY: Yes. The thought occurred to us as

11 a result of conversations that we had between some of our

12 people here in Washington with some of the people in

13 government that it is not beyond the realm of possibility

14 for the United States Government to take a pro-active role

15 and to negotiate with the European community, or any other

16 community, any other community, at least the possibility of

17 negotiating situation to have as a result of a declaration

18 by the United States Government as to the quality of the

19 ASTM standards which are used in so many government

20 agencies.

21

If it is good for the U.S. Government, why should

22 it not be good for other countries of the world, including

23 the European community?

Does that answer your question, John?

MR. DONALDSON: Yes. Thank you. 

20 Charles.

CHAIRMAN WARSHAW: Mr. Ludolph.

MR. LUDOLPH: Mr. O'Grady, I was struck with your comments about the need for financing.

MR. O'GRADY: Pardon?

MR. LUDOLPH: The need for financing in the standards system in the United States, and the issue before us is whether financing comes to an activity that is seen as relevant by the U.S. business community.

In the past, if, for example, the CEN process is closed to U.S. standards makers, it is not useful to attempt to develop a standard or to participate in something that is irrelevant to their decision-making, and there has been some discussion about how relevant ISO and IEC activity is for the standardization processes which international activities -- either multi-national activity or trade -- is not heavy in that sector.

With that being said, the U.S. standard system produced some of the best standards in the world --MR. O'GRADY: The best standards in the world,

MR. LUDOLPH: And therefore across the board they produced the best standards in the world --(Laughter.)

MR. LUDOLPH: The question I want to put before you is if there is two or three systems outside the United 
1 States that are bent on developing standards independent of

2 global standards or international standards, will the best

3 standards in the world be able to withstand the competitive

4 and government pressure coming from CEN and from other

5 standards organizations such as the Japanese Institute of

6 Standards, here, in this economy?

8 way?

MR. LUDOLPH: Yes.

MR. O'GRADY: Would you repeat the question?

MR. LUDOLPH: Can you compete?

MR. O'GRADY: Yes.

18 cooperative program could include but not be limited to

19 programs to provide adequate financial resources for the

20 attendance of U.S. experts at international meetings.

21 That, as far as ASTM is concerned, is an open-

22 ended statement because we know that there are organizations

23 and we know there are certain classes of people in the ASTM

24 constituency who have no resources because they don't have

25 the backing of a large or profitable corporation. 
We need to have those people at the standards

2 council and the standards meetings of ISO and IEC so that

3 the one avenue left open to American industry to access the

4 European community is through ISO.

There are those who think that ISO or IEC is not

6 effective or it's too slow or any of those other things that

7 we have all heard over the years, it is up to someone else

8 to say that.

From the ASTM perspective, we are having in some

10 of our members a serious difficulty in getting the funding

11 to go to Iso meetings. That was the essence, Charles, of

12 what I was saying without trying to reflect on any other

13 organization or to be critical of them.

MR. LUDOLPH: Thank you.

CHAIRMAN WARSHAW: If there are no other questions

16 from the panel, I thank you both for your presentations and

17 I would ask both the ASME and IEEE representatives if they

18 would come to the podium.

19 (Pause.)

20 CHAIRMAN WARSHAW: Thank you, gentlemen. We very

21 much appreciate everybody's effort to confine themselves to

22 the time frame and we appreciate your willingness to

23 participate today.

First we have Mr. Oscar Fisher of the ASME who is

25 Chairman of that Standards Council, and if you would 
1 introduce those accompanying you, Mr. Fisher.

MR. FISHER: Here is Mel Green, Associate Director

3 of ASME, and Director of Codes and Standards of ASME.

CHAIRMAN WARSHAW: Which one will make the

5 presentation?

MR. GREEN: I will make the presentation.

9 opportunity to present the views of the Council on Codes and 10 Standards of ASME.

As many of you know, ASME is a non-0profit

12 education and technical society that was founded in 1880 and

13 now has over 119,000 individual members including nearly

1419,000 student members.

A Board of Governors, elected by the membership,

16 manages the society. The Board of Governors has assigned

17 the duties associated with the operations of codes,

18 standards and related accreditation and certification

19 programs to the Council on Codes and Standards. This

20 statement reflects the views of that Council.

21 Since 1884, ASME has served the public through its

22 technical standards program. As early as 1898, ASME was

23 involved in international standards for testing materials.

24 When ASME began developing performance test codes and

25 criteria for testing materials, businessmen and engineers

\section{Heritage Reporting Corporation}

(202) $628-4888$ 
1 had no recognized baselines against which to write a

2 purchase order nor an institute through which to participate

3 in international standards.

From this early involvement in domestic and

5 international standards, ASME participated in the formation

6 of such organizations as the American Society for Testing

7 and Materials, ASTM, and the predecessor organization of the

8 American National Standards Institute, ANSI.

9 ASME codes, standards, and related accreditation

10 and certification programs involve 122 projects with

11 approximately 600 codes and standards and 10 accreditation

12 and certification activities.

13 Approximately 4,000 volunteers develop the codes

14 and standards and serve on the committees addressing

15 accreditation and certification. An inherent part of ASME's

16 codes, standards, accreditation and certification programs

17 is due process.

18 Although ASME has been involved in developing

19 international standards for over 100 years, the United

20 States Government showed little interest in codes, standards

21 and related accreditation activities within the last few

22 years. In fact, it was not until the Kennedy rounds to

23 remove tariff barriers that the U.S. Government seemed to

24 have an interest.

25

After some study, the United States Government 
1 brought an anti-trust suit against ASME so that we would

2 expand our accreditation activities from the United States

3 and Canada, to the rest of the world, and we did that.

4 Since October 1 of 1972, we have been operating on

5 accreditation programs and making our codes and standards

6 available throughout the world.

7 Today we are operating in 35 countries. Our

8 accreditation is recognized in 80 countries, so we have had

9 a great deal of experience with the government overview

10 because through the agreement that we have with the United

11 States Government, we have a host government who provides us

12 great services and some of the countries that we are

13 involved in today.

14 Just picture yourself going to some of the places

15 where our consultants and where the inspectors who work in

16 these plants must live and the U.S. Government has assisted

17 us in these areas for nearly 20 years.

18 Now, ASME is administrative secretariat of both

19 IEC and ISO related committees, both the administrative

20 secretariat and TAG'S where ASME has the interfacing

21 domestic committee, we have the technical advisory group

22 also.

23

24 secretariats to ANSI and we previously referred others to

25 ANSI for administration of secretariats. 
From our recent experience, this would suggest

2 little likelihood that industry will provide the necessary

3 financial support for the administrator or for the qualified

4 people necessary to represent the United States.

Therefore the United States Government must assure that Americans are properly represented. The standards negotiations involve government interface. It is essential that the United States Government provide leadership. There are parts of this written statement that I am omitting because of some restraints we have this morning, but this, as Dr. Warshaw has said, will be made available. An ASME bylaw provides for a Board on Accreditation and Certification. Part of the role of that Board is to provide internal audit of ASME. ASME has implemented that bylaw provision by having four agencies of the Federal Government who use our accreditation as a means of satisfying their regulatory requirements, to audit us on a regular basis on an unannounced basis.

Now, this program has worked very well. When we first asked the federal agencies to participate in the program, they questioned our motives as to whether we were trying to get a leg up in the courts or whatever. No, we are trying to make sure that we are living up to our own quality programs. We may go all over the world and review of peoples' quality assurance programs and 
1 we felt that we should have an outside body or an outside

2 agency monitoring us to make certain that we are meeting our

3 own programs.

4 The need for a level of due process is

5 particularly critical where there is a dominance occasioned

6 by a few in an essential industry.

In those situations, the American National

8 Standards Institute cannot provide the forum for objectivity

9 and fairness in decisions because of the dominance by a few

10 players. During the past two decades, there has been

11 situations where a dominance of power has prevented the

12 United States from having American national standards in

13 some areas that are vital to health, safety and resources

14 and probably just as important, this lack of a forum for

15 consensus has prevented the United states from having a

16 voice in developing international standards.

17 Now, the Council on Codes and Standards recommends

18 a United States of America standards, accreditation,

1.9 certification, oversight and investigative institute. This

20 institute will develop through consensus the criteria for

21 standards and accreditation bodies and audit accredited

22 organizations to assure compliance.

23 Such an institute would provide for a level of due

24 process to assure lack of bias and competitive opportunity.

25 It would also provide the necessary forum to develop United 
1 States positions on standards and accreditation issues and

2 represent the United States in negotiations with other

3 governments.

This institute may mean the difference between

5 disorganized private sector standards developers and

6 accreditation program administrators and a healthy worldwide

7 system for standards, accreditation and certification

8 programs.

As part of the creation of such an institute, it

10 would be required that any standards developer or

11 accreditation sponsor that desires to be referenced in

12 federal procurement contracts or regulations be accredited

13 by this institute and be willing to participate with

14 government, industry and the public in its management.

I thank you.

17 there any questions of ASME from the panel? Well, we thank you. Let us then move on to IEEE. Marc Migliaro is

20 Chairman of the Standards Board of IEEE. If you would 21 introduce your associate.

MR. MIGLIARO: Thank you. I have with me Andy

23 Salem who is the staff directors of standards for the

24 institute, and we also have with us who is in the audience,

25 today, Don Fleckenstein, past directors of standards for the 
1 institute.

I would like to thank you very much for the

3 opportunity to be here this morning.

IEEE is a scientific and educational institution

5 whose purpose is to advance the theory and practice of

6 electrical and electronic engineering and computer science.

It also strives to enhance the quality of life for

8 all people. IEEE is a trans-national organization with

9315,000 members through the world. The fastest growing

10 segment of its membership is the non-U.S. group.

11 One of the technical activities of IEEE, aimed at

12 carrying out its trans-national mission, is the development

13 and dissemination of standards. Historically, IEEE has been

14 closely associated with the U.S. voluntary standards

15 activities.

16 More recently, because of the trans-national

17 composition of its membership, the IEEE standards program

18 has addressed the need for standards that can serve all

19 nations. Indeed, some standards have been recognized and

20 used by other countries of the world and adopted by

21 international bodies.

22

23 IEEE views EC 92 as a significant event in the evolution of

24 the expanding need for and interest in global standards.

25 However, the event should not cause us to lose sight of the 
1 larger goal of global standardization.

It should be noted that IEEE is not at present in

3 certification or testing. Our discussion, therefore, is

4 limited to the international standardization aspect of this

5 hearing.

Whether the U.S. is adequately represented and

7 prepared to participate in the evolutionary process leading

8 to global standards is the thrust of this discussion. If

9 this were a simple issue, the simple answer would be yes.

10 But the subject and issues are not simple. In

11 order to maintain an affirmative view, a number of these

12 issues have to be explored with the goal of assuring

13 positive action for the continuation and growth of necessary

14 participation.

15 The output of a standards process are criteria

16 that serve in determining the acceptability of products,

17 processes, and information. To be used for such purposes,

18 the criteria have to be found acceptable by those that would

19 implement them.

20 A decision to accept the criteria has to take into

21 account national laws, consumer interests, environmental

22 matters, security issues when applicable, and perhaps a

23 myriad of other concerns.

24 Only when such factors are satisfied will a

25 standard be found acceptable for use. The process by which 
1 all these factors are considered is, by nature, time-

2 consuming but is essential to assuring the acceptance of

3 standards.

4 Fundamental to involvement in the global

5 standardization effort is adherence to the basic tenet: the

6 right of participation. Commitment to this principle is

7 critical, and any deviation from it weakens a position and

8 jeopardizes the acceptability of the result.

9 Therefore, it is essential that any

10 standardization be founded on this principle. Any move to

11 mitigate this right by requirements of organizational

12 affiliation, financial contributions, or other participation

13 constraints threatens acceptance at the international level.

14 In the U.S., the voluntary standards system is

15 dependent on financial support from membership fees,

16 contributions, and the sale of documents. These financial

17 underpinnings for international work have been threatened

18 recently by membership reduction due to corporate down-

19 sizing, mergers, and other steps taken to ready commercial

20 enterprises for competition in the world market.

21 In addition, fluctuations in currency values,

22 increased costs of foreign travel, and so forth, further

23 erode the already decreasing financial support. These

24 events strain the ability of the U.S. standards developers

25 to participate internationally, even assuming the domestic 
1 process was in order.

A major issue, therefore, is the funding required

3 to maintain membership in international standards

4 organizations and the support for delegates to attend off-

5 shore meetings.

At this point, let us consider the relationship

7 between the government and the private sector in global

8 standardization. The need for standards to serve a

9 worldwide market includes, for example, the European

10 Economic Community and the U.S./Canada Free Trade Agreement.

11 These government-to-government relationships are

12 exclusively in the province of the Federal Government.

13 Relationships with other governments and treaty

14 organizations include standards policy matters and may

15 include standards development programs.

17 comparable activities in the private sector have a common

18 goal of serving the nation's trading needs. It is timely

19 that the government and the private sector approaches to the 20 goal be aligned.

22 the European Community and the U.S./Canada Free Trade

23 Agreement. The changes, however, do not require the

24 assignment of international standards responsibility to the

25 Federal Government. Such a move through the Standards 
1 Council of the United States of America is seen as

2 diminishing the role of the private sector without regard to

3 its past involvement and successes.

4 What is needed at this juncture is a statement of

5 the respective roles of, and interfaces between, the private

6 and public sectors. Outlining the roles and interfaces

7 should be a first step in the development of appropriate

8 relations. This would strengthen the U.S. position in

9 international discussions.

10 It must be emphasized the IEEE does not promote

11 nor encourage the development of national standards as a

12 basis of negotiations internationally. Global

13 standardization and the pace of the worldwide market growth

14 requires rapid and proper development of positions for the

15 purpose of preparing internationally acceptable documents.

16 By definition, such documents should be applicable

17 within all nations. There is no time to lose in moving

18 toward this goal.

19 It is appropriate to repeat our earlier

20 affirmative position regarding the adequacy of U.S.

21 participation in the international arena, and that there are

22 other areas in need of attention, some of which have been

23 outlined above.

24 Therefore, it is proposed that these areas as well

25 as the others presented during this hearing serve as an 
1 agenda for a committee of experts on the subject. Such a

2 committee should be convened in the near future by the

3 Director, Office of Standards Services, NIST, to prepare

4 recommendations to the private and public sector on a

5 National Policy for International Standards.

In summary, the committee should address such

7 issues as assuring the right of participation of all parties

8 of interest; assuring the continuation of the present

9 participation level in international standardization and

10 take into account the expected growth in this area;

11 establishing viable, long-term funding for international

12 involvement; defining the respective roles of and interfaces

13 between the private and public sector.

14 Encouraging the development of international

15 standards is the first step in preparing national standards,

16 and finally, developing a national policy on international

17 standards. The policy should not be limited to EC 92, but

18 should speak to the need of global standardization in light

19 of the development of a world market.

20 This concludes IEEE's statement. Thank you very

21 much.

CHAIRMAN WARSHAW: Thank you very much, Mr.

23 Migliaro.

Are there any questions from the panel? And let 25 me say while we have both here, it could be to either ASME 
1 or IEEE.

2

4 that the IEEE membership is 315,000 , would you be able to

5 comment on what percentage of what the number is that are

6 non-U.S., please?

7 MR. MIGLIARO: I guess, if we look at non-U.S. and

8 that would then include Canada, Mexico, about a third are

9 non-U.S.

10

11

12 from the panel?

13

14

15 both ASME and also IEEE, in that both organizations are

16 international-recognized programs -- one that has an

17 accreditation program and one that purely develops

18 international standards.

19

I wanted to ask, first of all, the degree that you

20 find that your standards development activities here in the

21 United States are influenced, recently influenced by the

22 development of standards overseas and how relevant the Iso

23 activities are to your standardization activities here, and

24 second, the degree, particularly in Mr. Green's and ASME's

25 case, to use international standards for the international

Heritage Reporting Corporation

(202) $628-4888$ 
1 accreditation of programs -- whether your accreditation

2 program has a need to adopt more foreign or international

3 standards?

Obviously the last question is what affect would

5 that have on U.S., on your clients which are U.S.

6 manufacturers, and in some cases, state inspectors?

MR. GREEN: Well, you have a number of questions

8 there, so let me start from the back.

Insofar as our accreditation program is concerned,

10 well, we receive feedback from all of the countries where we

11 are operating. I think I mentioned before that we received

12 some 30,000 inquiries from users about the world to which we

13 respond.

of course, these inquiries served as input to

15 propose changes in our codes and standards.

Now, insofar as using standards of other

17 countries, other standards developers insofar as

18 accreditation, there will be an accreditation program that

19 ASME will begin on May 16th of 1990 where we will accept

20 specifications developed by standards developers outside the

21 United States and Canada.

22 We will insist upon our own quality assurance

23 criteria for this accreditation, but the specification to

24 which the product is manufactured can be from recognized

25 standards developers located in other parts of the world. 
CHAIRMAN WARSHAW: Mr. Salem, do you have

2 something you would like to say?

MR. SAIEM: Well, IEEE considers its international

4 involvement very important to the program. The standard

5 board really has taken the position that new programs should

6 be addressed at global standardization. Regional standards,

7 national standards, at this time really don't seem to be the 8 way to go.

The trans-national program that we have underway

10 does recognize standards of other countries and there is a

11 mechanism to adopt such standards into the IEEE system.

13 we find as we travel around from the Europeans and other

14 places in the world is the lack of adoption of Iso standards

15 in the U.S. We intend to address that subject in IEEE to

16 the degree that we can.

17 CHAIRMAN WARSHAW: Thank you, Mr. Salem. Is there 18 any other questions from the panel?

Well, we thank you both very much for your

20 presentations.

21

MR. MIGLIARO: Thank you for the opportunity.

22

CHAIRMAN WARSHAW: Since it is early, I would like

23 to move to the next two presentations, the Instrument

24 Society of America and the Industry Application Society.

(Pause.) 
We have Mr. William Calder, the Instrument Society

2 of America, if you would begin.

MR. CALDER: Thank you, Mr. Warshaw, and good

4 morning everyone. It is nice to know that I am at the right

5 spot at the right time, because I can confirm that my name

6 is William Calder and I am the President of the Instrument

7 Society of America.

I am here today to present ISA's position and

9 recommendations on improving United States participation in

10 international standards activities.

11 The Instrument Society of America is a non-profit,

12 educational organization and was founded in 1945 to advance

13 the application of instrumentation, measurement and control

14 in manufacturing and continuous process industries.

15 With more than 42,000 members, ISA is

16 internationally recognized as the leading organization for

17 instrumentation and control professionals. Our members

18 represent vendor, user, distributor, and general interest

19 groups and include engineers, scientists, managers, and

20 technicians.

21 Since its inception, ISA has operated an active

22 program for the development of consensus standards.

23 Currently, more than 3200 individuals participate in the

24 development of ISA standards and international standards in

25 the area of measurement and control technology. 
ISA is an organizational member of the American

2 National Standards Institute and has been an ANSI-accredited

3 standards organization since 1976. Prior to 1976, ISA

4 standards were developed under the canvas method for ANSI

5 approval.

Responsibility for the development ISA standards

7 and participation in the development of international

8 standards rests with the standards and practices department

9 of the society.

The standards and practices department is managed

11 by the standards and practice board, which oversees the

12 activity of more than 125 domestic committees and

13 subcommittees as well as eight United States technical

14 advisory groups.

ISA also holds the secretariat of two

16 international electrotechnical commission subcommittees and

17 provides technical and administrative support for numerous

18 IEC and international organization for standardization

19 working groups.

A full-time professional staff located in Research

21 Triangle Park, North Carolina, provides support to this

22 extensive volunteer effort. ISA budgets more than $\$ 650,000$

23 per year in direct support of its standards program and has

24 published over 80 standards.

Approximately one-third of this budget, or nearly 
1 a quarter of a million dollars per year is allocated for

2 international standards activities.

In addition, the society, with the support of industry, regularly sends representatives to participate in the international standards committee meetings.

These experts receive technical support and advice

7 from the corresponding ISA domestic standards committees.

8 Because of these close ties and as a result of our long-term

9 commitment to the international effort, United States

10 participation has been very effective in the area of

11 industrial process measurement and control.

As the importance of international standardization

13 escalates, more involvement and coordination with domestic

14 efforts will be necessary. ISA intends, as part of its

15 long-range strategic plan, to actively participate in

16 international standards and practices activities for the

17 measurement, control and automation industries.

ISA International, a subsidiary of the society,

19 serves ISA members outside North America. Its European

20 region is supported by a professional staff located in

21 Brussels, Belgium.

Because ISA is an international organization, the

23 society benefits from the worldwide input to its standards

24 program. Although overseas members cannot participate in 25 any of the technical advisory group activities, they do 
1 contribute to the other aspects of ISA's standardization

2 program.

We believe this open exchange of information and

4 early review of ISA proposals has lead to increased

5 acceptance of U.S. ideas in the international arena.

Based on our experience in both the international

7 and national standards arena, ISA strongly believes the

8 current standards system, managed by the private sector,

9 should continue.

Our voluntary system is sound and is supported by

11 industry. We have developed authoritative, widely-used

12 standards at the national level and continue to make

13 significant contributions internationally.

14 Despite the success we have enjoyed, we do,

15 however, believe significant improvements could be achieved

16 through government action in the following areas: First, by

17 increased participation by government employees; second, by

18 funding of standards developers; and third, by encouragement

19 for increased industry support.

20 ISA has an excellent support from the National

21 Institute for science and Technology and its predecessor,

22 the National Bureau of Standards. This support has been in

23 the form of NIST scientists who serve as managing directors

24 on ISA's standards and practices board, committee chairmen

25 and committee members. 
ISA encourages participation by NIST and other

2 government agencies such as the Department of Defense, the

3 Nuclear Regulatory Commission and others. ISA welcomes this

4 support and is open to expansion of it.

This support has, however, been severely limited

6 by the funds available for government personnel to attend

7 standards meetings in the United States and especially in

8 Europe. ISA believes very strongly that greater

9 participation by NIST personnel or other technical

10 government representatives in international standards

11 meetings would significantly strengthen the image and

12 effectiveness of the United States in the international

13 standards arena.

14 This increased level of participation could be

15 effected by two actions by the U.S. Department of Commerce.

16 First, authorization of funds to enable federal employees to

17 take a more active role in existing standards-developing

18 organizations; and second, encouragement by the heads of

19 federal agencies for the technical experts within the

20 agencies to seek out and accept more active roles in the

21 development of standards.

23 consensus standards-developing system in the United States

24 would be greatly improved if additional funding were made

25 available to support existing channels of participation in 
1 the international arena.

ISA recommends that the United States Government

3 establish a fund that would enable consensus standards-

4 developing organizations such as the Instrument society of

5 America to send a larger number of representatives of U.S.

6 industry to international standards meetings.

This type of funding would greatly increase

8 participation by qualified technical experts from U.S.

9 industry. And, in particular, additional funding could

10 increase the extent of participation by employees of small

11 and medium-sized companies who presently cannot afford to

12 send their technical experts to international standards

13 meetings.

14

The amount of funding would be small relative to

15 other government expenditures, funds on the order of a few

16 million dollars combined with the substantial financial

17 investment already committed by the private sector could

18 have a tremendous impact on U.S. participation in

19 international standards.

20 Administration of the funds could be on a grant

21 basis, using mechanisms similar to those already in place by

22 the National Science Foundation, the Army Research Office,

23 and other federal funding agencies.

24 Finally, the government could encourage increased

25 participation by the private sector by instituting a program 
1 of tax credits for industry standards participation similar

2 to the existing tax credits for research and development.

This action would provide a direct incentive for

4 increased support from industry. The resulting

5 participation would be market-driven and, as such, reflect

6 our free-enterprise system.

These three actions -- encouraging government

8 participation in voluntary standards development, making

9 funds available to standards developers, and extending tax

10 credits to industry -- could significantly strengthen U.S.

11 participation in the development of international standards

12 and improve the domestic standards system as well.

13 Now, the Office of standards Services -- NIST --

14 has distributed the description of a proposed standards

15 council of the United States of America as a general model

16 to be considered as the way to solve the United States'

17 problems with international standards.

18 The proposed purpose of this model is to enhance

19 U.S. international commercial interests by creating an

20 infrastructure to sustain a cohesive national standards

21 system with oversight by a Board of Governors composed of

22 the representative public and private interests.

23 ISA is strongly opposed to the creation of a super

24 standards coordinating agency to displace the private sector

25 systems that are presently in place for the following 
1 reasons:

Present mechanisms such as the American National

3 Standards Institute and the U.S. National Committee of the

4 IEC are effectively coordinating U.S. participation in

5 international standards development at the present time.

6 The current system is sound and is serving

7 industry and the American public well. Speaking on behalf

8 of the industrial process measurement and control community,

9 we have been successful in having U.S. concepts and

10 standards adopted by international standards organizations.

11 U.S. Industry recognizes that international standardization

12 is a key factor in the competitiveness of U.S. firms.

13 Improvements in the present U.S. mechanism could

14 be made by greater participation from both the private and

15 public sectors, but that participation would be possible

16 only if increased funding were available.

17 It would be a much more efficient use of federal

18 funds to strengthen these existing mechanisms rather than

19 create a bureaucracy to replace them.

20 I see the red light is on so I will wind down here

21 and bring you to the summary.

22 The Instrument Society of America would welcome

23 the opportunity to expand on any of the points that we have

24 made by preparing more detailed information reports, by

25 working with NIST, or by working with ANSI, USNC/IEC, and 
1 other bodies presently involved with coordinating and

2 representing ISA participation in the development of

3 international standards.

In conclusion, ISA supports the current standards

5 development system and recommends that the government work

6 with industry and the private sector to strengthen and

7 improve our international standards participation.

8 Specifically we recommend increased participation by

9 government employees; second, government funding for

10 standards development; and third, incentives for increased

11 industry participation and support.

ISA does not support the SCUSA model, nor do we

13 endorse government control over the voluntary, private

14 sector effort.

15 The Instrument Society of America welcomes this

16 opportunity to present our views on these important issues

17 facing the United States. We look forward to continued

18 cooperation and support among industry, government and the

19 standards developing community.

20 Thank you. I would also like to enter a copy of

21 this for the record.

22 CHAIRMAN WARSHAW: We appreciate it. Yes, we will

23 be happy to include your full text for the record.

24 Questions from the panel? Mr. Leight

25 MR. LEIGHT: Yes, when you talk about government 
1 funding and tax credits, may we presume you are talking

2 about legislation?

MR. CALDER: I presume that sort of mechanism

4 would be required.

5 CHAIRMAN WARSHAW: Does the panel have any other

6 question of $\mathrm{Mr}$. Calder?

Thank you, Mr. Calder.

MR. CALDER: You're welcome.

CHAIRMAN WARSHAW: Mr. Johnson nOW from the

10 Industry Applications Society. Mr. Johnson.

12 indeed a pleasure to be here today. The Industry

13 Applications society is a society of the IEEE and our

14 position, or the position of IEEE was presented by Mr.

15 Migliaro and we certainly support that position.

It is my point to bring to this hearing the

17 opinions of the Industry Applications Society and my views

18 as 14 years experience as an IEC delegate and as a U.S.

19 manufacturer to those delegations.

20 I would like to say that the standards process

21 inside the United States is in good hands. It works. We

22 produce excellent standards and I believe it has already

23 been stated as the best in the world and I certainly support 24 that. 
1 States is maybe not as in good hands. We definitely need a

2 more coordinated position on our technical issues outside

3 the United States.

All of the various standard agencies in the United

5 States have not had a coordinated effort to carry the U.S.

6 position to the international marketplace. In today's

7 experience, the U.S. manufacturer who takes the initiative,

8 may represent the United States on a given technical

9 committee without the obligation to represent a specific

10 U.S. position. The only obligation he has is to represent

11 his own commercial interests.

12 The process of carrying the U.S. standards to the

13 international arena is further impeded as delegates from

14 other countries, particularly in Europe, are funded to

15 participate in their activities, and the U.S. manufacturer

16 is not always in a position to do so.

17 Standards coming into the United States, the U.S.

18 manufacturer should have a voice in acceptance and the

19 coordination of standards produced in other countries which

20 are being considered for acceptance in the United States.

21 In general terms, the U.S. manufacturers have

22 relied on technical groups such as the IEEE, the ASTM and

23 others, as a forum for producing standards. In addition,

24 special industry groups such as NEMA and others have

25 produced and coordinated with the above technical groups 
1 such as IEEE and Underwriters Laboratories, Factory Mutual, 2 and others.

The U.S. manufacturer believes that his technical

4 base is protected because U.S. and other manufacturers are

5 required to produce to these standards. Coordination of any

6 standards coming into the United States involving products

7 to be marketed here with other standards definitely has a

8 Federal Government role.

As a starting point in better coordination of U.S.

10 international standards activities, it may be appropriate to

11 keep in place the current domestic standards process through

12 the various technical groups and third party certification

13 agencies and the national standards groups coordinating the

14 same.

On the international scene, it appears that there

16 is a definite need for a coordinating body to ensure that

17 the U.S. has accurate and complete representation on the

18 broad base of activities in the international standards

19 arena.

20

Additional points I would like to consider for a

21 government role is that the U.S. manufacturer should be able

22 to comment on standards in the draft stage which are being

23 put together outside of the United States in other

24 countries.

The U.S. manufacturer needs the same access to 
1 test laboratories and information, particularly in Europe,

2 as the Europeans have here.

There is definitely a role for the Federal

4 Government to ensure the U.S. has a balanced voting position

5 in the IEC activities. The European community with the 12

6 voting countries can very often sway the ballot on a

7 particular technical issue.

And finally, the European community has and is

9 developing a strong infrastructure for quality certification

10 along with product certification. We are yet in the United

11 States in a position to do the same.

12 That concludes my remarks and I will answer

13 questions from the pane.

14 CHAIRMAN WARSHAW: Thank you very much, Mr.

15 Johnson.

17 presenter? Charles?

18 MR. LUDOLPH: Mr. Johnson, there are some aspects

19 of your testimony that would help with a little

20 clarification from my standpoint.

21 I believe you said at about midpoint in your

22 statement that there was, you saw a need or there was

23 concern on your part about a need to coordinate standards

24 that are coming into the United States.

25 Is that a representations of what you said? 
MR. JOHNSON: Well, there is a very broad base of

2 activities in that regard, as you heard earlier here today.

3 Also, in our certification agencies, there are agreements

4 between -- existing today -- between certain U.S.

5 certification agencies and those outside the United States

6 for accepting products.

7 However, there is not a coordinated effort that

8 goes to the U.S. manufacturer base for seeing that the

9 standards from which we might accept products into the

10 United States agree with the products that are manufactured

11 by U.S. based companies.

MR. LUDOLPH: As you see it, does that impose or

13 has that imposed a burden on the U.S. manufacturer's

14 competitiveness to get products accepted or to compete on a 15 level playing field in the U.S. market?

16 MR. JOHNSON: I believe it is a chip in the card

17 game of the international standards activities. As we

18 negotiate our standards position outside the United states,

19 one of those cards that must be played is how we accept

20 standards inside the United States.

21 MR. LUDOLPH: So is the issue, as we have already

22 established from previous statements, that the world, the

23 United States has developed world class standards that are

24 the best in the world and are able to compete against

25 anything certainly in the U.S. market, and in that case 
I then, products that are developed that way, where is the

2 disadvantage in having an acceptance body accept a lower-

3 grade product or something manufactured to a standard that

4 isn't of the same level?

MR. JOHNSON: From my experience, it is very

6 subtle and it sometimes is because the products that are

7 manufactured outside the United States may be manufactured

8 to a same standard but through a different practice, a

9 different code of practice.

10 MR. LUDOLPH: If I could just switch gears one

II minute, earlier in your statement, you indicated that you

12 felt there was a need or that there was a concern over more

13 closely coordinating the position of U.S. participants in

14 international standardization, that the idea of speaking

15 with one voice not only was a difficulty perhaps between

16 government and the private sector in the United States, as

17 has been stated in earlier testimony here this morning, but

18 also that companies were representing views that may be

19 proprietary or at least represented one single position

20 rather than a coordinated position.

21 That is something new to me and I was always under

22 the impression that coordination in certain international

23 standards bodies was handled through a coordinating

24 mechanism that ensured one voice. I wonder if you could

25 elaborate on that. 
MR. JOHNSON: On the broad base, I can only give

2 you the benefit of my particular experience in that arena,

3 and the views that have been carried through certain

4 international technical commission meetings, IEC meetings,

5 have been those on occasion which were definitely

6 representing specific commercial interests.

MR. LUDOLPH: As it stands now, with the kind of

8 -- you elaborated at the end of your statement about some of

9 the concerns you had with your ability to participate in

10 international standardization and that tracks very well with

11 statements that were earlier made, that the key to good

12 competition and good standards is to have open and direct

13 participation in all standards development.

14 Do you see, in your opinion, a growing threat to

15 your competitiveness or your society's memberships'

16 competitiveness because of the generation of standards in

17 areas other than the United States on a closed basis?

18 MR. JOHNSON: I don't think the basis is closed,

19 but I think it is certainly slanted in favor of our

20 competitive countries outside the United States, from my

21 participation.

MR. LUDOLPH: Does that burden your manufacturers

23 or your participants?

MR. JOHNSON: Yes, it has.

MR. LUDOLPH: Thank you very much. 
CHAIRMAN WARSHAW: Thank you. Are there any other

2 questions from any panel member?

Well, we thank both you gentlemen for presenting

4 us with your views. Thank you for your time.

We will now have a break and reconvene at 11:15.

a.m. until 11:15 a.m.)

CHAIRMAN WARSHAW: If we could have the

9 representatives of the American Society of Civil Engineers

10 and the American Welding society join us at the podium, we

11 would appreciate it.

(Pause.)

Gentlemen, it is a pleasure for us to have you

14 here. We would like to start with Mr. Decker of the

15 American Society of Civil Engineers.

Mr. Decker.

MR. DECKER: Thank you very much.

19 president of the engineering firm of Wilbur Smith Associates

20 and I currently manage international engineering design and

21 construction projects for that firm in Columbia, South

22 Carolina.

However, I am here today on behalf of the American

24 Society of Civil Engineers where I serve on the National

25 Board of Direction and I am the Board's contact member on 
1 the management group dealing with codes and standards.

ASCE is a non-profit educational, technical and

3 professional society, founded in 1852 with the objective of

4 the advancement of science and profession of engineering to

5 enhance the welfare of mankind. ASCE currently has over

6100,000 members of whom 10,000 are in foreign countries.

ASCE has been involved with standards development

8 since 1875 and from 1976 has been an accredited standards

9 development organization.

It is appropriate to note, for today's hearing

11 record, the importance of engineering and construction

12 standards to public health, safety and welfare. If building

13 and structural codes are the whole body of technical

14 guidelines for design and construction, then standards are

15 the essential bone and marrow of that body.

16

What begins as a private sector voluntary

17 standards effort ultimately becomes part of building and

18 construction codes and manuals in the hands of thousands of

19 federal, state and local government officials.

20 The architectural and engineering community then

21 designs public and private buildings and structures to

22 conform to these codes. By recognizing that each of us is

23 touched by the far-reaching effects of codes, we realize

24 that it can make a difference whether those code-referenced

25 standards are domestic or international; U.S. or German. 
Although there are continuing efforts in the

2 United States to harmonize the existing three major building

3 codes, we understand that the EEC has already drafted a

4 European community-wide compendium of model provisions for

5 building regulations.

The stated purpose of the unprecedented compendium

7 is international harmonization of building requirements. We

8 are not aware of any involvement of the U.S. private sector

9 in the development of this compendium.

10 It is conceivable that the European Compendium

11 could exert a great deal of influence on building

12 regulations and codes worldwide.

13 As the United States endeavors to maintain a

14 strong competitive position in the global marketplace, the

15 importance of compatibility among national and multi-

16 national codes and standards becomes very apparent.

17 In our opinion, ANSI has not been able to

18 adequately fulfill its role. Generally, ASCE -- that is,

19 the society -- believes that the public and private sectors

20 should develop a joint standards policy with no reduction of

21 the private sector's time-honored role in standards

22 development.

23

After 115 years of involvement in the U.S.

24 domestic standard development system, ASCE believes that our 25 voluntary decentralized standards system is among the most 
1 effective and fair systems in the world.

The society opposes the accreditation function of

3 the proposed standards council of the United States of

4 America which would have that organization accrediting U.S.

5 standards developers. On the domestic side, ASCE supports

6 maintaining and strengthening the existing standards

7 development system.

On the other hand, we are confronted with two

9 major obstacles in our drive to improve international

10 standards participation. One is the lack of committed

11 resources. The other is lack of coordination among those

12 concerned with international standards.

ASCE believes some government action is necessary

14 to overcome these obstacles and recommends a private

15 sector/government partnership in standards activities. It

16 is unlikely that the many segments of the domestic standards

17 development system will be able to agree on a unified focus

18 and a common voice in international standards without the

19 government playing a collaborative role.

20 Current U.S. participation in international

21 construction-related standards is weak and inadequate. It

22 must be improved to broaden the acceptance of U.S.

23 technology, professional services and construction products 24 in the global marketplace.

Goods and services of the design and construction 
1 industry are exported, imported, marketed and regulated

2 through the common language of standards.

of particular interest to the engineering

4 profession are the nine Eurocodes for structural design

5 developed by the European community. ASCE does have

6 counterpart standards in most of these areas, but these need

7 to be harmonized for international trade.

In some areas, there are major differences to iron

9 out before we can attain truly international standards.

11 international standards activities, the engineering

12 professions have not been adequately involved. Nor have the

13 construction contractors nor the construction products

14 manufacturers been involved.

16 financial resources. We need to find the mechanisms that

17 will permit greater cooperation between the public and

18 private sectors, in supporting U.S. participation in

19 international standards.

Perhaps there should be contributions from the

21 Federal Government, but industry contributions must also

22 increase in order to ensure a stable source of funding. Therefore, what is the ASCE blueprint for

24 improving U.S. participation?

The need for improving that participation in 
1 international standards activities has been identified. The

2 next step is to develop a national consensus on the means

3 for that improvement.

4 ASCE recommends that a national study commission

5 be quickly established through an act of Congress and

6 appointment by the President. The commission should be

7 charged with recommending a structure or procedure for

8 enhancing the effectiveness of the United States in

9 international standards activities.

10

The study commission must have a balanced

11 membership, broadly representing all affected interests,

12 including but not limited to standards developers, technical

13 and engineering societies, code authorities, government

14 procurement and regulatory agencies, international trade

15 interests and industrial groups.

16 The study commission should be adequately budgeted

17 and staffed and should have no more than 12 months from its

18 establishment to report its recommendations to the President

19 and the Congress.

20

If such a commission existed today, ASCE would

21 offer the following six principles as a framework for its

22 deliberations: One, the existing domestic standards

23 development system should be maintained and strengthened.

24 Two, a unified focus on standards activities should be

25 developed. 
Three, a private sector/government partnership on

2 international standards activities including financial

3 responsibility on the part of both sectors, should be

4 established and nurtured.

Four, a private sector voice in international

6 standards should be preserved.

Five, increased private sector understanding and

8 support for participation in international standards

9 development is deemed essential, and six, the deliberations

10 of the commission should result in a consensus of thought

11 and a recommended process for enhanced U.S. participation in

12 international codes and standards activities.

13 ASCE does not believe it has all the answers,

14 obviously, on this complex question of international

15 standards, but ASCE believes strongly that these six

16 guidelines enunciate the correct initial approach for the

17 United States to take in improving the effectiveness of

18 participation in the international standards arena.

19 In closing, the American Society of Civil

20 Engineers offers its assistance to the federal government

21 and any interested party in working actively to resolve the

22 thorny issues of this dialogue.

We commend the National Institute of Standards and

24 Technology for demonstrating leadership and concern for the

25 long-term health of American science and technology by 
1 convening this hearing.

Thank you, Mr. Chairman.

CHAIRMAN WARSHAW: Thank you, Mr. Decker. We will

4 be happy to include the full text of you and everyone else

5 in this hearing in the record.

Are there questions from the panel? Mr. White.

MR. WHITE: Mr. Decker, you gave a very good

8 example of differences in standards both within the United

9 States as well as the fact that Europe has proposed some

10 standards in structural design area and I assume you are

11 using that synonymous with the building bode reference you

12 made earlier, correct?

MR. DECKER: Yes, correct.

MR. WHITE: I was just wondering in terms of the

15 focus of this hearing if you could comment specifically on

16 what the different parties in the United States need to do

17 specifically about dealing with the fact that number one, we

18 don't have coordination in the United States with respect to

19 the building codes -- I think you said there are three

20 different building codes.

21 And second of all, the European community has

22 already proposed some building codes so I was wondering if

23 you could expand upon your testimony and speak specifically

24 on these differences as to what you think needs to be done

25 about it, both by the government as well as by standards 
1 developers here in the private sector. MR. DECKER: It is a subject that the society has

3 talked about at some length. Unfortunately, ASCE does not

4 have a unanimity of opinion even within the various

5 committees.

I don't think that I personally can address your

7 question, Mr. White, of exactly what role the society is

8 going to be playing in this coordination. We identify it as

9 a problem. We identify it particularly that when we look at

10 international competition, we feel as a society that the

11 European community is doing a lot more towards this

12 coordination, a lot more than we are in this country.

13 But specifically, the society doesn't have a

14 program addressing this so I can't be any more specific than

15 that, I'm sorry.

16 CHAIRMAN WARSHAW: Mr. Donaldson.

17 MR. DONALDSON: Mr. Decker, you've confined your

18 remarks to the standards development side and yet in the

19 United States, the majority of the testing and certification

20 activity does relate to the building community and building

21 products industries.

I wondered if there is anything you might care to

23 comment or offer as an observation with respect to testing

24 and certification as it might bear on the issues we' re

25 looking at here. 
MR. DECKER: The reason for the focus of our

2 remarks is the fact that we are a standards development

3 organization. That's where we put our energies. We realize

4 that the other organizations do exist and we realize that

5 there are issues in the testing and the certification area.

6 I think I would leave that to others to comment on because

7 our remarks are really from the perspective of ASCE as a

8 standards development group.

9

10

11 23 question.

MS. MOORE: I guess the question is, is increased

MR. DONALDSON: So there was no intention.

MR. DECKER: No intention to eliminate it or no intention to -- it is really to focus in on what we do best. MR. DONALDSON: Thank you. CHAIRMAN WARSHAW: Ms. MOOIE. MS. MOORE: You have mentioned the need, as have other participants, for increased private sector participation and support for international standards activities.

I wonder, could you tell us, in your vision, does that include increased acceptance of existing international standards where those are not well-disseminated in American manufacturing?

MR. DECKER: I'm afraid I don't quite follow your

participation in international standardization a two-way 
1 street in your opinion?

In other words, when you go out to develop new

3 standards, does that also involve an increased commitment to

4 existing international standards which are not now being

5 used in the United States?

MR. DECKER: Well, I think the increased support

7 from the private sector that we are talking about is

8 mandatory. I guess I would generally agree that it is a

9 two-way street, as you have described.

I don't really have any further comment on that.

12 Decker. CHAIRMAN WARSHAW: Thank you very much, Mr.

18 appreciation to the National Institute of Standards and

19 Technology for the opportunity to express its views on the

20 subject of international standards participation. AWS is a professional technical society with over 36,000 individual members throughout the world.

A fact sheet on AWS is attached to the statement.

To establish our credibility in the field of standards, the following information is relevant. AWS first 
1 issued its welding standard in 1922. Today it has over 100

2 current standards on welding and related subjects.

Most of these are American National Standards,

4 having been approved by the American National Standards

5 Institute, ANSI. AWS has been an accredited standards

6 developing organization in the ANSI system since 1979.

Twenty-five technical committees with over 1000

8 volunteer experts comprise the workforce that develop and

9 maintain our standards.

10 Internationally, AWS has been delegated the

11 administration of two committees: ISO TC 44, for Welding

12 and Allied Processes, and IEC TC 26, for Electric Welding.

13 In addition, it is the secretariat for the American Council

14 of the International Institute of Welding, an ISO approved

15 international standards developing organization.

16 As a result of the Single European Act of 1992 and

17 other global market initiatives, it is only natural for the

18 United States to examine the mechanics in place to deal with

19 these issues.

20 AWS has participated in discussions with other

21 peer organizations and concludes that no significant

22 problems have been identified to warrant a change to

23 different systems of operation.

As an organizational member of ANSI we have also

25 concluded that, while the structure is sound, there is 
1 certainly a larger role for the government to play in the 2 system.

In addition to the areas where only government can

4 operate such as treaties and regulatory areas, the

5 government could accelerate its program of adoption of non-

6 government standards, and the acceptance of these standards

7 in lieu of what is generally referred to as military

8 specifications.

This will pay dividends in at least two ways.

10 First, it will eliminate an inordinate amount of unnecessary

11 duplication of effort in maintaining military specifications

12 for civilian items.

13 Second, it will allow government experts to

14 participate on the standards developing committees of

15 voluntary standards organizations. This second point will

16 enhance the position of the United States in international

17 standards activities since it is these committees that

18 provide the experts for those activities.

In response to questions relating to government

20 financial support for international standardization

21 activities, it would appear that no direct support is

22 warranted.

Indirect support in the form of tax credits to

24 companies that participate in international standards

25 activities would be a more prudent, consistent, and long- 
1 term solution.

There is concern that direct government financial

3 support could lead to government control. This would

4 undermine the fundamental philosophy of the voluntary

5 consensus system that has operated well for decades.

In conclusion, AWS wishes to suggest that the

7 current system of handling international standards

8 activities administered by the American National Standards

9 Institute is adequate and that no significant changes are

10 warranted.

Indirect government support in the form of tax

12 credits to companies that participate in international

13 standards activities is one way to assist in providing

14 greater participation in those activities.

Thank you for the opportunity to present these

16 views.

CHAIRMAN WARSHAW: Thank you, sir. Does any panel

18 member have a question?

19 Well, I thank you both very much for your fine

20 presentations and the time you spent.

21 I would now like to ask Mr. Hahn of the American

22 Society of Agricultural Engineers if he could come forward.

$23 \quad$ (Pause.)

24 We are running about a half hour ahead of schedule 25 so this will allow people to have a somewhat lengthier lunch 
1 hour. We will reconvene at 1:30. At the conclusion of this

2 morning's session, we will break for lunch. 17 Engineers. represent.

We have both Mr. Russell Hahn and Mr. Robert Lanphier, the American Society of Agricultural Engineers. Welcome and please comment.

MR. LANPHIER: Good morning. Thank you, Dr. Warshaw and members of the panel.

I believe that we ought to recommend, Dr. Warshaw, that you be named protocol officer for hearings in Washington for the way you run these hearings, which is extremely well.

CHAIRMAN WARSHAW: We have sandbags above. (Laughter.)

MR. LANPHIER: I am Robert Lanphier, President and Chairman of AGMED, Inc. in Springfield, Illinois and President-Elect of the American Society of Agricultural

With me today is Russell Hahn, Director of Standards and Technical Services for ASAE, the society we

ASAE welcomes the opportunity to provide comments to the National Institute of Standards and Technology in their evaluation of the role of the Federal Government in international standards activities.

The Anerican Society of Agricultural Engineers is

\section{Heritage Reporting Corporation} (202) $628-4888$ 
1 a professional and technical organization of 11,000 members,

2 active worldwide in the application of engineering knowledge

3 and technology for agriculture.

Standardization has been a principal mission of

5 the society for 80 years, and standardization continues to

6 grow in importance to the agricultural industry.

The ASAE holds an important niche in the

8 federation of technical societies, trade associations and

9 agencies that develop and maintain consensus standards for

10 the U.S. economy.

11 The ASAE Cooperative Standards Program is the only

12 voluntary standards program in the world devoted exclusively

13 to the development of a system of standards and engineering

14 practices for agricultural equipment and processes.

ASAE is accredited by ANSI as a developer of

16 consensus standards. Under the auspices of ANSI, the U.S.

17 member body if ISO, ASAE administers U.S. Technical Advisory

18 Groups for several ISO subcommittees. The society works

19 cooperatively with the Equipment Manufacturers Institute and

20 the Irrigation Association in this area.

21 The notice for this hearing and the subsequent

22 materials distributed by the Office of Standards services of

23 NIST implied an interest in assuming some level of

24 government control over the voluntary consensus standards

25 system that presently serves the interests of the United

Heritage Reporting Corporation

(202) $628-4888$ 
States.

I refer especially to the outline for a standards

3 Council of the United States of America.

4

5 imposition of any fundamental change in the present

6 voluntary consensus standards system. The present, self-

7 regulating amalgam of organizations and agencies is

8 consistent with the principle of free enterprise and the

9 concept of volunteerism fundamental to the United States.

16 accreditation requirements assure that developers of

17 consensus standards follow a policy of openness and due

18 process. These elements are essential to the development of

19 standards to meet the needs of industry and commerce without

20 violation of antitrust law.

21

22 receive the level of attention from corporate America that

23 has been needed for the last 20 years. Activities in

24 Western Europe toward a single unified market are

25 stimulating the standards-writing community in the United 
1 States to greater involvement with ISO and IEC and to the

2 harmonization of the U.S. and international standards.

Continuation of a strong partnership between the

4 Department of Commerce and the voluntary standards

5 developers is essential. ASAE deplores a divisiveness

6 implied by some correspondence and materials distributed in

7 relation to this hearing.

ASAE endorses principles set forth in the August

922 , 1989 letter from Manuel Peralta, President of the

10 American National Standards Institute, to the Honorable Doug

11 Walgren, Chairman of the Subcommittee on Science Research

12 and Technology of the House Committee on Science Space and

13 Technology.

14 This letter concerns Mr. Pealta's testimony before

15 the subcommittee's hearing on July 25, 1989 concerning

16 international voluntary standards activities and the role of

17 the Federal Government.

18 These principles are stated: One, the formulation

19 of international trade policy for the United states is the

20 responsibility of the Federal Government. That policy has

21 been and should continue to be the realization of the global

22 marketplace free from artificial barriers to trade in any

23 form.

Two, voluntary consensus standards that are

25 developed and approved by private, non-treaty international 
1 organizations such as ISO and IEC, are consistent with a

2 free trade policy and should be encouraged.

And three, in accordance with our free enterprise

4 system and considerations of efficiency and the proper

5 allocation of resources, the United States should be

6 represented in private, non-treaty international

7 organizations by a private sector coordinator of voluntary

8 standards development activity.

These principles make the respective roles of the

10 Federal Government and the federation of standards

11 organizations in the private sector quite clear.

13 made great strides in recent months to address the concerns

14 and to provide information relating to EC 92 as evidenced by

15 the ANSI Global Standardization News, Volume 2 and the

16 results of continuing meetings between ANSI-coordinated

17 private sector delegations and CEN, and CENELEC

18 representatives.

The exchange of correspondence between Assistant

20 Secretary for International Economic Policy, Thomas J.

21 Duesterberg and Mr. Peralta in letters dated September 18th

22 and November 15th, 1989, plus Mr. Duesterberg's address last

23 week at the ANSI conference confirm that the framework is

24 already in place for a strong partnership and coordination

25 between the private sector and the Department of Commerce 
1 regarding international standardization.

ASAE applauds and encourages these efforts. ANSI

3 and its federation of U.S. standards-writing organizations

4 must maintain a lead role in relationship with international

5 private sector standards bodies such as CEN and CENELEC, ISO

6 and IEC.

The Department of Commerce of course must play the

8 key role in government interactions and trade policy. These 9 areas, however, must be carefully coordinated to best serve

10 the long-term interests of the United States.

11 There are areas where NIST and other offices of

12 the Department of Commerce can help strengthen U.S.

13 participation in international standardization. ASAE

14 encourages Federal Government assistance in educating

15 corporate America to the importance of standards.

Too few industry leaders recognize the full

17 benefit of standards to their companies and customers. The

18 Industry too often has taken the voluntary standards setting 19 process for granted. This deficiency makes it difficult for 20 engineers and others with technical expertise employed by 21 these companies to participate fully in the standards 22 development process both domestically and internationally. Further, standards writing organizations such as

24 the ASAE Cooperative standards Program need to be more fully 25 funded through direct company support on a consistent and 
1 equitable basis.

Employee participation and financial support are

3 generally forthcoming when company management realizes the

4 impact of consensus standards.

We need your voice, the voice of the Department of

6 Commerce, to help educate corporate America to the benefits

7 of both domestic and international standardization. Also

8 the Department of Commerce can lead the way in educating the 9 general public to the importance of standards in daily life. ASAE encourages the Department of Commerce through

11 the Interagency Committee on Standards Policy to continue

12 the use of private sector standards by the government

13 whenever practical, and to encourage broader participation

14 of government employees in the private sector standards

15 development process both domestically and internationally.

16 ASAE is fortunate to have the participation of

17 engineers from the USDA ARS, USDA SCS, EPA and other

18 government agencies. However government employees are

19 frequently unable to full lend their expertise to

20 international standardization because time and travel

21 support for that purpose are not available. Funding of international standards participation

23 is difficult for technically qualified people employed in

24 industry, particularly for smaller companies to participate 25 and to be heard. The government should consider additional 
1 tax or other incentives for direct industry support of

2 standards organizations such as the ASAE Cooperative

3 Standards Program and for direct expenses associated with

4 participation of employees in standards work.

In summary, ASAE sees no need for a fundamental

6 change in the U.S. voluntary consensus standards system. As

7 was pointed out earlier this morning, the system works very

8 well, and if it isn't broken, don't fix it, and certainly

9 don't screw it up.

$10 \quad$ (Laughter.)

11 I'm supposed to smile when I say that.

12 Further, ASAE urges a close and cooperative effort

13 between the standards development community and the

14 Department of Commerce in regard to EC 92 and the

15 relationships between standardization and international

16 trade.

ASAE encourages the Department of Commerce to

18 further support standardization by supporting educational

19 programs for corporate America, by encouraging and

20 supporting greater government employee participation in the

21 private sector standards process, and by promoting

22 additional incentives for industry support of private sector

23 standardization both domestically and internationally.

24 If the U.S. Government correctly wishes to support

25 the standards system through funding and other resources, 
1 then let them do so in coordination with and through the

2 existing private sector standards infrastructure.

Thank you for this opportunity to be with you and

4 express the views of the American Society of Agricultural

5 Engineers.

CHAIRMAN WARSHAW: Thank you, Mr. Lanphier. We

7 appreciate your comments.

Any panel questions? Mr. Donaldson.

MR. DONALDSON: I am afraid this sounds a little

10 bit like the repetition of the question I asked the

11 gentleman from ASCE, but in the case of ASAE, do you have

12 any relationship with EMI, the Equipment Manufacturers

13 Institute, or other trade associations that are concerned

14 more in the testing side where it has been brought to our

15 attention that there had been questions in the past?

16 If you do have any involvement there, do you wish

17 to comment?

18 MR. LANPHIER: ASAE is concerned, as was expressed

19 earlier, with the standards setting and that is what we do

20 primarily as contract certification and accreditation.

21 CHAIRMAN WARSHAW: AnY other questions? Ms.

22 Moore.

MS. MOORE: I would just like to round off by

24 asking you a little information about your organization. 25 You have 11,000 members. Are they all within the United 
1 States or do you have overseas membership as well?

MR. LANPHIER: No, we have overseas members.

MS. MOORE: And to what extent are the standards

4 you developed used overseas, to your knowledge?

MR. LANPHIER: Pardon?

MS. MOORE: To what extent are the standards you

7 developed used in other countries, to your knowledge?

MR. IANPHIER: We have contributed to a number of

9 the ISO standards. Russ, do you want to comment?

MR. HAHN: This is a short leash. ASAE standards

11 frequently provide the technical basis for the U.S. position

12 in the development of international standards so to that

13 extent, at least, they are very supportive of the Iso

14 process.

Additionally, I am aware that many ASAE standards

16 are purchased not only by our members but others in overseas

17 countries.

I might respond a little further to your question.

19 We have members in over 100 countries, representing probably 20 roughly ten to fifteen percent of our membership.

21 MR. I.ANPHIER: If I might comment, it is a policy

22 also of ASAE to look at any existing ISO standards before we 23 start the domestic standards process.

MR. DONALDSON: I must say that your last

25 statement anticipated my question, but having thus said it, 
1 I would like to follow up. Having looked at those

2 standards, is that a point of departure? Do you, in fact,

3 incorporate them? What do you do when you look at them?

MR. LANPHIER: Russ deals on these on an

5 operational basis.

MR. HAHN: Mr. Donaldson, we are really only at

7 the beginning stages of this entire process. We see the

8 great need for increasing efforts towards harmonization of

9 U.S. and international standards.

The intent would be, whenever possible, to adopt

11 the international standard. There may be circumstances

12 because of cultural practices or other safety reasons, for

13 example, that may not be practical for the United States to

14 follow the international standard.

15 In those cases, we should work towards changing

16 the international standard.

17 CHAIRMAN WARSHAW: I want to thank you both, Mr.

18 Lanphier, Mr. Hahn, for your fine contribution.

19 We will now adjourn for lunch. I would ask

20 everybody to be back here at 1:25 so that the first two

21 presenters can appear at 1:30 sharply. The first two will

22 be the National Fire Protection Association and the american

23 Association for Medical Instrumentation.

24 We are adjourned. 
(Whereupon, at 12:15 p.m., the hearing was

2 adjourned, to reconvene the same day at 1:25 p.m.)

3

4

5

6

7

8

9

10

11

12

13

14

15

16

17

18

19

20

21

22

23

24

25

Heritage Reporting Corporation

(202) $628-4888$ 
A E T E R N O O N S E S S I O N CHAIRMAN WARSHAW: Welcome back. We'll open the afternoon session. Again, for some of you that may have missed the announcement earlier this morning, there is a Federal Register notice out and we have extended the comment period -- that is, for the receipt of written comments --

7 until June 5th, until the close of business June 5th,

8 another 60 days following this hearing in view of the number 9 of comments that we have received to date, as well as the 10 fact that some may be inspired as a consequence of these 11 oral presentations to submit additional comments. So the comment period has been extended until June 135 th. This afternoon we are starting with two

15 organizations, the National Fire Protection Association and 16 the Association for the Advancement of Medical

17 Instrumentation.

So I will ask Mr. Tony o'Neill, Vice President of

19 the NEPA to introduce those with him and to offer his 20 comments.

MR. O'NEILL: Thank you very much, Mr, Chairman,

22 and thank you behalf of the NFPA and its 53,000 members for 23 this opportunity to present NFPA's views on the U.S. 24 standards system here today. 
1 chief engineer of NFPA and runs our standards-making system,

2 and also Dan Piliero, NFPA's general counsel.

3

4

13 the time allotted.

15 United States participation in international standards. As

16 was stated in the Federal Register notice which stan has

17 just mentioned, the intent of this hearing is "the gathering

18 of information, insights, and comments related to improving

19 U.S. participation in international standards-related

20 activities and to possible government actions," and I

21 emphasize that last part.

23 namely the Department of Commerce is exploring the

24 possibility of establishing a standards Council of the

25 United States whose role would be to oversee and accredit

\section{Heritage Reporting Corporation} (202) $628-4888$ 
1 American private sector standards writers.

We are opposed to any additional government regulation in this area, and I will elaborate on that, but first let me tell you a little bit about NFPA.

I have mentioned we have 53,000 members. We have 4500 volunteers who work on our standards-making committees. We have a staff of 350 who 90 percent of their activity is in support of that operation.

And following my colleague, Joe O'Grady, this morning, we would be more than happy to submit for the record the 12 volumes of National Fire Code, some 8,000 pages of standards that are available from the NFPA for the record.

In addition, internationally, NEPA has launched a project with the Canadian Standards Association, CSA, to harmonize the National Electrical Code and the Canadian electrical code as a result of the Canadian/U.S. free trade agreement.

The NEC, National Electrical Code, is one of the most widely used safety standards in the world. We distributed about a million copies of these over a three year period.

It is sponsored by NFPA, along with the some 270 other codes and standards.

I should mention that NFPA has members in over 90 
1 countries throughout the world. Our standards are quite

2 widely distributed and used in that fashion.

Now I would like to move on to why NFPA opposes

4 further government oversight by accreditation of private

5 sector standards-making organizations.

Simply stated, it is not necessary and it would be

7 counterproductive. Why? Eirst and foremost, the U.S.

8 voluntary standards system is efficient, cost-effective,

9 highly productive and results in the promulgation of

10 thousands of quality standards each year.

11 No other nation produces as many quality standards

12 in as short a period of time at such a relatively small

13 cost.

14 Secondly, as the single largest users of private

15 sector developed standards, the Federal Government which is

16 represented here today, benefits most from the private

17 sector standard system and the volunteer structures that are 18 in place.

19 Thirdly, U.S. standards systems mirrors the unique 20 United States cultural commitment to free enterprise. The

21 market dictates the extent of participation by companies,

22 small and large, in standards work. This results, we

23 believe, in an optimum utilization and allocation of

24 resources.

It would be a serious mistake in our view to alter 
1 the basic character and nature of the system used so

2 successfully for so many years in the United States,

3 especially at a time when the Federal Government is trying

4 to reduce its budget by encouraging private initiatives.

5 Government control involves more time, more cost

6 and often produces a less effective and less responsive

7 product. I would remind the participants here today of the

8 mobile home standard, the Mobile Home Construction Safety

9 Standard which was formerly the ANSI NEPA Standard 501 (b)

10 which was taken over by HUD, Housing and Urban Development,

11 nearly 15 years ago.

12 It has been virtually frozen in the state-of-the-

13 art of 15 years ago without any real change allowed.

14 Pursuant to OMB Circular A-119, agencies of the

15 executive branch are required to defer to the private sector

16 for the development of consensus standards as much as

17 possible. Numerous government agencies use these standards.

18 The proposed Standards Council of the United

19 States or SCUSA would impose government regulation of the

20 voluntary standards system in the United States. While

21 SCUSA would presumably not have authority to make

22 substantive changes in standards, it would accredit

23 standards developers.

24 The impact would be major. As Professor Robert

25 Dixon points out in his classic treatise, standards 
1 Development in the Private Sector, Thoughts on Interest

2 Representative, and I quote him and I would submit this for

3 the record, Mr. Chairman, "the line between procedure and

4 substance is not nearly so bright and perhaps not as

5 different in influence on outcomes as many assume. Former

6 Senator Wayne Morris is said to have proclaimed in his law

7 teaching days that with authority over procedure, he could

8 arrange substance."

9 In our written testimony, and we have extra copies

10 of that through our Washington representative, Jack Gerard

11 who is here today, we have provided your panel with an

12 extensive discussion of legal considerations of private

13 sector standards development which has been put forth and

14 prepared by NEPA's general counsel, Dan Piliero.

15 We would like to supplement our written testimony

16 previously submitted with an NFPA position paper which this

17 position paper specifically addresses the legal issues as

18 they relate to section 413 of the Trade Act of 1979 . We

19 will leave that with the panel and submit it for the record.

20 Now, our position, as you can see, is the current

21 NIST proposal would add an additional layer of regulation

22 that would go much further by adding the requirement of

23 accreditation. That proposal would fundamentally change the

24 role of the U.S. Government in the standards development

25 area.

Heritage Reporting Corporation

(202) 628-4888 
What is now voluntary and private would be co-

2 opted into the governmental, or with accreditation,

3 necessarily comes government standards by which that

4 accreditation is to occur.

5

In short, those who regulate through accreditation

6 have the power to control.

There have been numerous prior proposals from the

8 Department of Commerce, the Office of Management Budget and

9 the Federal Trade Commission which are highlighted in these

10 documents for the record.

Each of these concluded that the private sector

12 standards-making organizations should be strengthened but

13 should not be taken over and supervised by the Federal

14 Government.

It is obvious that the U.S. system of

16 international standards, and I would like to talk about

17 international for just a moment, that system of

18 international standards representation is different from the

19 system used by many other nations.

To the extent that international standards are

21 perceived to have an important and meaningful impact on a

22 particular industry or interest group, participation in

23 international standards development will receive active

24 support financially and otherwise.

This has certainly been our experience at NFPA. 
1 Those interested parties who participate in international

2 standards development process bear the expense associated

3 with that activity. This is what is known as the free

4 enterprise system at its best.

We would look at any direct funding by the Federal

6 Government of international standards activity with great

7 caution because with direct funding comes strings attached

8 and the vagaries of federal budget cycles.

It should be clear by now that the historic and

10 current view is that the U.S. Government does not and should

11 not be the sole representative of the standards-making

12 system in this country.

Our government has a clear, active role to play in

14 U.S. participation in European developments. That role is

15 as a partner with the private sector standards-making

16 system, not its overseer.

As to government funding, it is our view that the

18 users of standards should bear the cost of their

19 development. To that extent, the government should pay its

20 fair share of the cost of developing those standards which

21 it uses.

This, we believe, is the sole funding issue. As

23 one of the greatest users, the government is probably the

24 single largest beneficiary of the voluntary consensus

25 standards system and therefore should be one of the systems

\section{Heritage Reporting Corporation \\ (202) $628-4888$}


1 largest supporters, not with grants, gifts or contracts, but

2 with appropriate recompense for benefit received.

In conclusion, and I would like to conclude by saying the private sector standards-making system in the

5 United States is functioning in parallel with our nation's

6 free market system. As long as the standards promulgated by 7 the various standards-making organizations are state-of-the8 art, provide a forum for differing views, are open to all

9 affected interests and provide due process through consensus 10 and balance, then private sector interest will be motivated

11 to participate even when their individuals views are not 12 necessarily carried forth as consensus in the standards. 13 Thank you, Mr. Chairman and the panelists for the 14 opportunity to express our views today and we would be 15 pleased to answer any questions or submit additional

16 documents for the record.

17 CHAIRMAN WARSHAW: Thank you, Mr. O'Neill. If you 18 would leave those with us, we will put them in the record as 19 you wish.

Are there any questions from the panel? Mr.

21 Donaldson.

MR. DONALDSON: Mr. O'Neill, in your reference to

23 the agreement or the arrangement between NFPA and CSA,

24 working on making the standards compatible, is there any

25 government involvement on either side in that? Or is that 
1 strictly through private sector organizations involved in

2 that process?

MR. O'NEILL: It is strictly two private sector

4 organizations. Our Board of Directors directed that we

5 establish a liaison with the Canadian Standards Association

6 which we did. We have set up a steering group on both sides

7 of the border. They will be meeting for the first time in

8 April and they have identified some six or eight areas which

9 we believe and they believe can be harmonized between those

10 two standards. That process is going forward.

11 MR. DONALDSON: And there is no government

12 involvement on the CSA site other. Do you have to report to 13 the SEC?

MR. O'NEILI: Other than those officials who might 15 participate on that standards review group, they have -- and 16 I am not certain but I will check that on the records to see

17 if there are any Canadian government officials on that

18 review group -- but in terms of and as far as my

19 recollection is, the answer would be no. I do not believe

20 that there is any Canadian government officials on that

21 steering group.

MR. DONALDSON: Okay, thank you.

CHAIRMAN WARSHAW: Mr. Ludolph.

MR. LUDOLPH: Mr. O'Neill, I am familiar with your

25 program. I had the good fortune to share in one of your 
1 long-range planning meetings. I know that you were at a

2 very early instance beginning to look at the 1992 program,

3 and certainly I know that you have world interests in the

4 same way. 21 that.

I was wondering, in that light in the past two years, have you had interest on the part of your membership or on the part of your Board in developing compatible codes, electrical codes with the European codes that are being developed in the electrical area.

MR. O'NEILL: First of all, let me address the earlier question or point. Yes, our Board of Directors long-range planning committee has established this as a priority, the EC 92 and world events. You were good enough to come down and brief us on your program at the Department of Commerce and that was much appreciated.

It remains a high visibility item within the longrange planning committee.

As to the specific question in terms of electrical correlation across the Atlantic Ocean, no, that has not started yet. There has been no real push within NEPA to do

I think one has to recognize that there is some 23 major, major changes in the infrastructure of electric power 24 distribution within Europe as compared to the United States, 25 but I would foresee and I would guess that there will be an 
1 opportunity to proceed on that line of cooperation in the

2 future.

I can't predict when, but to answer your question,

4 there has been no real pressure at this end to do that. MR. LUDOLPH: Is the lack of pressure so far from

6 a perception that the contacts in developing codes or

7 standards in the international standardization area

8 sufficient?

MR. O'NEILL: Yes, I think we are very comfortable

10 with the IEC and the U.S. National Committee representation

11 and what is being achieved there under the chairmanship or

12 presidency of Ron Reimer who will be talking to you this

13 afternoon, and many of the same folks who participate in the

14 development of the National Electric Code and there are

15 what, some 250 that participate in this and also, Mr.

16 Ludolph, are heavily involved in that IEC process.

MR. LUDOLPH: Just to switch gears slightly, on

18 another matter, do you see among your manufacturers or

19 participants and certainly the fire code inspectors, a

20 movement within the United States driven by the marketplace

21 or private sector forces to more uniformity among inspection

22 entities across the United States in the electrical or fire 23 code area?

MR. O'NEILL: In terms of electrical inspection,

25 there is a high level of uniformity throughout the United 
1 States because you have a National Electrical Code which is

2 adopted in over 40 states within the United States.

With the infrastructure of our staff, the electrical inspector staff, the National Electrical Manufacturers' support, the IBEW, all of the NECA, National Electrical Contractors Association, $A B C$, I could go on and on and on, who gather together around the code to make sure that it is properly and adequately interpreted and enforced. Does that hit the question?

Here in the United States, anyway, that's the way it's done. Same way by the way in Canada with the Canadian electrical code as we understand it.

MR. LUDOLPH: And I also understand there is a fire code in building construction, is that true? MR. O'NEIIL: Okay, let's talk about that. The NFPA produces what is known as a set of National Fire Codes which are both code required for installation of various types of equipment such as electrical or flammable liquids, gases, that type of thing.

But we also have a whole cadre of what I would call installation standards that tell you how to protect our built environment. An example would be the automatic sprinkler standard which is the most widely used sprinkler standard in the world. There are fire extinguisher standards, that type of thing. 
The model building codes which are represented

2 here today and which will be testifying later on, adopt

3 these NFPA standards and some up to 90 or 100 standards as

4 the requirements for that model code.

5

6 13 happy to go on and on. o'Neill, we appreciate it.

(Iaughter.) have as well.

So then when the model code is adopted by a state or a local government, the reference standards go along with that. That is true of ASTM standards and numerous other standards that go towards building an infrastructure to make the environment and the places where we live safer.

CHAIRMAN WARSHAW: Okay, thank you very much, Mr.

MR. O'NEILL: As you can see, I would be more than

CHAIRMAN WARSHAW: Well, we know you have voluminous material and we would be happy from now to June 5th to receive any additional information or thoughts you

MR. O'NEILL: Thank you, Mr. Chairman, again. CHAIRMAN WARSHAW: Mr. Miller, would you care to introduce the members of the Association for Advancement of Medical Instrumentation that you have with you. MR. MIILER: Yes. My name is Michael J. Miller and I am Executive Director of the Association for the Advancement of Medical Instrumentation, or AAMI, as it is

\section{Heritage Reporting Corporation (202) $628-4888$}


1 called.

Accompanying me today are AAMI President Dennis R.

3 Stupak, president of The Stupak Network; Robert Flink, co-

4 Chairman of the AAMI Standards Board and Director of

5 International Regulatory Affairs at Medtronic, Inc.; and

6 Mort Levin, chairman of the AAMI International Standards

7 Committee and Quality and Regulatory Affairs consultant at

8 Hewlett-Packard.

As I sit here and see the people to my left, I see

10 including myself, about 60 years of standards experience,

11 and as I look to my right, I see another 60. That adds up

12 to about 120 years of standards experience and I think we

13 finally achieved parity with the impression array of experts

14 sitting across the room today.

(Laughter.)

17 result of these hearings today.

18 AAMI is a membership association of 5,000 health

19 care professionals employed by manufacturers, health care

20 facilities, academic and research institutions and

21 government agencies that develop, manage, or use medical

22 technology.

AAMI develops standards for complex medical

24 devices such as programmable, implantable pacemakers, heart

25 valves, drug infusion devices, and patient monitoring 
1 equipment.

AAMI's standards are used by U.S. Government agencies, industry and health care facilities for design, procurement, technology assessment and management. Our standards are used or adopted by foreign governments, the United Nations, and such international organizations as IEC and ISO. These standards, as you know, are essential to national and international commerce and trade.

We will respond to the issues you have raised in the context of our experience with how government agencies have contributed to AAMI's national and international standards programs.

According to recent Department of Commerce estimates, medical devices represent a U.S. trade surplus of $\$ 1.7$ billion and this surplus is growing.

To ensure that the United States industry maintains its competitive position internationally, the U.S. must, through government and private sector agreement and coordination, communicate its positions on international standards, testing, and certification issues with one voice. The unified voice of the government and private sector has been fundamental to the success of AAMI's national and international standards programs -- a success that benefits industry and the public.

AAMI believes that important roles exist for both 
1 the public and private sectors in international standards

2 and that the strength of the U.S. system must continue to be

3 based upon a defined and shared responsibility.

4

5 its role and will bear its portion of the cost. While we

6 feel that government is an essential participant, it should

7 not direct international standards development.

17 and fund experts.

22 forums.

24 of the government and the American National Standards 25 Institute is helping the private sector gain access to

The issues related to certification and testing are complex and require further cooperative study and resolution by government and the private sector.

Underlying our testimony is the fundamental belief that the management and technical knowledge necessary for effectively directing and coordinating international standards exists inherently within the private sector. Private sector experts who must use standards are in the best position to determine priorities and to select Representation of national interests by knowledgeable U.S. technical experts -- from government and the private sector -- at the working level is essential to the acceptance of U.S. positions in international standards

One of the most important shared responsibilities 
1 international standards forums and fair opportunities for

2 the expression of U.S. positions on important technical

3 issues.

U.S. experts speaking to foreign experts, who have

5 a practical, working knowledge of specific medical devices,

6 is the most effective way to ensure harmonization of U.S.

7 technical positions with those of other countries.

8 In our experience, this kind of interaction has

9 cut through bureaucratic red tape to resolve important

10 technical issues that could have affected U.S. companies

11 adversely if not resolved.

12. Quite frankly, the red tape that the experts have had

13 to cut through has often been created by sCUSA-type

14 organizations that accredit representatives who do not have 15 a practical knowledge of medical devices. We feel that the

16 government and the private sector must coordinate and

17 cooperate in the selection of these types of experts.

18 The American National Standards Institute, of

19 which AAMI is a member, has proved to be an important link

20 between the many industries and voluntary organizations that

21 are involved in national and international standards.

22 ANSI plays an important coordination role and has

23 assisted our efforts to gain U.S. representation in

24 international standards activities. I might mention that

25 AAMI's standards program is accredited by ANSI.

\section{Heritage Reporting Corporation}

(202) $628-4888$ 
To date, we have no evidence that the existing

2 system presents an obstacle to our gaining adequate

3 representation in international standards activities.

4

5

11 integrate support of voluntary international standards

12 efforts into its formal trade policies. The government

13 should help ANSI protect U.S. interests by ensuring that

14 international standards and the process for their

15 development are not used as trade barriers.

16

17 facilitate the support and participation we have received

18 from the FDA's Center for Devices and Radiological Health

19 and other agencies such as the National Institutes of

20 Health. FDA and $\mathrm{NIH}^{\prime} \mathrm{s}$ participation and influence has been

21 fundamental to our international standards work.
We are convinced that the proposal for a standards Council is an unnecessary and inappropriate response to complex issues. Strong government intervention would ultimately create an additional and unnecessary level of 
1 administration and control that would only produce

2 restrictions, delay, and additional expense to the public

3 and the American industry.

We seriously question whether SCUSA or any

5 government agency can direct U.S. participation in

6 international standards as effectively as the private sector

7 can.

As an alternative to the SCUSA proposal, ANSI and

9 the government should develop a working relationship that

10 will ensure an effective and coordinated role for the U.S.

11 in international standards setting, testing and

12 certification.

It is essential that this relationship continue to

14 provide the means for government agencies to endorse,

15 support and provide experts to assist our efforts. FDA and

16 NIH committee chairmen, for example, lend valuable

17 credibility to AAMI's international standards efforts.

18 The comprehensive inventory of medical device

19 standards developed by AAMI in the $70^{\prime} \mathrm{s}$ and $80^{\prime} \mathrm{s}$ is the

20 essential foundation upon which the AAMI international

21 standards program was built. The government was a catalyst

22 and an essential partner to the effort that produced these 23 standards.

As we outline in more detail in our submitted

25 statement, these precedent-setting experiences convince us 
1 that government and the private sector can coordinate their

2 roles in international standards activities without

3 additional government controls.

We emphasize that although the FDA had the authority, under the Medical Device Amendments of 1976, to become, in effect a powerful SCUSA, the FDA chose instead to rely on the private sector -- although it was, at all times an active, essential and contributing participant. The FDA has contributed leadership, experts, and

10 financial resources to expedite high priority standards work 11 as a response to its 1976 mandate. Most important, FDA 12 communicated to the industry the importance of good

13 voluntary standards and the need for rapid deployment of

14 resources to meet a congressional mandate.

15 Similarly, government can provide is leadership,

16 experts, financial resources, and credibility to educate

17 industry about the strategic importance of international

18 standards and to help secure industry support and

19 participation.

The kind of teamwork that AAMI is advocating

21 between government and the private sector has already

22 produced an effective program for advancing the U.S.

23 industry's position on EC and international standards. Working closely with ANSI, government, and HIMA,

25 AAMI has assumed leadership positions in strategic areas of 
1 standards development in ISO and IEC.

These leadership positions will expedite the

3 development of standards needed by the EC, which will help

4 persuade CEN and CENELEC to defer to IEC and ISO standards.

5 CEN and CENELEC have confirmed that their policy is to defer

6 to ISO and IEC standards when possible.

In short, AAMI proposes to help expedite ISO and

8 IEC work to help ensure that important EC standards will be

9 developed in ISO and IEC where the U.S. has defined rights

10 of participation. To date, this strategy has been

11 successful.

12

As anticipated, ANSI and AAMI have assumed

13 responsibility for national and international standards

14 secretariats for ISO and IEC committees, subcommittees,

15 working groups and U.S. advisory bodies in strategic areas.

I will provide examples of the practical results

17 of our cooperative efforts.

AAMI/ANSI will soon be designated secretariat of a

19 new and highly influential ISO Technical Committee on

20 medical device sterilization, a technology fundamental to

21 medical device development and use.

It is our objective that this technical committee

23 develop international standards that will be used by all

24 countries of the world. We are holding meetings with CEN

25 leaders to discuss coordination of this work in April. An 
1 FDA sterilization expert, Virginia Chamberlain, will chair

2 this important technical committee.

AAMI has also begun commenting directly to CEN on its standards for medical device sterilizers. We were alerted to the CEN sterilization standards through the ANSI Reporter. ANSI provides direct access to CEN and CENELEC. It is worth noting that the U.S. working group on biological testing and evaluation -- administered by AAMI -developed an important draft standard in less than two months -- an impressive feat to anyone who is familiar with standards setting.

The recently formed CEN committee that corresponds to the ISO biocompatibility effort has decided that it will defer to this and other work if expedited. CEN sees this document as a model document and is holding it up to other working groups and committees in this area.

The private sector and government have developed and implemented a program that provides industry access to important decision-making processes that will enhance the medical device industry's competitive position in western Europe and the rest of the world. This program has not required government intervention of the type envisioned by the SCUSA proposal.

Out ability to serve the U.S. industry can, however, be bolstered by additional support from the 
1 government and an effective and cooperative relationship

2 between ANSI and government.

The relationship between private sector

4 organizations and government agencies will determine how

5 effectively the United States industry is represented in

6 international standards and world trade. Because this

7 relationship will have significant impact on the public

8 interest and welfare, it requires careful thought and

9 definition.

10

Our experience in working with government agencies

11 on domestic and international standards convinces us that

12 government and the private sector can forge a partnership

13 that will greatly enhance the efforts of voluntary standards

14 bodies such as AAMI and advance the competitive position of

15 United States industry.

In conclusion, we offer our experts and experience

17 in defining this relationship. We would welcome the

18 opportunity to be part of the process of resolving these

19 important issues.

20

Thank you for the opportunity to present our

21 views.

22

CHAIRMAN WARSHAW: Thank you, Mr. Miller. Are

23 there any questions from the panel? Mr. White.

MR. WHITE: Mr. Miller, I have questions in two

25 different areas. 
The first has to do with your statement which

2 alluded to obstacles at times to the development of

3 international standards. I got the impression that there

4 are certain kinds of obstacles that exist that makes it

5 difficult at times to get involved and actually participate

6 in international standards.

Did I hear you right, or could you elaborate a

8 little on that?

MR. MILLER: Well, I think the reference that you

10 heard was in the context of times we find that monolithic

11 standards organizations around the world appoint experts

12 that aren't practically knowledgeable about medical devices.

13 We find this an impediment to moving standards

14 forward in ISO and IEC. I should have made it clear, if I

15 didn't, that the types of obstacles that I was talking about

16 are more in the international arenas than certainly in the

17 United States.

18 MR. WHITE: In terms of the government, and I

19 guess I want to follow through a little on that, in terms of

20 the role of ANSI and AAMI and the government and the private

21 sector, could you give us some suggestions to what we in the

22 United States should do besides funding, obviously, to

23 improve our participation in international standards?

You mentioned a cooperative approach, but I was

25 wondering if you could amplify that a little because there 
1 are a lot of issues involved, not only standards development

2 but testing and certification issues.

MR. MILLER: I am not sure that AAMI's experience

4 is really in the testing and certification area so I would

5 defer to other people on that, but I think in our

6 experience, what we have gained from government has been

7 very useful, and that is in effect an endorsement of our

8 activities in the international arena.

At all times, at international meetings, there are

10 at least one and sometimes as many as four FDA experts

11 participating in activities where AAMI is a U.S.

12 secretariat. That not only provides experts to help with

13 the work, that also lends credibility to the effort that is

14 invaluable. That's also true of people from NIH.

With that type of support and credibility and

16 experts, we have found that we have been able to do the job

17 we need to do for the industry in our international efforts.

18 If somehow the government can develop a policy to a similar

19 effect in other areas, we would hope that other industries

20 would share the benefits and reap the benefits of government

21 involvement that we have.

MR. WHITE: Do you think the medical device

23 industry is adequately supporting the development of

24 international standards?

MR. MILLER: I think that that transition is 
1 occurring very well. I think that this is an area where

2 both the government and the private sector can work

3 together. I know in your role as chairman of the medical

4 device standards board of ANSI this is one of our missions,

5 to get the word out that there are important priorities

6 here.

I think that that educational message is being,

8 the word is being sent out, but I think that we need to work

9 harder to get it out. We've received more than we expected

10 in some respects from the industry in terms of experts and

11 participation and financial support.

We contemplate that during the next two years, as

13 we continue to get the word out about these activities and

14 their importance, that we will gain additional support, but

15 once again, I think that efforts such as yours as chairman

16 of the MDSB and the MDSB and ANSI's effort to get the word

17 out is very important.

19 Miller.

MR. MILLER: Thank you.

CHAIRMAN WARSHAW: We very much appreciate the

22 contributions of both NFPA and AAMI today and please, if you

23 have anything additional that you would like to submit, we

24 would appreciate receiving it.

Thank you. 
MR. O'NEILL: Thank you, Mr. Chairman.

CHAIRMAN WARSHAW: NOW I would like to ask the

3 Council of American Building Officials and the American

4 Plywood Association if they would join us here.

(Pause.)

Good afternoon, gentlemen. Thank you. James Bihr

7 is leading off for $C A B O$. If you could introduce ---

MR. BIHR: Mr. Kuchnicki will.

CHAIRMAN WARSHAW: Okay, Mr. Kuchnicki.

MR. KUCHNICKI: Good afternoon. MY name is Dick

11 Kuchnicki. I am the president of the Council of American

12 Building Officials. We appreciate the opportunity to

13 testify at this public hearing and first of all, I would

14 like to start out by saying that CABO is the umbrella

15 organization for the three model code organizations that

16 were alluded to this morning -- Building Officials and Code

17 Administrators International, the publishers of the National

18 Building Code, the International Conference of Building

19 Officials which is the publisher of the Uniform Building

20 Code, and the Southern Building Code Congress International

21 which is the publisher of the Standard Building Code.

It was alluded to this morning that the fact that

23 there are three model codes rather than one leads to a

24 disjointed effort. I think it is not totally true because

25 since 1972 when CABO was formed, one of the major objectives 
1 was to work towards a uniform code requirements and that is

2 one of the basic philosophies behind CABO, however, in view

3 of the fact that these are three independent organizations

4 that have their own membership, own bylaws, we felt rather

5 than testifying as $C A B O$ at this hearing, that it is

6 important to hear from each of the three individual

7 organizations.

9 the President of the International Conference of Building

10 Officials; Mr. Paul Heilstedt who is the Executive Director

11 of BOCA and Mr. Bill Tangye who is the chief executive

12 officer of the Southern Building Code Congress

13 International.

14 So we are going to do this a little different than

15 the other groups. We are going to go through each

16 individual, starting down at the end with Mr. Bihr.

17 MR. BIHR: If I may, Mr. Chairman. Thank you for

18 the opportunity to speak to you today. We would certainly

19 like to made our codes and standards available as a matter

20 of the record also, and probably extend those at membership

21 rates if you are interested.

22

(Laughter.)

24 express purpose of developing a uniform building code, and 25 in 1927 such a code was introduced and has been re-
Heritage Reporting Corporation (202) $628-4888$ 
1 introduced every three years since that time.

It has been adopted widely throughout the United

3 States. It is a code produced largely by donated efforts

4 and the codes are adopted by a voluntary act by local,

5 regional, state, and federal agencies, both throughout the

6 United States as well as in foreign countries.

Recent studies indicate that over 95 percent of

8 the local communities in the United States use a model code,

9 generally by adoption by reference and with minimal

10 amendments.

11 Our organization provides a wide variety of

12 ancillary services in connection with the code development.

13 This involves education and training, certification of

14 inspectors, and evaluation of building products and systems.

15 With respect to product evaluation, we accomplish

16 this through a subsidiary corporation, ICBO Evaluation

17 Services, Incorporated. The reason for the subsidiary is

18 the liability issues that attend the approval of products

19 and systems. That is something you could very well help us

20 in.

21 We adopt through our model codes and implement the

22 standards produced by many other volunteer associations in

23 the United States, all of whom have talked here -- well, I

24 don't know if all of them have talked yet, but ASTM, ANSI,

25 NFPA and I think to speak later, UL, and many others.

\section{Heritage Reporting Corporation} (202) $628-4888$ 
Thus, when a model code is adopted into law as a

2. regulatory document, these national standards become part of

3 the law. It is a system which is a unique one when compared

4 to other countries, but it is highly successful and

5 relatively free of the layered bureaucracies that you find

6 in these other countries.

We do support a U.S. policy designed to improve

8 the acceptance of U.S. technology on an international scale.

9 Our codes presently serve such purpose by adoption or use in

10 other countries, and particularly in more recent years, as

11 guidelines in developing nations.

12 We support the policy statement that is embodied

13 in $O M B$ circular $A-119$ with respect to the Federal Government

14 role and we particularly applaud the recent efforts of the

15 federal agencies such as the Department of Defense and their

16 commitment to utilize model codes and the national voluntary

17 standards.

18 Our organization members are not in a position

19 financially to participate actively in the international

20 standards organization. There are substantial costs

21 involved that we simply are unable to finance ourselves.

22 This is unfortunate because standards very often

23 have a regulatory basis and the objective sometimes becomes

24 obscure by the activities of those that are unfamiliar with

25 the regulatory intent, but we do support and monitor the 
1 efforts of organizations such as ANSI, ASTM and UL and the

2 various members of the U.S. industry.

3

4

We assume that U.S. industrial firms that are multi-national in scope have been active in the formulation of ISO standards and we presume they are active in recent formulation of CEN/CENELEC standards.

At the recent ANSI public conference on standardization of the 90's, we were advised by a European spokesman that U.S. industry can submit products for use in European economic community by showing conformance to CEN/CENELEC standards and procedures.

In our evaluation practice, European products can be judged on the basis of the standards adopted in the country of origin, if these standards and their quality control system are comparable in performance to the standards that we have adopted.

In our view, the current posture of CEN/CENELEC does not result in a level playing field. We believe a broader European perspective is needed to be consistent with the objectives of GATT.

We do not favor the establishment of a Standards Council of the United States along the lines outlined in the December 20, 1989 communication from Dr. Warshaw, however we agree with some of the objectives in terms of national orientation and commitment. 
In our view, the U.S. voluntary system works very

2 well. The approach that we would favor would be the

3 emergence of a truly level playing field with product and

4 systems produced to U.S. standards judged on the integrity

5 of our entire system and processes as opposed to procedure

6 where they would have to be re-appraised.

$7 \quad$ This approach may be augmented by providing

8 adequate financial resources so that U.S. voluntary codes

9 and standards groups could meet and confer with their

10 international counterparts to develop the confidence needed

11 for the credibility of our respective efforts.

12 The Federal Government strategy should be to

13 support the current voluntary system extant in the United

14 States in their dialogue with other countries.

15 I appreciate this opportunity to address you.

16 CHAIRMAN WARSHAW: Excuse me. I might point out

17 that you have used about seven of your ten minutes.

18 MR. TANGYE: I'll be very quick. My name is Bill

19 Tangye and I am the Chief Executive officer of the Southern 20 Building Code Congress.

21 Let me open by clearly and emphatically stating

22 that the Southern Building Code Congress International

23 supports the existing American voluntary standards system

24 and ANSI in its role as coordinator.

25 The most visible measures of our support are 
1 membership in ANSI, active participation on ANSI committees,

2 and the unamended adopting by reference of more than 150

3 ANSI standards in our standard code.

In view of the fact that the standard codes are

5 adopted and enforced by more than 2500 local jurisdictions

6 in 17 Southwestern, Southern, Southeastern and Atlantic

7 Seaboard states, our use of these ANSI standards has had and

8 is having a very positive impact on the construction

9 industry and companies that participate in it.

10 This is even more important when you consider that

11 our geographical area of influence has been and continues to

12 be the most rapidly expanding area in both population growth

13 and industrial dollar development in this country.

14 While we are a regional code and standards setting

15 organization, we recognize the importance of international

16 standards and their impact on U.S. industry. This country

17 has benefited from the ANSI process for some 70-plus years.

18 Our system of private sector development of codes

19 and standards has placed American companies in international

20 leadership roles in virtually every industry.

21 While we agree with many of the issues raised by

22 the Department of Commerce, we believe the existing ANSI

23 system can be revised to effectively respond to these

24 issues.

In our view, there has been no evidence submitted 
1 that justifies the creation of another body be it a

2 Standards Council of the United States of America or other

3 body to oversee the development of codes and standards in

4 this country.

In our view, the most important statement the

6 Federal Government can make to our international friends and

7 competitors is one, to actively participate in the ANSI and

8 other private sector voluntary standards processes, number

9 two to adopt the resulting standards.

10

Such a straightforward implementation of OMB

11 policy 119 will provide the very basis of the important and

12 necessary public/private sector partnership mentioned by

13 many of today's speakers.

14 The solution is perhaps best stated in Mr.

15 Peraltas' November 15, 1989 letter to Dr. Duesterberg

16 wherein he said "if the system has warts, we should of

17 course address these."

It seems to us in the Southern Building Code

19 Congress that removing the warts rather than amputating the

20 finger is the more appropriate remedy.

21 We appreciate the opportunity to speak to this

22 body today.

CHAIRMAN WARSHAW: Thank you. 
CHAIRMAN WARSHAW: Just about.

MR. HEIISTEDT: Just a couple of points that I

3 would like to agree with the two previous speakers. BOCA

4 promulgates a complete package of model codes and regulates

5 a complete built environment -- building, mechanical,

6 plumbing, fire prevention and the like.

BOCA makes wide use of national standards. We

8 reference 600 standards promulgated by 62 organizations

9 throughout the United States. You can see a healthy, strong

10 standards environment is what we need in the code

11 enforcement arena.

12 The local governments, the state and local

13 governments who form our largest membership -- 11,000

14 members - are those who are the active, on-the-firing line

15 as far as code enforcement is concerned.

16

I will close with that. Thank you.

17

CHAIRMAN WARSHAW: Well, thank you. Again, I want

18 to emphasize that the record is open until June 5th.

19 MR. KUCHNICKI: Also, just for the record, we will

20 also submit copies of all of the model codes series of each

21 of the member organizations, as CABO and previous speakers

22 stated they would submit their documentation.

CHAIRMAN WARSHAW: We can't have copyrighted

24 material, obviously.

25

But we would like copies of your statement. That 
1 would be useful for the record.

$7 \quad$ Ludolph. 18 that?

MR. KUCHNICKI: You will get a written statement. CHAIRMAN WARSHAW: And we would like to put the statements in the record, and any additional thoughts you come up with in the interim too.

Are there any questions of the panel? Mr.

comments that as it stands now, you have provisions to accept standards in the United States of manufactured products, standards prepared overseas that are deemed comparable or acceptable under some system. Could you give me a little bit of an idea of how that decision is made as to how a standard is deemed comparable and equivalent and acceptable into a code? How it would work its way into the local mandatory building code, and what kind of marks or accreditation that accompany

MR. BIHR: Well, as you might expect, products that are manufactured in other countries that meet a code objective are generally under a standard which is very similar to the standards that we customarily use.

So it has been our practice to evaluate the test standard of the country of origin and to see if it has the same objectives and similar results as the standards that we 
1 require.

If it does, we do not require a re-test of the

3 product specifically under our test standards. We are able

4 to evaluate the standard on its own.

Also we utilize the quality assurance programs

6 that are active in the country of origin, if they meet our

7 objectives.

CHAIRMAN WARSHAW: Okay, thank you, Mr. Bihr. Mr.

9 Donaldson.

10 MR. DONALDSON: Mr. Bihr, you mentioned I believe

11 Evaluation Services, Inc., if I caught the name correctly.

MR. BIHR: That's correct.

MR. DONALDSON: Could you elaborate on what

14 services are performed?

MR. BIHR: The evaluation of building products and

16 systems, the listing of testing agencies and the listing of

17 quality control agencies, and the approval of fabricating

18 plants.

MR. DONALDSON: And for whom are these

20 evaluations, to whom are they provided?

MR. BIHR: They are directed to our members for

22 their utilization.

CHAIRMAN WARSHAW: Well, we thank you again and

24 encourage you, in view of the short time, to submit any

25 additional comments beyond those presented today.

\section{Heritage Reporting Corporation}

(202) $628-4888$ 
The American Plywood Association, Mr. Flint. MR. FLINT: My name is Tom Flint. I am vice president and director of Technical Services Division of the American Plywood Association. The APA is a national trade association representing more than 50 domestic companies that annually account for approximately 80 percent of the softwood plywood and non-veneer structural panels produced in the United States.

Collectively, those member companies operate 199 manufacturing plants located in the west, south, northeast and the north central states.

Voluntary standards and product certification together have played a major role in the growth and development of the U.S. structural panel industry. The APA and its predecessor organization, the Douglas Fir Plywood Association, has been an active participant in the voluntary standards system for nearly 60 years. Over the last 50 years, the industry has experienced an annual compounded growth rate of nearly seven percent. Standards and certification have been the cornerstone of that growth.

Our initial involvement with standards began in 1933 with the fledgling Voluntary Commercial standards Program of the Department of Commerce. The first plywood commercial standard was promulgated in 1933 and we have 
1 maintained that standard to this day and the relationship it

2 created with the National Institute of Standards and

3 Technology.

4

5

Throughout those years we have also been active in various ASTM committees and have been intimately involved in the development of several ASTM test method standards. APA is an organizational member of ANSI and participates in their committees that impact structural use panel uses. As part of our activity, APA operates a testing laboratory for structural research as well as laboratories for product quality testing. We can be characterized as a certification agency as well as a standards development organization.

In the early 1970's we became concerned by a proposed OSHA rule for the accreditation of testing laboratories involved in safety testing for OSHA standards. structural panel products are used in many applications where worker safety is involved.

Our concern with the OSHA proposal was that it discriminated against companies and association testing

\section{Heritage Reporting Corporation (202) $628-4888$}


1 laboratories that might be involved in safety testing. They

2 did this by a prescriptive definition in their rule that

3 excluded a relationship between the laboratory and the

4 product manufacturer.

No national vehicle existed at that time to assess

6 and accredit laboratories that could demonstrate their

7 competence and integrity to do safety testing. OSHA was

8 hanging its hat on a separate in organizational ties between

9 the product manufacturer and the testing laboratory. They

10 were insisting on complete organizational independence.

11 We felt strongly the emphasis should be on

12 demonstrated competence and ability to perform regardless of

13 organizational ties. Consequently, we became a vocal

14 advocate of the National Voluntary Laboratory Accreditation

15 Program, NVLAP, that was in the early stages of development

16 by the then Bureau of standards with the input of ASTM and

17 others in the laboratory community.

18 NVLAP is now well-established and well-recognized

19 as a vehicle through which a competent and qualified

20 laboratory can be identified, both nationally and

21 internationally.

Certainly NVLAP can be considered a viable part of

23 the U.S. voluntary standards system, inspite of arguments

24 some might wish to advocate or attribute to government. 
1 development for more than 25 years. During that time, we

2 have come face to face with numerous non-tariff standards

3 and product certification barriers. We have also been

4 involved in ISO activities related to structural panel

5 products during that period of time, and are currently the

6 ANSI TAG administrator of ISO Committee TC 89 and we fund

7 ANSI participation status on the TC 89 committee.

At times that we have participated in the Iso

9 committees, we have funded those on our own.

10 Most recently we have been deeply involved in many

11 of the negotiations the Department of Commerce and the U.S.

12 Trade Representatives Office have had with Canada on the

13 Canadian Free Trade Agreement, and with Japan in connection

14 with the Structural Impediments Initiative and Super 301

15 activity of the 1989 Trade Act.

16 Our involvement with government in these most

17 recent instances has given us an appreciation for how

18 important it is to have an industry/government working

19 relation in dealing with trade issues and other governments.

20 Plywood is the only commodity not scheduled for

21 tariff reduction to zero with Canada until after the non-

22 tariff standards issues have been resolved. There is no

23 question in my mind that the partnership and support of

24 government in these instances was a key to what was

25 accomplished. 
Particularly in dealing with the Japanese

2 bureaucrats, it is vitally important to have a strong

3 industry/government working relationship.

Currently we are involved, along with three other

5 organizations, in efforts to secure recognition as an

6 accredited certification organization in Canada. This has

7 been handicapped and certainly delayed by the fact that the

8 United States has no national counterpart certification

9 accreditation system to that administered by the standards

10 Council of Canada.

11 While we have not yet faced problems in Europe, we

12 anticipate they will be encountered as EC 92 unfolds. If

13 so, it could be extremely helpful in our view if a U.S.

14 national system for accrediting certification systems were

15 created that functioned in a manner similar to the NIST

16 NVLAP program.

17 Such an effort by all means should make full use

18 of the voluntary standards systems now in place and not

19 supplant existing organizations. Coupled with accreditation

20 certification, of course, should be activities of government

21 to secure reciprocal recognition of accredited U.S.

22 organizations by other countries, as you have done in the 23 laboratory field.

These are not activities currently being filled by 25 any U.S. organization, at least in a generic sense, yet we 
1 see them as critical in the years ahead.

In dealing with foreign countries in trade

3 matters, it has been our experience that the support of

4 government can be critically important and effective if done

5 cooperatively with industry and consumer interests.

To that end, government's involvement in standards and certification activities needs to be done in a forum of equal participation by all affected interests so that true national consensus can be achieved.

CHAIRMAN WARSHAW: Thank you, Mr. Flint. Is there any question for Mr. Flint?

Well, we thank you very much for your constructive statements and I now would like to call the next two panelists, the American Society of Heating, Refrigerating and Air Conditioning, ASHRAE, and the American Institute of Aeronautics and Astronautics.

(Pause.)

CHAIRMAN WARSHAW: Good afternoon, gentlemen. I appreciate your being here. We have Mr. Grumman.

$$
\text { MR. GRUMMAN : Yes. }
$$

CHAIRMAN WARSHAW: Of ASHRAE.

MR. GRUMMAN : Yes.

CHAIRMAN WARSHAW: If you would introduce your associates and continue from there.

MR. GRUMMAN: Yes. I am David L. Grumman. With

\section{Heritage Reporting Corporation} (202) $628-4888$ 
1 me here today are on my left, Frank Coda who is the

2 executive director of ASHRAE and on my right, Jim

3 Heldenbrand, the manager of standards.

4

5

21 method.

My name is David I. Grumman. I am a registered professional engineer and I practice as an engineering consultant in Illinois. I am current chairman of the standards committee of the American Society of Heating, Refrigerating and Air-Conditioning Engineers, or ASHRAE, on whose behalf I appear today.

ASHRAE welcomes the opportunity to submit comments to the NIST on international standards-related activities. Since ASHRAE is not engaged in testing and certification, our comments will not cover those topics.

ASHRAE is a technical society comprised of 50,000 members from 120 nations. It is recognized worldwide for its voluntary consensus standards which help industry and serve the public by offering uniform methods of testing and recommended engineering practice.

Since 1978, ASHRAE's procedures for standards has been recognized by ANSI under its accredited organization

ASHRAE's international standards responsibilities include secretariat for three subcommittees of ISO/TC 86 on refrigeration, and administrator of the U.S. TAG, along with that TAG's seven panels. 
We will make our presentation in the following

2 format. First, issues of concern to ASHRAE; second,

3 examples of successful public sector/private sector

4 cooperation; and third, comments on the Canadian model of

5 government involvement; and lastly, our key recommendations.

The issues of particular concern to ASHRAE are

7 accreditation of standards developers, roles of private and

8 public sectors, and coordination between sectors.

The essence of ASHRAE's position on these issues

10 is this: Accreditation, Accreditation of developers of

11 private sector standards should remain a private sector

12 function.

Roles, the private sector should continue to write

14 and process standards under private sector coordination.

15 Public sector experts and standards users - - whether

16 federal, state or local government employees -- should be

17 encouraged to participate directly in the committee work of

18 writing and processing consensus standards for which the

19 public sector has an abiding interest.

20 The results of government research should be

21 offered when appropriate as a basis for critically-needed

22 standards where the technology is new or rapidly evolving.

23 Coordination, the interests of public sector

24 standards need to be coordinated in a way that one,

25 identifies and prioritizes proposed standards projects that 
1 are critical from the public sector viewpoint.

Two, communicates these needs to the private

3 sector coordinator.

Three, summons the resources of the public sector

5 such as government researchers to actively work on domestic

6 and international standards development and revision

7 projects and on technical advisory groups, or TAG's.

Four, organizes and promotes tax incentives and

9 other methods of public financial support of the private

10 sector standards coordinator.

11 Examples of such needed support include sharing

12 costs of ISO/IEC fees, broadening the membership interest

13 categories on TAG's, and defraying costs of hosting or

14 traveling to TAG and international standards meetings.

15 Now some examples. We think excellent models for

16 private/public sector cooperation are the ASHRAE series of

17 standards in the field of energy efficient design in new

18 buildings, where research carried out principally by the

19 then NBS and ASHRAE over a period of four decades, and by

20 NIST and DOE's national labs over the last 16 years, have

21 resulted in the ASHRAE/IES 90 and 100 series of standards on

22 energy efficient design of new and existing buildings.

23 Further, ASHRAE solar collector test standards and

24 the DOE appliance efficiency test methods and standards have

25 similarly resulted from public/private cooperation. 
Preparation of ASHRAE Standard 90-75, energy

2 conservation in new building design, was initiated by a

3 private sector association of state officials, NCS/BCS, an

4 organization whose founding in 1967 was assisted by NBS.

Reacting to disparate legislative initiatives by

6 states in response to the energy crisis of the early $70^{\prime} \mathrm{s}$,

7 NCS/BCS asked NBS in 1973 to prepare a building energy

8 conservation standard that could be offered as a model code

9 to the states.

10 NBS produced a research report in the form of a

11 draft standard and recommended that it be turned over to an

12 appropriate standard developer to be processed as a

13 voluntary consensus standard.

14 ASHRAE accepted the task from NCS/BCS in February

15 of 1974 and the standard was prepared and published in

16 record time by July 1975.

17

ASHRAE standards now serve as the basis of energy

18 codes in all 50 states. Since buildings consume

19 approximately 35 percent of the nation's energy expenditure,

20 the role of ASHRAE's voluntary consensus standards is very

21 important in promoting efficient U.S. energy use.

ASHRAE participated in the rulemaking process for

23 the government's energy conservation standards for new

24 building, and of late has provided the underlying document, 25 namely ASHRAE/IES standard 90.1, for the new energy standard

\section{Heritage Reporting Corporation}

(202) $628-4888$ 
1 for the commercial and multi-family highrise-types of

2 federal buildings.

3

4

Further, issuance of the Model Energy Code in the $70^{\prime}$ s under CABO provided an important delivery mechanism for adopting a code language version of ASHRAE' $^{\prime}$ energy standard by building regulatory officials.

Now some comments on the Canadian model of government involvement in standards. While we may admire potential efficiencies in countries that have mandatory national building codes or standards, we do not wish to trade the freedom of the U.S. national voluntary consensus system for a more rigid one controlled by the public sector.

We think that the public sector could and should take better advantage of the opportunities to participate in the national voluntary consensus standards system -- and that this system would be stronger as a result. Domestically, the Departments of Defense and Energy seem more committed to taking advantage of and working to improve the present system than are some other standards-using federal agencies.

NIST traditionally has had a large percentage of its research staff constructively participating in standards development activities, and this work should once again receive institutional priority and recognition. 
The Standards Council of Canada works in a

2 different code environment than prevails in the U.S. The

3 powers there include accreditation of standards-writing and

4 testing and/or certification organizations and determination

5 of which standards are to be mandatory.

While such powers here would make discrete federal

7 legislation dealing with fragmented or overlapping state

8 activities unnecessary, we continue to hope with our present

9 system that the states will voluntarily cooperate.

10 We fear that creating such a standards council

11 organization in the U.S. - - and making it subject to the

12 annual federal appropriations process -- would create

13 uncertainty and a perceived, perhaps an actual, loss of

14 control by the private sector.

15 We urge that advocates of change in the present

16 system show evidence that its shortcomings would be improved

17 by such a change.

18

Our key recommendations: ASHRAE suggests that

19 public discussion be focused on the two-center approach. By

20 that we mean that separate but coordinated centers in the

21 private and public sectors, as suggested by the National

22 Standards Policy Advisory Committee in 1979.

23 Plan B, as advocated by the ANSI Blue Ribbon

24 Committee, appears to be based on this approach.

25 ANSI's plans $A$ and $B$ are described as market- 
1 driven systems. However, the secretariat's report at the TC

286 meeting in Moscow in september 1989, indicated that new

3 thrusts will affect the way ISO standards are prepared -- in

4 that each standard will be expected to address its impact on

5 health and safety of the product, system or practice.

6 We think something more than the term market-

7 driven is needed to describe the needs and motivations

8 concerning impacts of standards on safety, on health, on

9 energy efficiency and on environmental protection.

10 While economics must be included when considering

11 practical solutions, a solely market-driven system will not

12 always solve problems created the need to address the above

13 concerns.

14 In a cooperative mode, the public sector should

15 lead by setting policy and pointing out problems and

16 potential solutions; the private sector should advise how

17 problems can be solved most efficiently.

18 Thank you for the opportunity to participate in

19 this review of the state of health of U.S. activities

20 related to domestic and international consensus standards

21 activities.

CHAIRMAN WARSHAW: Thank you, Mr. Grumman. Are

23 there any questions from the panel? Mr. Donaldson.

24 MR. DONALDSON: Does ASHRAE have a policy or a

25 procedure whereby it considers the prevailing international

Heritage Reporting Corporation

(202) $628-4888$ 
1 standards before it begins standards development? And if

2 so, how is that implemented?

MR. GRUMMAN: Well, in my experience with ASHRAE,

4 it has never adopted an international standard. It

5 considered it once about five or six years ago when I was on

6 the Standards Committee. Perhaps if, with your permission,

7 if the manager of standards might want to comment on his

8 experience with that.

MR. HELDENBRAND: We do consider them in the sense

10 that we, as a matter of policy, look at existing Iso

11 standards. A case in point would be a project committee we

12 have now on a computer protocol for energy management

13 control systems.

14 This standard project committee 135-P has studied

15 over 50 Iso standards thoroughly and is working to try to

16 make sure that what the committee comes up with is

17 compatible.

MR. DONAIDSON: To what extent do the ISO or IEC

19 standards reflect prevailing ASHRAE wisdom? To what extent

20 have you been able to be influential in having your

21 positions adopted?

22

MR. GRUMMAN: As I mentioned, ASHRAE has a

23 secretariat, one of the ISO TC's. So I think his experience

24 might be appropriate for comment here.

25 MR. HELDENBRAND: Within the ISO realm, our 
1 experience or effectiveness has been principally in the TC

286 realm which is titled Refrigeration, however it covers

3 refrigeration and air-conditioning and is a broader

4 committee than the title indicates.

There are other ISO committees and IEC committees

6 that we could and should be participating in.

CHAIRMAN WARSHAW: Thank you very much, Mr.

8 Grumman, and your associates, from ASHRAE.

We now have Mr. French of the American Institute

10 of Aeronautics and Astronautics. Mr. French.

MR. FRENCH: Thank you. Good afternoon. My name

12 is James French. I manage the Standards Program for the

13 American Institute of Aeronautics and Astronautics, known

14 throughout the aerospace community as AIAA.

This Institute is a non-profit professional

16 society dedicated to advancing the arts, sciences, and

17 technology of aeronautics and astronautics and to promoting

18 the professionalism to those engaged in these pursuits.

We have a membership of over 43,000 drawn from all

20 levels of American industry, academia, private research

21 organizations, and government, as well as from numerous

22 nations abroad.

The cornerstones of AIAA programs have always been

24 technical meetings and publications. The AIAA Standards

25 Program was begun just ten years ago. This timing was 
1 indicative of the recognition of the importance of modular

2 designs and reusable spacecraft.

The program has received close attention by our

4 Board of Directors from the outset. Once AIAA standards

5 publications complete our procedures, they are submitted to

6 ANSI for recognition as American National Standards.

Increasingly, related organizations in other

8 space-faring nations are examining the projects underway in

9 AIAA and are participating with us toward a goal of common

10 international package related to design and deployment of

11 spacecraft.

12 Just last year, the Iso Technical Committee

13 responsible for space vehicles, TC 20, formed its first

14 subcommittee dealing specifically with astronautics.

15 In response to the questions put before this

16 public hearing, AIAA has found that the U.S. standards

17 system, as presently constituted, serves the needs of the

18 aerospace community. In fact, there is an increasing trend

19 for the several trade and professional organizations in this

20 field to collaborate on technical questions of mutual

21 interest.

22

This condition extends to such organizations in

23 other countries. Standardization has benefited both the

24 aircraft and the air transportation industries dramatically;

25 it is hoped that engineering harmonization in space can

\section{Heritage Reporting Corporation}

(202) $628-4888$ 
achieve comparable results. participate in standardization to the full extent of their own mission interests or those of their constituencies.

In aerospace standards work, some federal agencies participate more fully than others, but none are unaware of or are left out of the planning or conduct of new activities. At this time, the means for coordinating this work is adequate because the total number of players is small.

On the international scene, AIAA staff and committee representatives attend international standards meetings regularly. To date, the expenses for committee representatives have been borne by their employers. We are looking into common funding techniques such as those used by other professional societies for many years in order to send the most qualified representatives irrespective of their employers' resources.

The international and domestic aspects of aerospace standards are assigned to the same committee under AIAA practices. At this time, it appears that we, in the United States, are better equipped to lead aerospace standardization because there are society and association mechanisms in place.

In Europe, technical issues regarding aircraft are 
1 being addressed in a similar manner, but little attention

2 has been given to standardization for spacecraft through the 3 customary techniques.

AIAA would like to take this opportunity to

5 propose that the hearing consider the establishment of a

6 standards foundation, directed by a public board and funded

7 by appropriation.

The Secretariat for such a foundation could reside

9 in the Department of Commerce, if desired. The principal

10 role for the standards foundation would be to make financial

11 grants to accelerate the development of standards and guides

12 used in the development, production and testing of U.S.

13 products and services.

14 Grant approval could be made for any of the

15 following reasons: For standards development -- that is the

16 development of consensus standards for products identified

17 as particularly trade-sensitive. Funds would be subject to

18 competition among U.S. entities affected by the relevant

19 projects.

20 For travel, lack of funds for this purpose has

21 been a deterrent in promoting U.S. technology in many

22 spheres of influence and for obtaining the most qualified

23 representatives. Secretariats, TAG administrators, and

24 other concerned parties could be potential grant recipients

25 for funds to send participants to domestic or international

\section{Heritage Reporting Corporation}

(202) $628-4888$ 
1 meetings, conferences, and workshops to establish or present

2 U.S. positions.

For fees, the cost of participating in national and international standards development organizations is substantial. Some of the funds could be allocated for assuring participation in tarde-sensitive areas that might

7 be otherwise neglected.

For publication and reproduction, the initial cost

9 of publishing and reproducing standards documents for

10 international use is substantial. Grant recipients might

11 receive such funds on a matching basis.

For translation, leadership in standards requires

13 translation into other languages which is a feat that is

14 more expensive in the United States than in Europe because

15 of our principal reliance on English in this country.

At the same time, mere utilization of standard

17 practices, as encouraged under the GATT Code, can be

18 difficult when the source documents are in an unfamiliar

19 language. Perhaps the foundation could sponsor translations

20 in major cases and match grant recipients' funding in

21 others.

Astronautics standardization is a young discipline

23 because so many projects have been characterized by single-

24 use equipment. With the current space shuttle and plans

25 underway in several areas for modular satellites, 
1 serviceable spacecraft, and space robotics, the utility of

2 standards will increase exponentially.

It is predicted that internationally harmonized

4 standards for space activities will be necessary in the near

5 future to prevent serious space accidents, loss of major

6 missions, and the mitigation of debris.

The issue of testing and certification for space

8 flight equipment is just beginning to be addressed. There

9 is essentially no background experience on the reciprocal

10 acceptance of test data in this field.

11 As qualification test methods suitable for use in

12 scaled-up production of space flight equipment are

13 developed, it is likely that they will be harmonized among

14 interested nations from the beginning.

15 When certification methods are determined, it also

16 seems likely that techniques will be drawn from the Iso

17 Guides. Hopefully trade barriers can be avoided as

18 commercial space activity grows in greater service to

19 mankind.

20

We are providing additional explanatory material

21 about the AAIA Standards Program with our presentation.

CHAIRMAN WARSHAW: Thank you, Mr. French. Mr.

23 Donaldson.

MR. DONALDSON: Jim, I was interested in your

25 reference to techniques used by other societies that are 
1 proven techniques for sharing the wealth, so-to-speak, among

2 the less affluent members.

Would you be able to share with us either some

4 society names as examples, and/or a technique or two that

5 are currently in use, if you have that at your fingertips?

MR. FRENCH: Well, I believe the Instrument

7 Society of America, one of the earlier testifiers, maintains

8 a common funding pool. When I worked for the Trade

9 Association of Process Control Manufacturers and we held a

10 Secretariat, we did that technique -- that is, a standards

11 travel budget for each year was established.

12 The contributions of participating firms was

13 pooled together so that delegates could be people from other

14 than the immediate membership, according to needed

15 expertise.

MR. DONALDSON: Sorry, you put that in the past

17 tense. Do you know if that is still the practice?

18 MR. FRENCH: I do not know whether that is still

19 the practice.

MR. DONALDSON: Thank you.

CHAIRMAN WARSHAW: AnY other questions? Well,

22 thank you very much. We appreciate you presenting us with

23 your comments today.

Next we have the Society of Automotive Engineers.

25 As you recall, they were switching slots at ANSI's request 
1 so that the Society of Automotive Engineers and the U.S.

2 National Committee for the IEC represented by its chairman,

3 Ron Reimer will step forward.

4

(Pause.)

CHAIRMAN WARSHAW: We will start out with the Society of Automotive Engineers and I will ask Max Rumbaugh, the President of that society to introduce his associate and please offer his comments.

MR. RUMBAUGH: Thank you. Dr. John Mason who is the 1990 SAE President, sends his regrets for not being able to be here today.

Joining me is Dr. Lamont Entinge, director of research at Eaton Corporation, SAE's president-nominee for 1991 and currently an SAE fellow in the Office of Science and Technology Policy.

I am here on behalf of Dr. Mason, SAE's president. As you indicated, my name is Max Rumbaugh, Jr., and I am SAE's executive vice president.

I am here today to present $\mathrm{SAE}^{\prime} \mathrm{s}$ response to the central purpose of this hearing described in the Federal Register on improving U.S. participation in international standards activities, opportunity for interested parties to comment.

As background, SAE is a worldwide organization whose membership tops 50,000. The purpose of SAE is to 
1 advance the knowledge of the arts, sciences, standards, and

2 engineering practices connected with the development,

3 design, construction, and use of self-propelled machines.

One of SAE's primary services is the development

9 Standards Institute, ANSI, system.

ANSI effectively serves as the coordinating and

11 accrediting body for the U.S. standards-writing system.

12 ANSI also serves as the official U.S. member to the

13 International Organizations of Standardization, Iso.

SAE likewise plays an important role in the

15 international standards arena by supporting several U.S.

16 Technical Advisory Groups and secretariats for ISO and IEC.

17 These groups include TC 20, Aircraft and Space

18 Vehicles; TC 22, Road Vehicles; TC 70, Internal Combustion

19 Engines; and TC 127, Earthmoving Machinery.

SAE also administers various quality assessment

21 and accreditation programs which are partially sponsored by

22 the U.S. Government.

SAE has been successful in having its standards

24 accepted worldwide. For example, and only examples, only

25 four of the total, is the RPHE' $\mathrm{s}$ which is the rollover 
1 protection of highway equipment, oil Viscosity Rating that

2 are used worldwide, threads for the aerospace fasteners and

3 VIN, the vehicle identification number system used worldwide

4 for vehicles.

5

6 the proposal by NIST to establish SCUSA which is being

7 designed to increase government influence on the standards8 writing process and which may impair the effectiveness and 9 efficiency of this system.

10

11 developed with input from two of its operating boards,

12 namely the Technical Board which develops standards and the

13 Performance Review Board which administers quality

14 assessment and accreditation programs.

our position responds primarily to the proposal

16 distributed by Dr. Stanley warshaw. In our judgment, this

17 proposal is sketchy and leaves a number of unanswered

18 questions.

19

20

21

22 bodies?

23

Two, what is the optimal degree of government

24 participation in and financial support for U.S. standards25 writing and product certification?

Heritage Reporting Corporation (202) $628-4888$ 
Three, how can the U.S. best meet the challenges

2 of EC 92 in the international standards field?

SAE's response to the issues: How can we most

4 effectively coordinate the U.S. standards developers and

5 certification bodies?

The NIST/SCUSA proposal calls for government

accreditation of standards developers which is tantamount to the government regulation the standards process. This is a

10 standards community. The current ANSI system is strong

11 because of its fairness and openness to all participants. SAE believes that the standards system works more

13 effectively with government participation, not government 14 control. Therefore, the government and NIST in particular, 15 should rejuvenate its support of the ANSI system and 16 participate in programs where government, industry and the

17 standards development organizations form a broad-based 18 constituency.

19 The proposal as stated puts SCUSA, with limited 20 membership, in an oversight and control position which would 21 create an imbalance in the system. This is not necessary, 22 nor is it an effective way to manage the system. If, in effect, there are any weaknesses in the 24 current system, then we have an obligation to call these to 25 ANSI's attention and work with ANSI to ensure that 
1 corrective action is a high priority.

For example, the ANSI government member council

3 and NIST's membership on the ANSI board can be used for

4 governmental input into the ANSI system.

The second area, what is the optimum degree of

6 government participation in and financial support for U.S.

7 standards-writing and product certification?

Government support for the voluntary standards

9 system means that the government should participate in the

10 system, not control it. The primary role for government

11 should be to support the participation of government

12 employees in the process which SAE encourages.

13 The proposal suggests that funding could be made

14 available to the voluntary standards organizations to

15 support their standards-writing activities and participation

16 in the international standards development efforts.

17 The capability of NIST to provide direct funding

18 dollars should be seriously questioned. With the current

19 budget-cutting throughout the government, it is highly

20 improbable that NIST will have sufficient money to give to

21 standards-writing bodies.

Industry and the standards-writing community

23 contribute millions of dollars in manpower and direct

24 expense funds to the process. The Federal Government should

25 be capable of paying its fair share by supporting government 
1 employees' travel and time, and paying a fair share of the direct expenses to the standards developing organization.

Therefore, the government control over the process should come only through its participation and a contribution of a fair share of the expenses for the running of the program, as is the case with industry.

I would be remiss if I failed to mention the very

8 high degree of success SAE has had with the Department of

9 Defense in the standards process. For years, DoD has

10 participated and supported SAE, ANSI and the other

11 standards-writing bodies.

In November 1988, Dr. Robert Costello, then the

13 Under Secretary of Defense, published a report entitled,

14 "Enhancing Defense Standardization" in which he said,

15 "substantial savings could be achieved by even greater

16 reliance on non-government standards rather than overly-

17 restrictive military specifications for commercial products

18 and processes."

Mr. Chairman, it is my understanding that his

20 replacement, Mr. Betty, supports that same position.

This trend is the appropriate theory for

22 government participation.

Further, the involvement of employees of the FAA,

24 NASA, the EPA, DOT, DOD and NIST and SAE standards

25 committees is an excellent model.

\section{Heritage Reporting Corporation} (202) $628-4888$ 
Three, how can the U.S. best meet the challenge of

2 EC 92 in the international standards field?

There is no doubt that the impending changes in

4 Europe with regard to EC 92 is forcing the U.S. to alter its

5 view of the standards development process.

Relationships between the U.S. Government and the

7 European Community, EC, will have to be strengthened and the

8 Department of Commerce is the obvious agency to handle this.

9 Standards, however, are a different issue.

10 The EC has delegated the job of developing

11 standards to CEN/CENELEC. CEN/CENELEC consists of the

12 standards-writing organizations from the member countries of

13 the EC, similar to ANSI and its membership.

14 The relationship between CEN/CENELEC and the EC

15 should be similar to the relationship between ANSI, its

16 members, and the U.S. Government. With this free enterprise

17 system gaining strength in Europe, it is an inappropriate

18 time for the U.S. to consider a government-controlled

19 system.

20

SAE believes that a direct relationship between

21 ANSI and CEN/CENELEC will be the key to successful worldwide

22 standards coordination.

23 In summary, SAE opposes the stated proposal

24 because SAE believes that the current U.S. voluntary

25 standards system is efficient, cost-effective, and highly

\section{Heritage Reporting Corporation} (202) $628-4888$ 
1 productive.

The system produces thousands of high-quality

3 standards each year which are responsive to the needs of

4 American industry and government. The Federal Government

5 should participate and support this system just as industry

6 does.

The voluntary standards system mirrors our culture

8 and commitment to free enterprise. While government has an

9 important role to play, $\mathrm{SAE}$ believes it would be a serious

10 mistake to alter the basic character of the free enterprise-

11 based system.

12 Therefore, SAE offers the following

13 recommendations to upgrade, strengthen, and reaffirm the

14 current system.

15 One, NIST should endorse ANSI as the U.S.

16 voluntary standards system coordinator and accreditator.

17 Two, NIST should encourage participation and

18 provide support for the voluntary standards system by all

19 U.S. Government agencies.

20 Three, NIST should recognize and support ANSI as

21 the direct interface with CEN/CENELEC and ISO.

22 Four, the Federal Government should provide

23 limited designated funding in support of future standards

24 activities. Primary funding would continue to be provided

25 by free enterprise agents.

\section{Heritage Reporting Corporation} (202) 628-4888 
Thank you for your attention, Mr. Chairman. CHAIRMAN WARSHAW: Thank you, Mr. Rumbaugh. Are there any questions from the panel? Ms. Moore. MS. MOORE: You mentioned a number of other participants that you think the U.S. Government should pay

I notice that a number of other participants

9 suggested that increased government control of standards

10 development would leave the system open to the vagaries of

11 the federal budget allocation process.

Could you elaborate a little on how you think you

13 could avoid that problem in a fair share payment system?

15 of the government to pay their fair share of the cost when 16 many of the SAE standards are, in fact, adopted by various

17 government agencies and used for various purposes, just as 18 industry does the same thing.

Industry will adopt SAE standards and use them in

20 their process. We expect industry to pay their fair share

21 of that cost, dependent upon how much and what use they make

22 of it. We feel that the government should find a mechanism

23 for being able to do that.

Obviously, there is a concern that through the

25 budgeting process, which is one of the reasons we oppose the

\section{Heritage Reporting Corporation} (202) $628-4888$ 
1 NIST/SCUSA proposal, that through the government budgeting

2 process, that funding might be deleted.

We have the same problem in industry, that during

4 the budgeting process, that funding could be deleted, but it

5 is important that in the budgeting process, that a

6 recognition of the importance of standards and the

7 recognition of the importance of an obligation to pay the

8 fair share should be emphasized and should carry the weight

9 through the budgeting process.

CHAIRMAN WARSHAW: Mr. Leight.

MR. IEIGHT: I'd like to ask two quite different questions. First, what is the relationship of your SAE oil standards with international standards of the same kind? MR. RUMBAUGH: The relationship is generally one of de facto standards in that our standard is, in fact, used by other organizations for viscosity ratings. But I am not sure and I would have to check it out and find out if it, in fact, is an ISO standard. I do not believe that it is. I believe it is a de facto used standard throughout the world. Many of our standards in other areas are a basis for ISO standards also, but that particular one, I do not believe it is.

MR. LEIGHT: The second question has to do with the fact that you have talked virtually exclusively about standardization, as most other people have today, and yet 
1 you also are quite involved in certification programs. I wonder whether you would care to make a few

3 brief comments about your certification programs and how

4 this would affect our relationships with the European

5 community and other parts of the world?

MR. RUMBAUGH: Yes, thank you. I had the pleasure

7 of participating on the standards side with an ANSI group

8 that went to Europe in late July to participate in

9 CEN/CENELEC on both standards and certification processes.

10 So I am therefore familiar with the European

11 process, the status of their process of developing a

12 mechanism in Europe, and also followed, of course, the

13 results of the group that did go on March the 12th. I was

14 not able to go then, but was very pleased with the results

15 that came out of it.

My understanding is that Europe is far from having

17 a coordinated mechanism and they are still developing their

18 own process. As I understand it, they have encouraged the

19 United States to go very slow in developing any kind of

20 interfacing mechanism with them until they decide what they

21 want to do -- don't, for us, necessarily, get ahead of them

22 in anticipation that they are doing something.

23

To specifically answer your question, the USSAE

24 does have a certification process. It is primarily aimed at 25 the United States, secondarily at North America. We are 
1 establishing liaisons with those groups who are doing those 2 kinds of things in Europe, following the same lead, however,

3 that the CEN/CENELEC advised ANSI, not getting ahead of them 4 but staying in contact with them in order to monitor what 5 they are doing so we would be a in a position to coordinate. Our contacts are in the aerospace area and in the

7 ground vehicle area, both, in this regard. MR. LEIGHT: Thank you. CHAIRMAN WARSHAW: Thank you, Mr. Rumbaugh. Mr.

\section{Donaldson.}

MR. DONALDSON: Mr. Rumbaugh, I have two

12 questions. The first question pertains to what I think you 13 may have implied, and I certainly inferred, that you would 14 encourage NIST to rejuvenate its participation in some of 15 the standards activities.

I wonder if I should too infer that other

17 government agencies may have slipped over recent years or

18 not. Are there other government agencies that you have 19 perceived that their participation level may be down for 20 whatever reasons -- the funding vagaries we have heard of or 21 whatever else? That's my first question.

23 question, let me address the first issue first, and then the 24 second one. 
1 the ANSI system. I feel that it would be extremely

2 beneficial to the voluntary standards system if, in fact,

3 the Federal Government would officially recognize ANSI as

4 being the official coordinator. So that was the one

5 position or statement that I made.

The second one, then, has to do with participation

7 and support in the various parts of the system throughout.

8 This, again, is a personal observation and that personal one

9 would be that, in fact, we are not at the bottom of

10 government participation. That was probably a few years

11 ago.

12 I have been very pleased to see an increase in

13 participation over the last few years in the standards

14 development process by various government agencies -- NIST

15 and SAE working closely on the IJES, a process in the

16 certification effort. That is relatively new. That is

17 beneficial.

18 DoD has, under the strong support of Pete Yurcisin

19 and his organization is encouraging stronger participation 20 and new mechanisms of both funding support and development 21 in this area.

22 So I say we are coming up, not going down and not 23 at the bottom would be my perception. Certainly, an

24 increase in that regard would be beneficial. I would

25 personally, again, support the comments made earlier this

Heritage Reporting Corporation

(202) $628-4888$ 
1 morning that having funding and support for the government

2 experts in overseas standards-writing activities would be

3 beneficial. That would be the other specific area I was

4 addressing.

MR. DONALDSON: Going back to the comment you made

6 which really goes to the heart of what I think was your

7 first recommendation, that NIST should endorse ANSI's role

8 as coordinator and accreditor. I wondered accreditation of

9 what?

MR. RUMBAUGH: Primarily for coordination, the

11 efforts that are happening in the accrediting. I do not

12 believe that ANSI, themselves, has yet determined precisely

13 the role that they would play in this regard and there are

14 other agencies that are looking at that.

I recognize that, but I think that a coordinating

16 role in this regard and support by NIST of that coordinating

17 role would be beneficial and I do believe that the jury is

18 still out as to the precise role that they and other groups

19 would play, should play.

20 MR. DONALDSON: Thanks. You did mention

21 accreditor and I didn't know if you meant to restrict that

22 to accreditor of standards-writing bodies or not. Thank

23 you.

MR. RUMBAUGH: That is also the case, yes. 
MR. LUDOLPH: I have a couple of points of

2 clarification.

One regards your recent visit to Brussels on this

4 delegation. You indicated that the CEN/CENELEC delegation

5 cautioned the United States private sector not to move too

6 quickly in organizing. I assume that that refers to the

7 non-regulated product sectors involved in the EOTC rather

8 than the EC commission's advise that they want you to slow

9 down the time table on regulated products because they are

10 not going to implement very quickly their regulations before 111992.

12 Was it the regulated products that you were

13 talking about with CEN/CENELEC, or the unregulated products?

14 MR. RUMBAUGH: My comments are from only having

15 read the reports that came from the committee that went, so

16 I was not a party to those discussions.

17 My understanding of having read those reports is

18 -- and again I was directing my comments strictly to the

19 accreditation process, not to the standards-writing process

20 - and as I understood in both areas, the Europeans do not

21 yet have a mechanism for coordinating their own

22 accreditation process.

23 They are still in the process of developing some 24 kind of a mechanism for doing that, and their encouragement 25 to us was don't respond too quickly to what you are seeing

\section{Heritage Reporting Corporation (202) $628-4888$}


1 in Europe because we haven't got our act together yet. MR. LUDOLPH: I have one additional question. You

3 sit in a unique position, I think, of many of the people who

4 testified here today, in that you face in the European

5 community a mandatory standard situation for ground

6 vehicles, unlike anything we have faced in most of the other

7 product sectors we've heard about today.

Land vehicles, automobiles, as well as tractors

9 and other off-road vehicles are mandatory standards not

10 developed by CEN/CENELEC but could come from any place and

11 are cooked pretty much within the European community

12 commission.

14 here in the United States regarding certifying vehicles or 15 standards that come into the United States for use here in 16 the United States?

MR. RUMBAUGH: I do not anticipate that we will

18 get into the certification of that area from the point of 19 view that there are no discussions in that regard.

Allow me to address the first part of your

21 comment, also, is that you are very correct, we are unique

22 in that as a result of the ANSI interfaces with CEN/CENELEC,

23 we have been able to learn that, in fact, they are not 24 developing voluntary nor regulatory standards through the 25 CEN/CENELEC process for automobiles, nor for aircraft.

\section{Heritage Reporting Corporation} (202) $628-4888$ 
Therefore, we have a very unique situation in that

2 they are not centralizing their process in many of the areas

3 which we developed standards at all, so we must continue to

4 follow a number of different groups, not only each of the

5 national bodies but also coordinating bodies outside of

6 CEN/CENELEC for that process.

But the specific answer to your question is that

8 we are primarily looking at our certification processes in

9 the U.S. and interfacing with the bodies that have a

10 regional coordination of certifications in those areas.

Interfacing with them, we are still in the very

12 early stages of discussing how we can interface with them

13 because they aren't very far along and ours is strictly at a

14 U.S./North American process and we are not certifying

15 automobiles.

CHAIRMAN WARSHAW: If there are no further

17 questions, thank you very much, Mr. Rumbaugh, for a very

18 fine presentation.

19 Mr. Reimer, Chairman of the USNC, U.S. National

20 Committee of the IEC.

21 MR. REIMER: Thank you, Dr. Warshaw.

22 Good afternoon panelists and other ladies and

23 gentlemen. My name is Ron Reimer. I am with Allen Bradley

24 of Rockwell International Company where I coordinate my

25 company's participation in standards activities and look 
1 after product regulations affecting my company and our

2 customers worldwide.

Today I am here in my capacity as the President of

4 the United States National Committee of the International

5 Electrotechnical Commission and I present the USNC's

6 statement for these hearings.

The complete USNC's statement was previously sent

8 to Dr. Warshaw's office and I respectfully request that the

9 complete written USNC statement becomes a part of the record

10 of these proceedings.

CHAIRMAN WARSHAW: Yes.

MR. REIMER: Thank you.

The United States National Committee, USNC, of the

14 International Electrotechnical Commission, IEC, is the

15 member body of IEC and the major national focal point for

16 electrical and electrotechnical international

17 standardization, and through the relationships between IEC

18 and CENELEC for certification and tests.

Dr. Warshaw, if I were to introduce all of the

20 individuals in this room who are part of the USNC, I would

21 surely overrun the time allocated to me. This statement is

22 made to emphasize that the USNC is a volunteer managed and

23 staffed organization.

All of the members of the USNC's managing body,

25 the USNC Executive Committee, all of the managerial and 
1 technical expert participation in the International IEC

2 meetings, all of the U.S. individuals who serve as

3 international chairs and international secretariats, and all

4 of the participation in the corresponding U.S. support

5 organizations is by U.S. individuals.

All of the approximately 3,500 individuals whose

7 direct voluntary roles in the USNC I have just identified

8 are financially supported by their employers. These

9 volunteers are supported based on commercial justification

10 -- repeating, based on commercial justification -- by

11 individual user and producer companies, by professional and

12 trade associations, by segments of national and local

13 governmental agencies, by academia and by other concerned 14 interests.

The USNC recommends that NIST give consideration

16 to working with industry groups to develop tax incentive

17 legislation to encourage industry to put more resources to 18 work on standards and certification activities.

It is the considered opinion of the USNC that the

20 present U.S. standards system adequately serves the various

21 trading needs in today's climate.

As a separate submittal to these hearings, the IEC

23 Central Office Geneva provided documentation of the

24 successful management and technical participation of the

25 U.S., through the USNC in the IEC.

\section{Heritage Reporting Corporation \\ (202) $628-4888$}


I respectfully request that this IEC Central Office submittal also become part of the record of this hearing.

\section{CHAIRMAN WARSHAW: It will be.} MR. REIMER: The USNC feels that increased participation in the existing infrastructure by members from the U.S. Government is desirable and should be strongly encouraged by adherence to the spirit of OMB Circular A-119. We believe an effectively operating infrastructure, indeed, does exist and to tamper with that infrastructure would invite gross breakdown of U.S. industry's ability to compete internationally. Notwithstanding a statement made earlier today, the current U.S. system for participation in voluntary international electrotechnical standards activities is a centralized system which works effectively under the umbrella of the USNC.

The USNC has established procedures for U.S. participation in the IEC standardization process. This standards development system is open to all materially affected parties, both public and private, and the operating procedures are based upon due process and the development of consensus U.S. positions.

Through this process, U.S. positions to the IEC are developed and put forth. 
With regard to the use of the international

2 standards, the USNC has observed a marked trend toward the

3 U.S. adoption of international standards wherever possible.

4

5

At this point, I would add that this is not something that you can perceive simply by looking for IEC numbered standards in other associations. They are adopted either in context included in existing U.S. standards, renumbered or re-labeled.

The USNC believes that the issues involved in EC 92 certification and testing are extremely sensitive and vary from industry to industry. Because the European community's position on third nation relations is not fully developed, it is premature to provide constructive comments. However, the USNC supports the position that ANSI should serve as a catalyst to bring together a broad coalition of private sector interests to develop a national consensus on this certification and test issue. The USNC believes that a positive and cooperative environment for interaction between industry and government should be encouraged. However, the proposal to create a Standards Council of the United States of America is an unacceptable approach towards achieving this goal. Our written statement offers supporting comments to this position.

The USNC recommends that NIST work with ANSI in a

\section{Heritage Reporting Corporation} (202) $628-4888$ 
1 cooperative partnership to make broadly available a

2 comprehensive, user-friendly data base that contains all

3 world standards and possibly certification and testing

4 information, including new work items.

The USNC believes that this service would enhance

6 this country's competitive position.

Thank you, Mr. Chairman. I would be happy to

8 answer any questions you have.

CHAIRMAN WARSHAW: Thank you, Mr. Reimer. Are

10 there any questions from the panel? Mr. Ludolph.

11 MR. LUDOLPH: Mr. Reimer, I was interested in your

12 comment about midway through your statement. It refers to

13 the recommendation that ANSI serve as a catalyst to bring

14 together a broad coalition of private sector interests to

15 develop a national consensus on certification and testing.

16 In light of the issue that many certifications

17 derive from public sector interests in safety, health and

18 environmental protection, is there a role for government --

19 either at the state or local level -- in developing this

20 consensus?

21 MR. REIMER: If you are referring to certification

22 in the restricted arena, I guess the answer would have to be

23 yes. There are those certification programs in the United

24 States that are government regulated, if you will,

25 government-run, that match IEC certification programs.

\section{Heritage Reporting Corporation} (202) 628-4888 
Some IEC certification programs are conducted on a

2 voluntary basis in the U.S. and there is a mismatch, so

3 there are -- I think the idea of a coalition is most

4 appropriate because the European community, we would tend to

5 view it as being a unified governmental control kind of

6 thing, and we don't need to match that. There is no need

7 for us to change how the U.S. does business or writes

8 standards or does certification, simply because the

9 Europeans are changing the way they are doing business and 10 writing standards.

11 MR. LUDOLPH: Do you see this challenge coming

12 from other places other than the European community --

13 Canada, Japan? Any other areas?

14

MR. REIMER: The challenge of --

MR. IUDOLPH: The area of either regulated,

16 restricted or non-restricted certification systems causing a

17 need or a recommendation for a national consensus to be

18 developed.

MR. REIMER: Right now, obviously, the press is

20 all going to the EC 92 effort and that is not to diminish

21 the importance of whatever is happening between the United

22 States and Canada, but I think that's a more natural

23 harmonious evolution than we are looking at the European.

There is an aspect of what is happening in Europe,

25 in particular the development of standards from the point in

\section{Heritage Reporting Corporation} (202) 628-4888 
1 time after it is announced as a standards project until the

2 final draft or the first public comment draft where we still

3 have yet to achieve satisfactory exposure in all cases

4 across the line.

There are individual instances where through the

6 IEC participation we can get a look at - - well, I can't say

7 participate -- observe what is happening during that writing

8 process. What is an overall cure, there is nothing so that

9 is more of a concern at this time.

10 CHAIRMAN WARSHAW: Thank you. Any other

11 questions?

All right, thank you, Mr. Reimer. I want to point

13 out that Mr. Reimer did ask in his presentation to include

14 the submittal of the IEC with respect to our request for

15 written comments, and of course, the information is at the

16 back of your agenda, how that will be obtained, can be

17 obtained after these hearings, along with other written

18 comments.

We do have numerous written comments -- many, many

20 with very constructive suggestions and I suggest those

21 caring to peruse those in the DoC reading room as is

22 illustrated in the back of your agenda.

23 So again, I want to thank you very much for your

24 contribution today. We will now take a break and reconvene 25 at $3: 45$ where we will have the Underwriter Laboratories and

\section{Heritage Reporting Corporation} (202) $628-4888$ 
1 the American Council of Independent Laboratories who will

2 then make their presentations.

(Whereupon, a brief recess was taken from 3:25

4 p.m. until $3: 45$ p.m.)

CHAIRMAN WARSHAW: Ladies and gentlemen, we will

6 begin the afternoon session with a different category, if

7 you will, of laboratories, certifiers, etc., and we have

8 before us the first two entities, namely Underwriters

9 Laboratories and the American Council of Independent

10 Laboratories.

11 So I will ask Mr. Castino, the chief operating

12 officer, or about to be the chief operating officer of

13 Underwriters Laboratories if he would introduce his

14 associate and begin.

15 MR. CASTINO: With me today is Joe Bhatia of

16 Government Affairs and Joe and I will share the presentation

17 that we have for you.

18 Good afternoon, we are in the home stretch.

19 UL's involvement and interest in the areas of

20 standards, testing and certification both in the U.S. and

21 internationally, is very extensive. Therefore, we are most

22 pleased to present our views on U.S. participation in

23 international standards-related activities.

24 It seems clear that an appropriate coordinated

25 strategy between the government and private sectors has the

\section{Heritage Reporting Corporation (202) $628-4888$}


1 potential to provide opportunities for improvements in the

2 functioning of the present system.

However, in our attempts to do so and to achieve

4 the optimum solution, all the pertinent aspects of this

5 issue must be understood and carefully analyzed so as not to

6 expend misdirected efforts or unnecessarily disturb the

7 properly functioning aspects of the U.S. standardization

8 system.

9

10

11

12

The brief statement that Joe and I are planning to deliver today is a synopsis of the key observations and recommendations based on UL's many years of experience in these related areas.

We will focus on four areas: standardization, testing and certification, accreditation, and finally, international developments.

In the U.S., the overall standardization effort, as you have heard today, is shared jointly by the government and the private sectors.

This standardization system is strong, effective, but functionally it is delicately balanced with key roles being played by the government agencies, private sectors entities, jurisdictional authority, and consumer interest. The nature of the system is affected by state's rights and legal requirements, especially those pertaining to the products liability laws as they exist here in the 
1 U.S.

The private sector structure permits high quality

3 standards to be developed over a wide range of products and

4 associated activities, in a relatively short period of time

5 and at no cost to the Federal Government.

At the same time, this system permits the

7 introduction of new and innovative products into commerce by

8 providing a high degree of flexibility in the development

9 and revision of these standards. U.S. Government adoption

10 of thousands of private sector standards is a testimonial to

11 the quality and effectiveness of the U.S. standardization

12 system.

For all of its complexity, overall, the U.S.

14 standardization system is efficient, flexible, accessible

15 and perhaps, most significantly, it works. It is structured

16 to effectively respond to international developments as they

17 evolve. It should not be disturbed just to create a greater

18 degree of central coordination.

19 Now Joe Bhatia will cover some key points relating

20 to the issues I identified earlier.

21 MR. BHATIA: First of all, it is important to note

22 that most of the product testing carried out in this country 23 does not result in certification. Therefore, the number of

24 laboratories that conduct developmental, performance,

25 quality or other types of testing far exceeds those that

\section{Heritage Reporting Corporation} (202) 628-4888 
1 carry out testing for certification purposes. When considering the broad range of purposes for

3 which certification programs are conducted, it seems clear 4 that programs related to safety, health, and well-being of 5 the public are most critical.

In these activities, the role of the third party

7 certifier is vital because these organizations not only

8 determine compliance with a testing and construction

9 requirements of product standard, but also with all the

10 applicable national and local codes.

11 They also investigate product components, conduct

12 plant inspections on an on-going basis, and use and control

13 their certification marks. These are just some of the

14 elements that are necessary to maintain safety.

I would like to emphasize the point that this

16 process is not simple. The consequences of failing to

17 properly conduct a product safety certification are awesome.

18 People can be killed or injured. Certification agencies can

19 be sued. Mandatory government standards can replace the

20 more flexible voluntary standards. Regulators and consumers

21 can lose confidence in the certification process, and

22 perhaps most importantly, the loss of stability in the

23 marketplace can become a competitive headache for the

24 manufacturers. 
1 serious business.

Now, let's discuss accreditation.

Our views on laboratory as well as certifier

4 accreditation have been formulated based on our 96 years of 5 experience.

A principal concern in the accreditation programs

7 is this: They can be perceived as assuring that a

8 laboratory is conducting uniform and accurate results, and

9 the certifiers are applying all the essential elements when,

10 in fact, the evaluation criteria used in most accreditation

11 programs do not and cannot provide such assurance.

A one-time examination of a laboratory or a

13 paperwork review of the certification scheme does not mean

14 very much.

To be effective, accreditation filing processes

16 must be comprehensive. Periodic efficiency testing is

17 necessary. Initial and follow-up on-site inspections are

18 essential, and without the accreditation procedures and

19 controls, there really is no program.

20 This comprehensive approach requires extensive

21 time and monetary commitment both on the part of the

22 accreditator and the organization being accredited.

23 Unfortunately, to this date, we have not seen any

24 accreditation programs that include and apply all of the

25 critical elements that meaningfully demonstrate the

\section{Heritage Reporting Corporation} (202) 628-4888 
1 competence of an accredited organization.

For the purpose of our discussions here, it should

3 be noted that even if such a comprehensive national or

4 international accreditation program was developed, its

5 overall need, its value and its benefit, and its economic

6 impact would have to be determined before considering

7 implementation.

8

11 specifically. marketplace.

In the areas where safety is paramount, there is a great deal of concern in our nation today about products liability in general, and the safety of consumers

Federal agencies, regulatory officials, inspection authorities, insurance interests, major retailers, manufacturers and consumers often look for third party certification or some other assurance that every effort was made for the products to be both safe and reliable.

All these groups need a system that truly works and an accreditation program which does not contain all the essential elements will, at best, mislead, and at worst, result in non-complying and unsafe products in the

Now let's review international developments. Although EC 1992 is not the only international activity that should be considered, it is the key motivation behind the debate on how to improve the U.S. system. 
Presently several unanswered questions remain as

2 to how the EC system will work in the areas of testing,

3 certification and accreditation, especially as related to

4 non-EC, non-EFTA countries.

One fact is clear. The acceptance of products

6 into the EC system will be largely dependent on whether

7 these products are regulated or non-regulated.

8 Obviously, in the areas of products are regulated

9 by EC and U.S. both, the EC will logically want to interact

10 with the corresponding governmental authority in this

11 country, and that's fine.

However, in the non-regulated areas, the EC has

13 indicated a willingness to work with organizations in the

14 private sector. Also the creation of the EOTC further

15 facilitates private sector interaction.

While the international developments clearly

17 indicate a need for coordination of testing and

18 certification mechanisms, it is not mandatory that this

19 coordination take place in the governmental arena, nor is it

20 essential that a U.S.-based accreditation program be a part

21 of this effort.

22 MR. CASTINO: Let me summarize. First, the

23 present standards development in the U.S. is capable of

24 responding to the international needs, including the EC, to

25 the extent that industry desires and commits to responding 
1 to these needs.

A centralized structure would add little or no

3 benefit to the standards system and may well add an

4 extraneous and conflicting layer.

6 accreditation of U.S. testing and certification agencies or

7 programs by a governmental or quasi-governmental agency will

8 be required for EC 1992.

We recommend that developments in the European

10 community be closely watched before launching an expensive

11 and extensive program of accreditation. If accreditation by

12 a U.S. entity is required to support product acceptance in

13 the EC, UL will support an initiative based on the required

14 operational elements discussed earlier.

UL is ready to work with and assist government as

16 well as organizations in the private sector toward achieving

17 the ultimate objectives of fair trade and equal access to

18 all of the markets involved.

We thank you.

CHAIRMAN WARSHAW: Thank you very much, Mr.

21 Castino, Mr. Bhatia.

MR. CASTINO: We didn't get the red light yet.

24 light.

(Laughter.) 
CHAIRMAN WARSHAW: Mr. DONaldson.

MR. DONALDSON: I would like to address a question

3 to $\mathrm{Mr}$. Bhatia and his comments about national accreditation

4 programs.

I wondered if the criteria he was including in his

6 evaluation were consistent with the internationally

7 recognized criteria that were supported by ANSI, or if he

8 has his own set of criteria?

MR. BHATIA: I knew you would get a question to

10 me.

11

What we are telling you is based on our experience

12 primarily as a tester and certifier in areas which are of

13 vital interest and concern. Safety, health and environment

14 obviously need to be looked at slightly differently than the

15 general guidelines would cover which are intended to be used

16 in a broader and a generic sense.

17 The criteria that perhaps best work and best

18 protect the elements that need to be covered for an

19 effective and comprehensive program may or may not be all

20 parts of the Iso guides that you referred to, but that

21 doesn't make it unacceptable.

22 MR. DONALDSON: Do you see a need to go further

23 with what is currently the prevailing ISO/IEC approved

24 guides in order to meet what you feel needs to prevail?

MR. BHATIA: Well, the guides are just guides and

Heritage Reporting Corporation

(202) $628-4888$ 
1 as you very well know, the accreditation systems are not

2 using those guides and are not comparing the performance of

3 each of the elements in those guides to carry out the

4 approval and acceptance of organizations. MR. CASTINO: Don, I might just add, I mentioned

6 it to you during the break, I think the important thing is

7 to look at the guides with respect to the elements that are 8 in the guides.

What we are saying is all elements that are in the

10 guides must be covered, and then the level of criteria will

11 have to be adjusted based on globalization issues.

12 Globalization will involve a common denominator

13 approach to some extent, and UL knows to the extent that it

14 can within U.S. laws and within the U.S. market, will have

15 to adjust to some extent when reciprocity mechanisms

16 develop.

I urge, however, that we not leave out any element

18 of the guide and that all elements in the guide be covered

19 in criteria be set.

MR. DONALDSON: Of course, the implications of

21 your statement are clear, given that within the European

22 community they have adopted the EN 45000 series which are

23 based on those guides, it will say that you might have

24 difficulty accepting some of the systems that will be

25 advocated within the community. 
MR. CASTINO: With respect to both those two

2 elements, Don, ISO 9000 which is the quality registration of

3 factory operations and the quality operation of a laboratory

4 facility under EN 45000, we have begun to integrate those

5 elements into our programs.

I don't think UL will have a problem in being

7 capable of implementing it. The question again will be will

8 the marketplace be able to accept the level of product

9 design changes that might be brought about by the

10 implementation of such programs.

11 MR. BHATIA: If I might add a comment, even the EN

1245000 series criteria which are essentially the only element

13 for a notified body status as stated by EC, I perceive to be

14 as not being sufficient in all areas of application, and

15 that comment and statement has been made by several

16 individuals in the EC entity itself.

They recognize that they need to have a minimum

18 acceptable criteria that will be applicable across-the-

19 board, but if you recognize the differences of various

20 programs that exist within the EC nations, a full 40

21 percent, perhaps, of their entire effort in the first three

22 years is going to be devoted to elevating some of the

23 certification entities' competence so that they can be all

24 perhaps comparable and acceptable to everyone in the EC

25 system. 
The point is are you going to be able to have the

2 rights of refusal? Are you going to be able to make

3 decisions regarding the data packs or information that is

4 going to be used in your safety or health or environment

5 certification programs.

10 and then we will move on. going to be accepting.

The answer is you have to have some opportunity to determine competence and ability of those whose work you are

CHAIRMAN WARSHAW: Okay, thank you. Mr. Ludolph,

MR. LUDOLPH: A great deal of interest has been put on EN 45000 but we know that the system in the European community is based on essential requirements, not EN 45,000. MR. CASTINO: Right.

MR. LUDOLPH: The essential requirements are very much like the same concerns that U.S. regulators have in their interests in protecting safety and health.

Is there a recommendation that you have on how to achieve comparability or an interface between the two regulated entities in dealing with essential requirements that would bridge this non-compatibility and perhaps take us away from our emphasis on EN 45000 ISO 9000. MR. CASTINO: Yes, Charlie, we don't really -it's a separate subject. I talked a little bit about it at the ANSI conference but we feel that the data package 
1 approach is a way that it can be done.

By that, I mean a level of competence has got to

3 be built on the part of the Europeans as well as the U.S. -4 all entities, I mean manufacturing, regulatory and users --

5 that the essential requirements that exist in each country

6 will be met.

The way I think that has to be done is an

8 assurance, based upon the establishment of the system, that

9 will permit the certifying body to attest to compliance to

10 the prevailing standard or standards in that country, the

11 compliance with the quality systems approach that exists in

12 that country -- and we have counterpart systems, believe it

13 or not, to the ISO 9000 and the EN 45000 system -- and that

14 the data packages, when developed and submitted to a

15 designated third party in the other country, whichever way

16 it goes -- would then be able to review that data package

17 and have the right to refuse it if they felt that safety

18 requirements that prevailed in the area, and that area being

19 either a region, a state or the whole country if it is

20 federal in nature, have been met, and would have the right

21 to reject.

That will begin to build confidence that, in fact,

23 unique requirements indigenous to that area that are part of

24 the law of that area are being met.

Once that confidence exists, then I think 
1 acceptance will occur between those two agencies and you

2 will do that on a product sector by product sector basis

3 which would mean the agencies involved in those product

4 sectors would be picked up as you went through.

CHAIRMAN WARSHAW: Okay, thank you again, Mr.

6 Castino and Mr. Bhatia.

We will now move to the American Council of

8 Independent Labs and Herbert wilgus. Would you please

9 introduce your associate and please comment?

MR. WILGUS: Thank you, Dr. Warshaw.

12 Milton Bush who is director of public affairs for the

13 American Council of Independent Laboratories.

I, myself, am president of a small business,

15 Penniman and Browne, Incorporated. Our company is a member

16 of the American Council of Independent Laboratories, also

17 known as ACIL.

I am vice chairman of the government affairs

19 committee of ACIL and also chairman of its laboratory

20 accreditation subcommittee.

I am pleased to have the opportunity to speak on

22 behalf of ACIL today about what we believe may well be a

23 turning point in improving U.S. participation in

24 international standards-related activities.

I will summarize in ten minutes ACIL's prepared 
1 statement, however I would first ask the Chairman that our

2 entire statement be placed in the record. 12 life.

CHAIRMAN WARSHAW: It Will.

MR. WILGUS: ACIL is the trade association that represents independent, commercial laboratories. ACIL's membership is broad-based, representing all laboratory disciplines with the exception of clinical.

ACIL represents an industry of over 4,000 laboratories contributing an estimated \$11 billion annually to the nation's economy -- a number that is growing as American consumers demand a safer and better quality of

ACIL also has on-going relationships and affiliations with a number of sister societies, including those in the standards community, but there is one thing that I want to make abundantly clear. While we are members of, or affiliated with many of these organizations, ACIL is the only broad-based U.S. trade association representing the interests of the independent testing laboratory industry as a whole.

The standards community is not in a position to speak for the testing community, nor are individual laboratories or trade associations that represent specific product sectors.

We are a unique industry in our own right, and

\section{Heritage Reporting Corporation} (202) $\quad 628-4888$ 
1 although linked with standards issues, our needs are very 2 different.

While many of our members are active in some

4 standards organizations, ACIL members as a whole are, to a 5 much greater extent, users of standards.

As users, we have a direct interest in the quality

7 of standards. As testers and certifiers, we will not

8 comment on standards issues today, however because NIST is

9 also reviewing testing, certification and quality assurance

10 activities, we will discuss the needs of the U.S. testing

11 industry in light of evolving international developments.

Before I summarize the ACIL's position, I would

13 like to state my own high personal regard for the National

14 Institute of Standards and Technology, formerly the National

15 Bureau of Standards. This respect was gained initially in

16 my career, my former career, as an employee of the U.S.

17 Government.

During the 30 years that I served in diplomatic

19 and consular offices abroad and in the Department of state

20 in Washington, I participated in many negotiations, some of

21 which were technical in nature.

I am happy to report that foreign officials

23 invariably held NBS and the American standards community in

24 high regard. At the same time, I must report a certain

25 degree of frustration on the part of other nations in 
1 dealing with the fractured structure of our standards

2 system.

The same holds true of our system of dealing with testing, certification and accreditation issues. Today the government is groping to find its role in international testing and certification activities. ACIL believes that it can assist in this endeavor by first providing a brief historical background on efforts of the U.S. Government to organize and coordinate testing and certification and accreditation activities in the United states, by describing the present state of these activities in the United States and the European community and finally, by proposing a solution today that may offer competitive assistance to the U.S. testing industry in light of worldwide regional consolidation efforts tomorrow. As you review historical documented efforts of the Federal Government in testing and certification and accreditation, which ACIL has done in its statement for the record, you will see that the present system is not working. Testing laboratories are faced with the necessity of obtaining multiple certifications, each of which has limited utility because each has limited acceptance. You will also see that many of the same concepts that were discussed over a decade ago, are being discussed today. So what is different today that is driving a re- 
1 examination of these issues? In one word, international. The rest of the world is demanding a U.S. system that can interface more easily for the purposes of

4 international trade.

International demands now require a re-examination and reform of the undisciplined U.S. system by the

8 certification and accreditation at the federal level as

9 described in a March 1989 report by the General Accounting

10 Office, reveals that there is no coordinating mechanism

11 among government agencies. Terms, approaches, requirements,

12 accreditation procedures vary.

13 Again, this report was driven by national

14 considerations. It is obvious to ACIL that such an

15 uncoordinated and undisciplined approach cannot interface

16 effectively with international systems.

17 We explore this in great detail in our statement

18 during our discussion of the activities of the European

19 community.

In our written statement, ACIL explains the

21 operation of the European system, discusses policy issues

22 raised in specific EC directives, outlines specific

23 pronouncements to the European community on the European

24 organization of testing and certification known as EOTC, and 25 draws conclusions and proposes questions. 
4 for regulated areas. One such area is electromagnetic

5 compatibility testing, also known as EMC.

7 through the FCC and NVLAP. The U.S. system however is open

8 to foreign laboratory participation. In fact, 18 foreign

9 laboratories, many of them European, are certified to test

10 for the U.S. market.

12 the U.S. program for foreign laboratories participation,

13 unless the EC is willing to negotiate on the issue of

14 notified body status, we would have no leverage on the EC

15 and many small and medium-sized laboratories would be at a

16 serious competitive disadvantage.

17

18 receive subcontracts from EC notified bodies, but this

19 concession falls short of what is needed. There is

20 absolutely no competitive advantage for EC notified bodies

21 to subcontract.

22

23 between U.S. and EC laboratories in regulated product areas 24 will be subject to re-negotiation at the commission level 25 after 1992 .
Heritage Reporting Corporation (202) $628-4888$ 
Finally, while a U.S. laboratory could set up a

2 U.S. owned subsidiary in an EC member state and seek.

3 notified body status, this clearly is an artificial

4 incentive to invest in the EC, and well beyond the means of

5 many small and medium-sized laboratories.

The EOTC is a structure designed to organize the

7 private sector in the areas of testing and certification in

8 the EC. Agreement groups, part of EOTC, composed of test

9 houses and laboratories, will be open to foreign

10 participation.

How will small and medium-sized laboratories

12 currently serving U.S. suppliers to the EC market marshall

13 the resources necessary to participate in such groups.

14 It is imperative that incentives be provided for

15 such participation. Clearly ACIL believes that the current

16 unregulated U.S. system needs to be re-evaluated in the

17 light of the development of EOTC.

18 The most difficult part of the EC scheme to

19 understand is the treatment of products that are unregulated

20 in the U.S. but regulated in the EC. The construction

21 products directive is a useful example because all products

22 are covered.

While the EC would be willing to negotiate on a

24 product-by-product basis, the first question that needs to

25 answered is who will negotiate access? Because the product 
1 is regulated by the EC, the federal government to government

2 dialogue will be necessary.

The EC will not recognize the various state, local

4 or private sector entities for the purpose of binding

5 national legal obligations.

The second question is, with such a decentralized

7 and unorganized system, how can the U.S. offer the EC a

8 balanced situation which it will seek for the purposes of

9 mutual recognition agreements.

Finally, in the areas of laboratory services yet

11 to be addressed by the EC -- for example, environmental

12 services -- the present situation is equally bleak.

14 concerned about the competitiveness of the United States and 15 its ability to respond creatively to development worldwide 16 in the testing, certification and accreditation forum. ACIL believes there is a legitimate role for both

18 the public and private sector in fashioning a coordinated 19 and systematic U.S. response to worldwide developments in 20 the testing and certification market.

In order to develop such a response, a complete

22 re-examination of the U.S. testing, certification and

23 accreditation industry needs to be undertaken, squared with

24 developments internationally, and performed by a

25 congressionally chartered national commission. 
In summary, a system that ACIL could support would

2 include, but would not be limited to, some of the following

3 elements: Principally, private sector subject to

4 congressional oversight, open and transparent, subject to

5 administrative procedures required by law, non-preemptive of

6 existing federal programs unless requested by the affected

7 agency, and equipped with sufficient checks and balances. Functions of such a system would include, but not

9 be limited to, one, the reciprocal acceptance of test data 10 internationally.

Two, the recognition of U.S. laboratory

12 accreditation schemes.

And three, the negotiation of U.S. laboratory

14 access internationally.

Thank you, Mr. Chairman. CHAIRMAN WARSHAW: Thank you, Mr. Wilgus. Are there any questions from the panel?

Well, I think your remarks were all encompassing. MR. WILGUS: Thank you.

CHAIRMAN WARSHAW: I want to thank you both very much for a very fine presentation and again, we do have the comment period open until June 5th, should you have some additional comments you wish to submit.

MR. CASTINO: Thank you.

MR. WILGUS: Thank you. 
CHAIRMAN WARSHAW: I will now ask the final three

2 presenters for this afternoon, if they would come to the

3 podium, namely the American Gas Association, Retlif Testing

4 Laboratories, and Hartford Steam Boiler Inspection and

5 Insurance Company.

6

7

8

9

12 the panel.

16 of AGA concerning the U.S. Government's role in standards

17 development, product testing, certification and quality

18 assurance.

My testimony and comments are in response to the

20 notice of hearing published in the Federal Register,

21 November 29, 1989. My presentation will consist of oral

22 remarks supplemented by a written document for the record

23 which has been submitted to your organization on March 22, $24 \quad 1990$.

\section{Heritage Reporting Corporation} (202) $628-4888$ 
1 association consisting of approximately 250 gas utility and

2 pipeline companies who transport, distribute and sell over

380 percent of the natural gas used in the United States. The Association has its headquarters in Arlington, Virginia.

10 throughout the U.S.

AGA Iaboratories is the administrative secretariat

12 for approximately 23 committees and subcommittees that

13 maintain design standards and the National Fuel Gas Code for

14 gas-fired appliances and accessory equipment.

We are also one of the first U.S. organizations

16 offering to audit and register manufacturers' quality

17 assurance programs that comply with international standard

18 ISO 9000

From this introduction, you can see that virtually

20 all of the topics raised in your Notice of Hearing are part

21 of our day-to-day domestic business.

We are also engaged in international activity.

23 Approximately 15 percent of our certification customers are

24 located in foreign countries. The gas appliance sector that

25 we serve is one of those subject to the new approach

\section{Heritage Reporting Corporation} (202) $628-4888$ 
1 directives of the European Economic Community.

We have a family of bilateral agreements installed

3 or under negotiation with counterpart agencies in Canada,

4 Europe and Asia. Consequently, we are interested in and

5 involved in foreign trade matters.

From this national and international vantage

7 point, I appear here to make four general statements

8 concerning the role of the U.S. Government in standards,

9 testing, certification and quality assurance matters

10 affecting the gas industry.

For purposes of this hearing, I use the term gas

12 industry to include consumers, local code officials, gas

13 pipelines, gas distribution utilities and equipment

14 manufacturers and laboratories.

15 Next the Association's position in summary.

16 First, the U.S. gas industry uses private sector systems for

17 developing standards, writing model installation codes,

18 certifying gas-fired equipment, and monitoring

19 manufacturers' quality assurance programs.

20 These systems are highly developed and widely

21 accepted in our domestic market. The same systems are

22 evolving through appropriate steps to satisfy new

23 requirements for international markets.

AGA believes that the gas industry's private

25 sector approach to standards development, product 
1 certification and quality assurance will continue to be more

2 than adequate to serve future U.S. interests at home and

3 abroad.

Thus, we do not believe that our systems need to

5 be augmented by creation of a new quasi-governmental

6 accreditation body or adoption of new federal regulations in

7 this area.

The gas industry is one area where business and

9 local government have already demonstrated competence and

10 foresight in protecting the consumer while constraining

11 costs in a competitive environment.

12 Second, $A G A$ is convinced that both the U.S.

13 Government and private sector organizations, ANSI, for

14 example, have a shared responsibility for the success of

15 U.S. trade with other nations.

We believe the U.S. Government and the private

17 sector have complementary roles that require cooperation and

18 communication across a broad front. We look for the U.S.

19 trade representative, the Department of Commerce and the

20 State Department to (a) conduct government-to-government

21 negotiations where required, to remove barriers including

22 the marketing of U.S.-made products abroad; and (b) to

23 provide timely communications to U.S. industry as to the

24 status and impact of such negotiations.

At the same time, AGA expects the U.S. Government 
1 will show restraint in a supportive role while private

2 sector interests work out international arrangements for

3 harmonizing standards, testing products and evaluating

4 manufacturers' quality systems.

$A G A$, along with others who have spoken earlier, is

6 an advocate for a partnership or alliance between government

7 and private bodies. This alliance should operate to create

8 an international environment wherein each U.S. industrial

9 sector -- steel, gas medical equipment, for example -- can

10 work with its foreign counterparts to develop and use

11 standards, test methods and certification procedures

12 appropriate for that industry.

13 The alliance of U.S. Government and private

14 industry should seek to operate by use of existing

15 organizations without creating new agencies and imposing new

16 administrative burdens and costs on business or the Federal

17 Treasury.

Consistent with this philosophy, AGA has endorsed

19 formation of the Department of Commerce Federal Advisory

20 Committee on the European Community approach to standards,

21 testing and certification. Our endorsement is based on the

22 expectation and belief that both U.S. Government and private

23 sector interests can make creative use of this committee to

24 better develop and effective and well-reasoned U.S. response

25 to European initiatives.

\section{Heritage Reporting Corporation}

(202) $628-4888$ 
Third, AGA Laboratories has agreements in place

2 for exchanging certification services with counterpart

3 agencies in Europe. The EC Commission may require re-

4 negotiation of these agreements with U.S. Government

5 participation.

AGA looks forward to receiving assistance from

7 U.S. Government agencies if such negotiations are required.

8 However, if EC approval of our agreements should require

9 imposition of additional accreditation requirements,

10 regulation and expense on the U.S. gas industry, AGA will

11 look upon these costs as a failure in the negotiating

12 process.

We believe that the European and U.S. systems for

14 standards development, testing, product certification and

15 quality assurance can be different, and co-exist and

16 interact successfully without being forced into a common

17 mold.

Fourth, we encourage the U.S. Government and the

19 U.S. Department of Commerce in particular, to become a

20 constructive participant in U.S. private sector forums that

21 are already available to receive, debate, find consensus and

22 act on proposals for improving U.S. standards, testing,

23 certification and quality assurance programs.

I serve as a director of the American National

25 Standards Institute, as does the Director of the National 
1 Institute of Standards and Technology, NIST. AGA stands

2 ready to receive through that forum, from NIST, a

3 description of those real or perceived obstacles to trade

4 that the Department of commerce and the ANSI federation

5 should address together.

These remarks comprise the oral testimony from

7 AGA. We made written comments which are submitted for the

8 record.

They show, by way of example, the substantial

10 progress being made by the American Gas Association, its

11 customers and foreign partners to position the U.S. gas

12 industry for future business success at home and abroad.

13 These activities of the gas industry have not yet

14 required U.S. Government intervention, mandate or direction

15 to be successful.

16 I thank you for this opportunity to address this

17 panel.

18 CHAIRMAN WARSHAW: Thank you, Mr. Schulte. Are

19 there any questions of AGA? Mr. Ludolph.

20 MR. LUDOLPH: Mr. Schulte, how is it in your

21 certification program here in the states that you accept

22 foreign manufactured products and certify them? Do you

23 certify them to a foreign standard, international standard?

24 MR. SCHULTE: At the current time, all of our

25 certification is for products that are manufactured, whoever

Heritage Reporting Corporation
(202) 628-4888 
1 manufactures for sale in the United States, that we are

2 certifying foreign-made products to U.S. standards for sale 3 in the U.S.

MR. LUDOLPH: Does your program contemplate the expansion of acceptance of foreign standards, or acceptance of foreign marks into the U.S. system?

MR. SCHULTE: Yes, it does. The principal trading partner with the U.S. in the gas product area at the moment is Canada.

We are in the process of harmonizing with the Canadian industry the standards which cover these products to develop a North American standard, for example, that will cover products sold in both the U.S. and Canada in the gas appliance regime. That's underway.

I foresee that in the longer haul, we will have harmonized standards, particularly in the gas controls area, with European entities leading to further harmonization of standards with other European product lines.

MR. LUDOLPH: And how do you contemplate that acceptance to be integrated into the acceptance criteria for inspection bodies at the state level?

MR. SCHULTE: I'm sorry, would you repeat your question?

MR. LUDOLPH: Well, if a state or locality looked for a safety acceptance, how do you work with the state 
1 inspectors to develop the acceptance criteria?

MR. SCHULTE: Well, at the moment and for the

3 foreseeable future, the local inspector or local code

4 official, when he is making application of a gas product,

5 looks for a certification mark. In our case, it would be

6 HEA or it might be from some other third party agency.

8 applied. That is, if we are working with a product made in

9 a foreign country, and perhaps made to a harmonized

10 standard, we would still be the certification body testing

11 against that standard.

12 In the longer haul, I think we will be in a

13 position to exchange data packages so that the testing could

14 be done in a foreign location and we would continue to apply 15 our mark.

That is, in fact, the form of an agreement we have

17 just installed with the Canadian Gas Association in which

18 our customers, our mutual customers, can be tested now in

19 either laboratory and we exchange data packages to provide

20 certification in both nations.

21

CHAIRMAN WARSHAW: Mr. DONaldson.

MR. DONAIDSON: Mr. Schulte, I may have missed,

23 but did you happen to touch on the AGA participation at the

24 international level? I know you referred to some of your

25 bilateral work with groups of other countries, but did you

\section{Heritage Reporting Corporation} (202) $628-4888$ 
1 happen to mention the international work? If you did, did I miss it? MR. SCHULTE: The only remarks that I made were

4 those that we have in place -- bilateral agreements at very

5 low levels for exchanges of certain certification services 6 with parties in both Europe and Asia, and those agreements 7 currently cover relatively limited activities like the 8 exchange of factory inspection services.

MR. DONALDSON: No, I'm sorry, I guess my question

10 really was is there standards activity at the international

11 level that $A G A$ is involved in as an organization through

12 setting up TAG's, secretariats and that kind of thing?

14 product area, there is only one Iso committee, TC 161 which 15 deals with gas controls. The Gas Appliance Manufacturers 16 Association holds the secretariat for that. Outside of that activity, there is, in our sector, 18 or has been, very little activity with the international 19 standards arena, principally because there has been so 20 little product movement, let's say, between Europe and this 21 country. Most of the product movement is between Canada and 22 this country, and so our emphasis has been there. CHAIRMAN WARSHAW: Well, thank you, Mr. Schulte. 25 Laboratories. Mr. Poggi. 
MR. POGGI: Good afternoon. My name is walter

2 Poggi and I am president of Retlif Testing Laboratories, an

3 independent testing laboratory specializing in both

4 commercial and military electromagnetic interference

5 testing.

Retlif maintains its headquarters in Ronkonkoma,

7 New York, and a branch laboratory in Manchester, New

8 Hampshire.

Its staffing consists of 16 employees in

10 Ronkonkoma and six in Manchester. Our services are provided

11 to a customer base of over 500, including the likes of IBM,

12 Soundesign and Phillips Medical on the commercial side,

13 Hamilton Standard and Northrup and Pratt and Whitney on the

14 military side.

15 Retlif is small business, as is most independent

16 laboratories in this country. It is from the small business

17 viewpoint that I wish to make my comments on what I believe

18 would be proper steps to improve the U.S. participation in

19 international standards and testing activity.

20 First, I believe some additional points of

21 background information might be of help. Retlif Testing

22 Laboratories was founded in 1978 and has since that date

23 experienced very measured and consistent growth both

24 financially and internally as well as externally in regards

25 to our organizational involvement.

\section{Heritage Reporting Corporation}

(202) 628-4888 
The company and its employees hold either

2 individual or organizational memberships in the American

3 Council of Independent Laboratories, the American National

4 Standards Institute, the Institute of Electronic and

5 Electrical Engineers, the National Conference of Standard

6 Iaboratories, the Acoustical society of america, the

7 American society for Quality Control, the society of

8 Automotive Engineers, the U.S. Chamber of Commerce, the

9 National Federation of Independent Business and the Long

10 Island Association.

I personaliy am Chairman of the Government

12 Relations Committee of the ACIL as well as its Eastern

13 Division Chairman. In addition, I am a member of the ANSI $\mathrm{Z}$

1434 committee on third party certification and the ANSI C 63

15 committee on Electromagnetic compatibility.

16 I am also a member of the Iong Island

17 Association's Small Business Council and was a congressional

18 appointee to the 1986 White House Conference on Small

19 Business.

Since the thrust of my presentation will center on

21 the small business issues, I have not included much of the

22 technical, historical and bureaucratic issues which I am

23 sure have been or will be addressed in prior or future

24 presentations.

The issue is simple: How do we make certain that 
1 the position of small business in this country, in this case

2 both manufacturing and testing, are protected in the areas

3 of standards writing and testing and certification?

4

5

As we are all aware, the fastest growing segment of our economy for the past two decades has been small

business. In that time period, employment in small business has steadily increased while it has steadily decreased in the big business sector.

Clearly, we must make certain that small business is protected and that we foster the proper environment for the continued development of small business in this country. As our economy becomes more and more global, I find as a small business that it is increasingly more difficult to remain involved in the many developing areas which will and do have a direct effect on the very existence of my company.

What in the past required one association or society meeting a month, is now requiring one a week. In our own case alone, we must monitor the issues such as EC 1992 as it relates to standards development and laboratory notification, the Accreditation and Standards development programs in both the military and the FCC areas as related to EMI testing, ANSI committees C 63 and $\mathrm{Z} 34$, ASQC programs for certification of manufacturer's Q.A. program, and related developments in Canada as a minimum, since all of

Heritage Reporting Corporation (202) 628-4888 
1 these issues directly effect our organization on a daily

2 basis. 10 protected. to it.

And all of this monitoring must be done by a company which has slightly less than 25 employees. It is easy then to see why in our case our efforts can only be to monitor rather than to shape.

Clearly this is where our interest can begin to erode since we in small business do not have the time, the money or the people to make certain that our interests are

Regrettably, but predictably, the volunteer standards-writing concept as it is based in this country is in most cases driven by and controlled by big business. They have the people to support it and the money to devote

Seldom if ever is the impact on small business consciously considered by these groups. It is my opinion that this in itself is one of the most important reasons why government must have an important role in the overall standards-writing effort in this country.

Beyond the issue of protection of small business, government involvement is required in the coordination of the overall system, including the areas of standardswriting, testing, certification and accreditation. It is only then, that we can hope to eliminate

\section{Heritage Reporting Corporation} (202) $628-4888$ 
1 both the many duplication of efforts and the many special

2 interests which now exist.

As an EMI laboratory, we maintain both a NVLAP

4 accreditation and an FCC listing for performing testing to

5 FCC standards. In addition, we all maintain a Canadian DOC

6 approval for performing telecommunication testing for

7 Canada. Why?

Why must we maintain three accreditation,

9 approvals, or whatever you want to call them, all related to

10 basically the same testing?

11

I might add that a recent GAO paper severely

12 criticized the fact that the NVLAP and FCC program exist

13 separately and strongly suggested the elimination of one.

14 However, even within these two government agencies, there

15 are special interests at work, each protecting their own

16 territory at the expense of small businesses such as my own

17 which again, must provide the time, money and people to

18 support and maintain these programs.

Another example, to highlight the need for

20 government coordination, can be seen by a brief review the

21 generation of the present NVLAP accreditation in the field

22 of FCC testing.

23 I myself requested the generation of this

24 laboratory accreditation program and helped in its

25 generation based on my involvement at the time with the

\section{Heritage Reporting Corporation} (202) 628-4888 
13 in pla
14 indepe
15 been
16 request
17
18 effect
19 even b
20 it is
21 market
22

23

At the time USTR was deeply involved in

Japanese Based on USTR felt that a laboratory am for laboratories certifying such s would be helpful in its negotiations. Interestingly enough they felt that the ation had to come from NVLAP since in their opinion 
1 problem only occurs one way, that being when it comes to

2 accepting U.S.-generated data. Clearly it is not the case with our FCC since the

4 FCC in their listing program is accepting data from

5 approximately 19 Japanese laboratories and 12 European

6 laboratories.

The fact is, and rightfully so, the ECC will

8 accept data from any laboratory worldwide that shows that it 9 is capable of performing the testing it is certifying to. 10 Now, we may take exception to the methods the

11 commission uses to determine a laboratory's capabilities,

12 however we cannot and should not take exception to their

13 acceptance of data from all qualified sources.

14 However, what about us? What about the small U.S.

15 laboratory who is totally qualified to perform testing to

16 Japanese standards or European standards but are denied

17 acceptance in those marketplaces?

Who is going to champion our cause? ANSI? NVLAP?

19 There is no answer because there is no solution to the

20 problem as our system now exists. In a recent special

21 edition of the ANSI reporter, the headline states, "If it's

22 not broken, don't fix it."

Who is it not broken for? IBM? General Motors?

24 UL? I don't know. I do know that in my opinion as it 25 relates to my company, the system is broken. I see more and

\section{Heritage Reporting Corporation}

(202) $628-4888$ 
1 more competition from Europe, from Japan and from Canada,

2 who can all offer acceptance in their country as well as 3 ours, while we cannot because of their closed door policies. For better or for worse, the times are changing and we must change with them in order to remain cooperative and productive in the developing global marketplace. The present voluntary consensus standard-writing approach used in this country for so long is clearly a burden on small business whose involvement represents a much greater financial and organizational commitment on their behalf as compared to big business who by virtue of their size and staff, can much easier support such a system while clearly protecting their interests.

The continuing developments in the EC and in the Pacific Rim are in many ways clearly troubling for small business such as Retlif and quite honestly, I would feel much more comfortable if I knew my government, who in many ways is answerable to me, was negotiating for me rather than an industry group or volunteer association which may, as in many cases, be driven by those capable of the greatest financial and personnel support.

I would recommend the organization of a governmental body as follows: Principally government run with strong private sector involvement through direct representation; subject to congressional oversight; subject 
1 to administrative procedures required by law; pre-emptive of

2 existing federal and private sector programs which are

3 directly involved in international trade; responsible for

4 the recognition of U.S. laboratory accreditation programs;

5 and responsible for the acceptance of U.S. laboratory test

6 data internationally.

Government-run, sponsored, or coordinated

8 organizations to handle the tasks of standards-writing,

9 testing, certification and accreditation are being developed

10 in many countries.

11 Witness the Standards Council of Canada and the

12 EC's newly formed EOTC. As these developments unfold before

13 us, we must move forward to develop our own in order to

14 remain competitive in this ever changing world marketplace.

I can only hope that NIST and the Department of

16 commerce will rise to this occasion and seize the leadership

17 role which is solely lacking in our present system.

18 Thank you for offering me the opportunity to

19 present my viewpoints to you and I would be only to glad to

20 answer any questions you may have.

21 CHAIRMAN WARSHAW: Thank you, mr. Poggi. Are

22 there any questions? Mr. Ludolph.

23 MR. DONALDSON: Mr. POggi, you mentioned several

24 forms of recognition that your laboratory has achieved and

25 then you mentioned a problem, potential problem with Japan

\section{Heritage Reporting Corporation} (202) 628-4888 
1 or European nations or elsewhere.

Does your lab personally have any experience in

3 having test reports turned down by acceptance bodies in

4 these other countries where a statement was made that you

5 did carry this form of recognition?

MR. POGGI: Well, the way we have been attempting

7 to penetrate those marketplaces, that it has been through

8 agreements, so-to-speak. Those agreements have been with

9 organizations such as TUV, as an example, in Europe.

The acceptance or recognition by NVLAP for the FCC

11 holds very little weight with them. They still have

12 required us to go through their own self-certifying type

13 program before they would accept our data.

14 So I think it is a question of - I don't want to

15 put the blame on NVLAP because I don't think it's NVLAP's

16 job necessarily to go out and sell its systems, but it is

17 somebody's job in government to go out and sell the systems.

18 MR. DONALDSON: But as I understand what you're

19 saying, in the case of TUV, you were seeking to establish

20 some form of agreement with TUV, is that correct?

22 accepted.

MR. DONALDSON: BY them?

24

MR. POGGI: Right.

MR. DONALDSON: Thank you. 
CHAIRMAN WARSHAW: Mr. Ludolph.

MR. LUDOLPH: As it stands now, according to the

3 December 21 st council resolution of the European community,

4 you can either be a notified body or you can attempt to

5 subcontract with notified bodies in Europe, the statement

6 before of the American Council of Independent Laboratories

7 indicated that there was a competitive problem in being

8 accepted as a subcontract, and that notified bodies who are

9 European who have subsidiaries in the United States, can

10 offer one-stop testing both to U.S. and European standards,

11 and that there is no incentive for them to subcontract with

12 a competitor in order to give that same service.

13 Do you concur with ACIL's evaluation that there is

14 an advantage for your type of lab or for your business to

15 become a notified body? And is there a time frame that you

16 see as required for you to become a notified body? Are

17 existing European subsidiaries attempting to enter the U.S.

18 market as notified bodies to compete with you?

19 MR. POGGI: Well, I might be talking out of turn

20 and putting some of my own internal company secrets out, but

21 I can assure you that $T U V$ is much less interested in putting

22 together agreements with me today than they were about six

23 or seven months ago.

24 So I sense that as they perceived that they have

25 acquired the acceptance that the necessarily need in this

\section{Heritage Reporting Corporation}

(202) $628-4888$ 
1 country, they have less of a need for me.

I am not interested in moving forward with those

3 type of arrangements in the future.

4

5

Similarly to the FCC situation, they accept data from qualified sources. I expect the same.

CHAIRMAN WARSHAW: Well, thank you, Mr. Poggi. We appreciate your comments.

Now we have Mr. Richard Feigel of the Hartford Steam Boiler Inspection and Insurance Company. Mr. Feigel, did I pronounce it right?

MR. FEIGEL: Yes, you did. Very rare.

(Laughter.)

MR. FEIGEL: Thank you, Dr. Warshaw. My name is, I go by my middle name which is Gene. I am Gene Feigel, the director of engineering operations for the Hartford Steam Boiler Inspection and Insurance Company. In that capacity, I am responsible for the management of my company's standards participation and standards development, both internally and our participation with consensus standards development bodies outside the company.

My company's name is hardly a household word. We are the largest boiler machinery insurer in the United States, and through a joint venture indirectly and through various re-insurance treaties, we also provide industrial insurance throughout the world. 
In addition, directly and through various

2 subsidiaries, we provide engineering, environmental and

3 software services of a wide variety. Probably most germane

4 to this forum, we are the largest third party inspection

5 agency operating under the American Society of Mechanical

6 Engineers, Boiler and Pressure Vessel third party inspection

7 concept.

We provide those inspection services throughout

9 the world, wherever they are required.

10 My company has had a longstanding commitment to

11 participating in standards developing activities, again

12 primarily through ASME but certainly with a number of

13 organizations. We have been involved in standards

14 development for over 75 years. We have a very long-term,

15 very serious commitment.

16 Since I am the last speaker today and I have

17 provided extensive written comments and suggestions, I am

18 going to keep my comments extemporaneous and brief.

19 I would like to make two points. One is that at

20 least currently we believe very strongly in de-coupling the

21 commercial and technical issues in standards development,

22 that we do believe that the government has a primary role

23 certainly in championing international trade issues and

24 probably there is no body or organization certainly that

25 could champion that cause. 
However, we believe that in terms of the technical and administrative management of actual standards

3 development, that the OMB circular A 119 certainly provides 4 an adequate framework, and that that framework is not a 5 hypothetical one. It has been shown to work and I would 6 cite as, in my mind, a very successful example that I have 7 been personally involved with -- the Coast Guard's adoption 8 of various sections of the ASME boiler and pressure vessel 9 code for the technical regulations for boilers and pressure 10 vessels under their purview. I worked personally with them in their internal

12 regulatory process when they were adopting that, and have 13 watched what they have done since and how they have both 14 participated and provided personnel to participate in the 15 code committee activities that continue to develop those 16 standards, and what they have done in terms of actually 17 embodying them in the regulations, very much along the lines 18 of the A 119 scenario.

In my estimation, it has been very successful and

20 the feedback we have gotten from the Coast Guard is, in

21 fact, that they are reasonably satisfied. There are

22 certainly other federal and obviously state agencies that

23 have taken that tact and we believe that it was well-founded 24 and continues to be well-founded for the foreseeable future. 
1 is just in the general area of communications. We have

2 found that often the trade barriers that appear to be and in

3 fact are more a lack of information or accessibility of

4 information than an actual technical trade barriers.

Once American companies find out what, in fact,

6 they have got to do to participate or compete in various

7 areas internationally, they very often are able to. It is

8 simply a lack or a difficult time finding information,

9 particularly for small companies.

10 One of the engineers on my staff essentially is

11 working full-time with our clients in the U.S. to attempt to

12 help them understand and find information on foreign codes

13 and standards so they can compete in exporting. And again,

14 the particular product we are interested in here is in the

15 boiler/pressure vessel piping area.

16 So we would urge the government to take an

17 appropriate agencies, wherever those might be, to take a

18 much more aggressive and positive approach to providing that

19 kind of technical informational assistance to American

20 companies.

21

There are models that seem to be working fairly

22 well in the world. One, of course, is the technical help or

23 the exporters arm of the British Standards Institution

24 which, depending on how you look at them, they are a quasi-

25 governmental organization, and of course, the NOREX-AFNOR

\section{Heritage Reporting Corporation (202) $628-4888$}


1 group in France which provides much the same type of service

2 and we think that something modeled along those lines in the

3 United States would certainly be of substantial benefit.

5 can.

7 there any questions? Mr. Ludolph.

MR. LUDOLPH: Mr. Feigel, I appreciate the brevity

9 of your remarks, but in your written submission, and just so

10 we are all working from the same document, this is the

11 letter to Mr. Warshaw of March 16th.

MR. FEIGEL: Yes.

MR. LUDOLPH: You make a couple of statements in

14 your paragraphs I would like to get a little bit of

15 elaboration on.

16 On the last or second page, you allude to subtle

17 non-tariff in the EC 1992 directives regarding simple

18 pressure vessels and the requirement for independent

19 inspections required on vessels under its scope be performed

20 by organizations approved one of the EC member states.

21 The criteria, the point you make is that the

22 criteria for application to become an approved inspection

23 body is not specific and would apparently permit EC members

24 considerable latitude in interpretation and implementation.

25 Do you have any recommendations in that sentence?

\section{Heritage Reporting Corporation (202) $628-4888$}


1 From that, do you make recommendations on how the U.S.

2 should comport itself regarding elaboration of

3 interpretation and implementation for approval of inspection

4 bodies?

MR. FEIGEL: I would make two comments. One is I

6 am not, I think the problem at the moment at this juncture

7 in time is simply a lack of the EC fleshing out what the

8 specific requirements are going to be.

So any specific recommendations would be sort of

10 hypothetical and premature on my part.

11 On the supposition that they do something fairly

12 onerous and fall down on the side of essentially approving

13 existing European-based inspection organizations only, to

14 the exclusion of American companies say, such as mine which

15 are in that sort of business, our response is to joint

16 venture.

We don't frankly, we are a little skeptical of

18 butting heads on this type of issue. We are working with a

19 subsidiary in Europe to joint venture and come through the

20 back door and be approved that way.

21 MR. LUDOLPH: And you are comfortable with the

22 accreditation you receive here in the United States for

23 inspections to particular types of groups of standards such

24 as pressure vessels under ASME?

25 MR. FEIGEL: Yes. 
MR. LUDOLPH: Those kind of criteria you found to

2 be compatible with U.S. manufacturing and could be applied

3 in other environments.

MR. FEIGEL: Our general experience and exposure

5 to other inspection authorities outside of the U.S. is that

6 our requirements and theirs could be harmonized. They are

7 not radically different, certainly on a technical basis.

MR. LUDOLPH: There is another area in your

9 written statement that would help me understand a little

10 bit, if you could give me an elaboration.

11 In the next paragraph, you allude to the EM 29,000

12 series of documents which are open to a wide range of

13 interpretation and you are concerned that there is no

14 transparent adjudication mechanism available for equal

15 access to both European and U.S. entities.

16 Are you referring in that area to an adjudication

17 mechanism here in the United States, or are you referring to

18 an adjudication mechanism that deals with a North Atlantic

19 inspection?

20 MR. FEIGEL: My comment was generic to that set of 21 standards, not in terms of favoring or disfavoring American

22 competition. I have been unable to determine where any

23 company anywhere in the world might go for an adjudication

24 of a concern about how those quality requirements were being 25 imposed or applied to.

\section{Heritage Reporting Corporation} (202) $628-4888$ 
MR. LUDOLPH: Thank you, and the last question

2 from me is -- I don't have a yellow light so I don't have to

3 worry -- on that same page, you refer to specific

4 suggestions for consideration, when competing U.S. standards

5 have been developed, preference should be given to a

6 standard developed under ANSI consensus committee method,

7 over those developed by canvas and other methods.

What are these distinctions that you make? Why is

9 the ANSI consensus committee method to be given preference?

10 MR. FEIGEL: Because in my estimation at least, it

11 better assures a participation in the actual development of

12 that standard by a broader range of interest, as opposed to

13 the canvas method which on the face of it, frankly, is --

14 the people writing the actual standard very well likely have 15 a parochial interest, and then disseminate it for after-the16 fact comment.

17 My personal opinion is that on that simple basis,

18 the consensus method is superior.

19 MR. IUDOLPH: All right, so is this a personal

20 opinion, or is this the position of the Hartford steam

21 Boiler company?

22 MR. FEIGEL: What you see in these written

23 comments are acceptable to my senior management.

24 MR. LUDOLPH: Let me ask you ---

25 MR. FEIGEL: They are my company's position. 
MR. LUDOLPH: Do you have an opinion or

2 recommendation about how the development of consensus

3 committee methods should be carried out? Is that something

4 that you see continuing to develop in the private sector, or

5 are you recommending a government role in assuring a

6 preference for consensus committee methods?

9 sure I am able to give a very brief answer to that. MR. LUDOLPH: That's all right. MR. FEIGEL: I think that is something that

13 issue for some government oversight. To that extent, I 14 would agree.

MR. IUDOLPH: Thanks very much. CHAIRMAN WARSHAW: Thank you, Mr. Ludolph. Ms.

17 Moore.

MS. MOORE: This is a question the panel has

19 raised with a couple of other panelists. I am referring 20 once again to your written statement where you say when it 21 is clear that explicit recognition of U.S. standards either 22 by direct reference or reciprocal agreement is not feasible, 23 the government should encourage the use of international 24 standards development mechanisms such as ISO. That seems to imply a preference for U.S. 
1 standards first, and international standards a poor second.

2 What are your views on efforts to try to incorporate

3 international standards into U.S. systems almost as a

4 primary source for use standardization?

MR. FEIGEL: I think the issue here is we can't

6 sort of in a vacuum pick out what would be technically

7 preferable. There are historical antecedents at work here

8 and I think the going-in position, not in all cases pushed

9 very vigorously, should be to promote the use of American

10 standards wherever, not on a sort of vicious parochial

11 basis, if you will, but I think on a clear commercial basis.

12 I think, again, the focus very much is today, our

13 mindset is toward the European economic community. Well,

14 that is simply not apropos.

15 There are other areas of the world where it very

16 much is, and I think it is very feasible for us to get out

17 standards verbatim at least recognized, if not actually

18 incorporated, in local law and regulation in some areas of

19 the world, and if that is to our benefit and technically

20 acceptable to the appropriate authorities there, I think it

21 should be pursued.

CHAIRMAN WARSHAW: Thank you, Mr. Feigel.

If there are no more questions, I would like to

24 thank all three panelists today. I particularly want to

25 thank all the panelists today for holding so well to the

\section{Heritage Reporting Corporation (202) 628-4888}


1 very short time frame that we had for everybody. Tomorrow we will begin at 9:00 sharp in the same

3 room.

5 adjourned, to reconvene on Tuesday, April 3, 1990 at 9:00

6 a.m.) 
3 DOCKET NO.: NATIONAL INSTITUTE OF STANDARDS AND TECHNOLOGY

4 CASE TITLE: DEPARTMENT OF COMMERCE

5 HEARING DATE:

6 LOCATION :

$$
\text { April 3, } 1990
$$

$$
\text { Washington, D.C. }
$$

7

8

I hereby certify that the proceedings and evidence are 9 contained fully and accurately on the tapes and notes

10 reported by me at the hearing in the above case before the

11 National Institute of Standards and Technology. 



\section{ADDENDUM}

The following presenters have submitted supplementary material for the record in addition to their presentations. This material is available in the U.S. Department of Commerce Central Reference and Records Inspection Facility, Room 6628, Hoover Building, Washington, DC 20230, (202/377-3271).

\section{STANDARDS DEVELOPERS \& PROFESSIONAL SOCIETIES}

James Pearse, Manuel Peralta, Jeff Smith

American National Standards Institute

Joseph 0'Grady

American Society for Testing and Materials

Oscar Fisher, Melvin Green American Society of Mechanical Engineers

Marco Migliaro, Andrew Salem Institute of Electrical and Electronics Engineers

William Calder Instrument Society of America

Ben Johnson

Industry Applications Society

James Decker

American Society of Civil Engineers

Richard Alley

American Welding Society

Russel1 Hahn, Robert Lanphier American Society of Agricultural Engineers

Anthony 0'Neill, Arthur Cote, Daniel Piliero National Fire Protection Association

Michael Miller, Dennis Stupak, Robert Flink, Mort Levin Association for the Advancement of Medical Instrumeritation

James Bihr, Richard Kuchnicki, William Tangye, Paul K. Heilstedt Council of American Building Officials

Thomas Flint American Plywood Association

David Grumman, Frank Coda, Jim Heldenbrand American Society of Heating, Refrigerating and Air Conditioning Engineers 

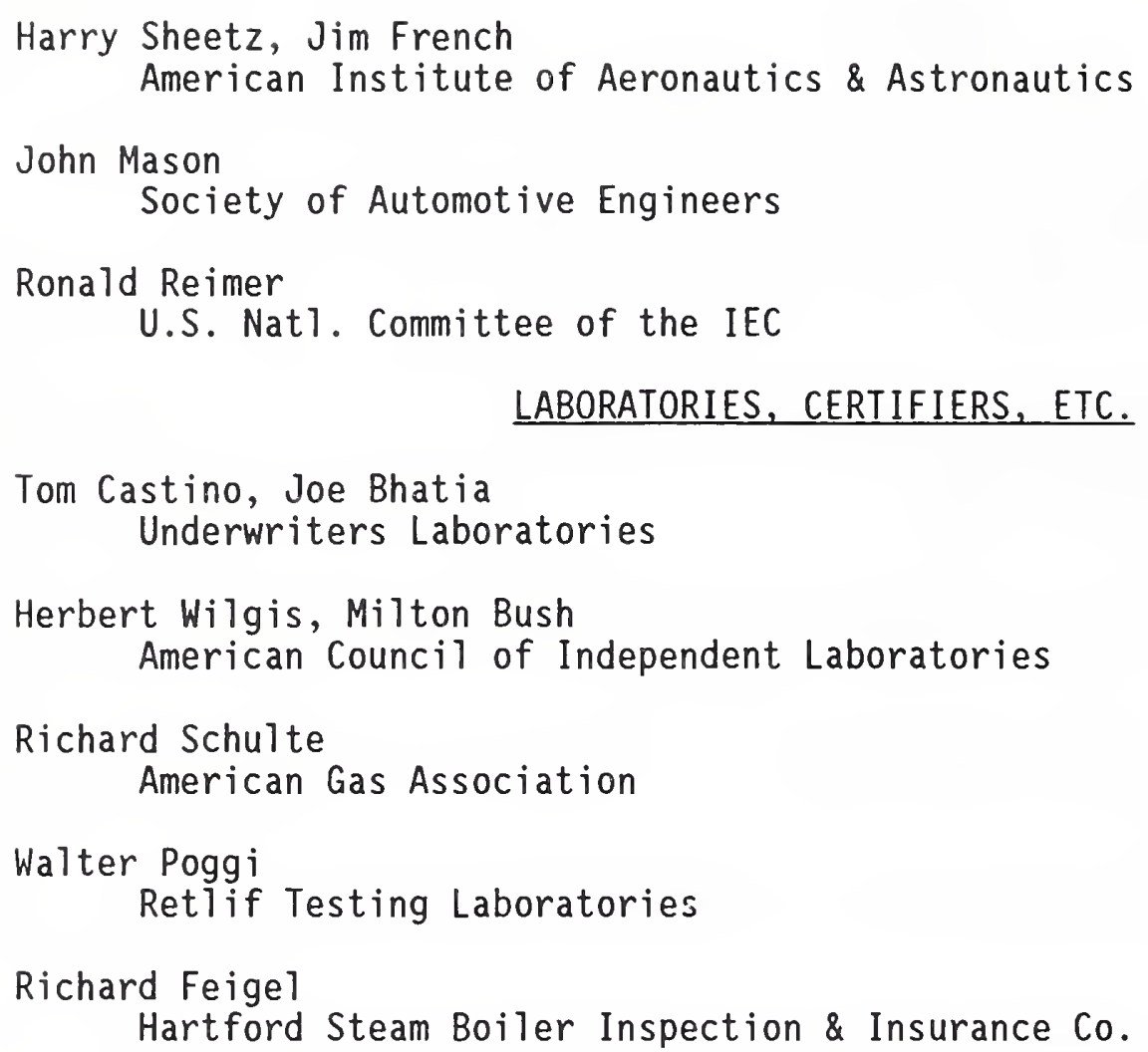
\begin{tabular}{lr}
\hline NIST-114A & U.S. DEPARTMENT OF COMMERCE \\
(REV. 3-89) & NATIONAL INSTITUTE OF STANDARDS AND TECHNOLOGY
\end{tabular}

BIBLIOGRAPHIC DATA SHEET
1. PUBLCATION OR REPORT NUMBER

NISTIR 4304

2. PEAFORMING ORGANIZATION REPORT NUMBER

3. PUBUCATION DATE

APRIL 1990

4. TITLE AND SUBTITLE

Transcript of Hearing on Improving U.S. Participation in International Standards Activities

First Day: April 3, 1990

5. AUTHOR(S)

6. PERFORMING ORGANIZATION (IF JOINT OR OTHER THAN NIST, SEE INSTRUCTIONS)

U.S. DEPARTMENT OF COMMERCE

MATIONAL INSTITUTE OF STANDARDS AND TECHNOLOGY

GAITMERSBURG, MD 20899

7. CONTRACT/QRANT NUMBER

8. TYPE OF REPORT AND PERIOD COVERED

NISTIR $\quad 4 / 3 / 90$

9. SPONSORIMG ORGANIZATION NAME AND COMPLETE ADDRESS (STREET, CTY, STATE, ZIP)

10. SUPPLEMENTARY NOTES

DOCUMENT DESCRIBES A COMPUTER PROGRAM; SF-185, FIPS SOFTWARE SUMMARY, IS ATTACHED.

11. ABSTRACT (A 200-WORD OR LESS FACTUAL SUMMARY OF MOST SIGNIFICANT INFORMATION. IF DOCUMENT INCLUDES A SIGNIFICANT BIBLOQRAPHY OR UTERATURE SUAVEY, MENTION IT HERE.)

The National Institute of Standards and Technology (NIST) held a hearing in the Department of Commerce Auditorium on April 3, 1990, through April 5, 1990, to gather information, insights, and comments related to U.S. participation in international standards-related activities and to possible Government actions.

The written comments received regarding the Apri1 3-5, 1990, hearing on U.S. Participation in International Standards activities will be on file after April 5, 1990, in the U.S. Department of Commerce Central Reference and Records Inspection Facility, Room 6628, Hoover Building, Washington, DC 20230, (202/377-3271), for the individual's perusal or copying. Copies of the test of the hearing can be obtained from the National Technical information Service, 5285 Port Royal Road, Springfield, VA 22161, (703/487-4650); a copy of this text will also be made available in the same DOC Reference and Records Inspection facility after April 25, 1990.

12 KEY WORDS (6 TO 12 ENTRIES; ALPHABETICAL ORDER; CAPITALZE ONLY PROPER MAMES; AND SEPARATE KEY WORDS BY SEMICOLONS)

Certification; hearing; international activities; laboratory accreditation; standards; testing.

13. AVALABIUTTY

-

UNUMUTED

FOR OFFICIAL DISTRIBUTION. DO NOT RELEASE TO NATIONAL TECHMICAL INFORMATION SERVICE (NTIS).

ORDER FROM SUPERINTENDENT OF DOCUMENTS, U.S. GOVERNMENT PRINTING OFFICE, WASHINOTON, DC 20402

ORDER FROM MATIONAL TECHNICAL INFORMATION SERVICE (NTIS), SPRINGFIELD, VA 22161.
14. NUMBER OF PRINTED PAQES

$$
232
$$

15. PRICE 

